UNIVERSIDADE DE SÃO PAULO

FACULDADE DE MEDICINA DE RIBEIRÃO PRETO

DEPARTAMENTO DE MEDICINA SOCIAL

\title{
Análise Estatística Para Dados de Contagem Longitudinais na Presença de Covariáveis: Aplicações na Área Médica
}

EMÍLIO AUGUSTO COELHO BARROS

Ribeirão Preto 


\section{Análise Estatística Para Dados de Contagem Longitudinais na Presença de Covariáveis: Aplicações na Área Médica}

Dissertação apresentada ao Departamento de Medicina Social da Faculdade de Medicina de Ribeirão Preto da Universidade de São Paulo para a obtenção do título de Mestre.

Área de Concentração: Saúde na Comunidade

Orientador: Prof. Dr. Jorge Alberto Achcar

Ribeirão Preto

2009 
Autorizo a reprodução e divulgação total ou parcial deste trabalho, por qualquer meio convencional ou eletrônico, para fins de estudo e pesquisa, desde que citada a fonte.

\section{Ficha Catalográfica}

Coelho-Barros, E. A.

Análise estatística para dados de contagem longitudinais na presença de covariáveis: Aplicações na área médica. Ribeirão Preto, 2009.

XX p.:il.; $30 \mathrm{~cm}$

Dissertação de Mestrado apresentada à Faculdade de Medicina de Ribeirão Preto - USP. Área de concentração: Saúde na Comunidade.

Orientador: Jorge Alberto Achcar

1. Dados de contagem. 2. Dados longitudinais. 3. Inferência Bayesiana. 


\section{Folha de Aprovação}

Emílio Augusto Coelho Barros

Análise estatística para dados de contagem longitudinais na presença de covariáveis: Aplicações na área médica

Dissertação apresentada ao Departamento de Medicina Social da Faculdade de Medicina de Ribeirão Preto da Universidade de São Paulo para a obtenção do título de Mestre em Saúde na Comunidade.

Área de Concentração: Saúde na Comunidade

Aprovado em:

\section{Banca Examinadora}

Prof.(a) Dr.(a):

Instituição: Assinatura:

Prof.(a) Dr.(a):

Instituição: Assinatura:

Prof.(a) Dr.(a):

Instituição: Assinatura: 


\section{Dedicatória}

Aos meus pais, Carlos e Dulce, e a minha avó, Wanda, com amor e gratidão, pelo apoio e pela educação dada ao longo desses 25 anos. 


\section{Agradecimentos}

A Deus, primeiramente, que sempre esteve ao meu lado.

Ao meu orientador, Prof. Dr. Jorge Alberto Achcar, pela ótima e competente orientação que somente uma pessoa como ele pode proporcionar, por ter investido em meu talento de pesquisador e pelos inúmeros artigos publicados.

Ao meu "co-orientador" Prof. Dr. Josmar Mazucheli, pela ajuda na elaboração e leitura da dissertação e por me ajudar na iniciação da minha vida como pesquisador, dando muita força para meu crescimento profissional, se não fosse por ele não teria iniciado este importante estágio da minha vida.

Ao amigo, Josmar Mazucheli, pelos conselhos e conversas jogadas fora nos momentos de descontração numa boa mesa de bar.

Ao Prof. Dr. Edson Zangiacomi Martinez, pelo incentivo e contribuição para o meu crescimento científico.

Ao amigo, Roberto Souza, no começo foi difícil morando junto e dividindo despesas, mas agora estamos aqui finalizando nosso duro e suado mestrado. Muito obrigado por me aturar esse tempo todo!

Aos meus irmãos, Adélio e Aluízio, e a minha irmã, Stéfani, que sempre me apoiaram.

Aos meus amigos de aventura, Danielle (Tixa), Davi (Campeão), Douglas (Assis), Henrique (Tukinha), Roberto (Betão), Rubens (Rubão). Obrigado por fazerem parte da minha vida.

À Fundação de Amparo à Pesquisa do Estado de São Paulo (FAPESP), pelo auxílio financeiro. 
"I like working on applied and theoretical problems at the same time and one thing nice about statistics is that you can be useful in a wide variety of areas. So my current applications include biostatistics and also astrophysical applications. The surprising thing is that the methods used are similar in both areas." 


\section{Resumo}

COElHO-BARROS, E. A. Análise estatística para dados de contagem longitudinais na presença de covariáveis: Aplicações na área médica. Dissertação (mestrado) - Faculdade de Medicina de Ribeirão Preto - USP, Ribeirão Preto - SP - Brasil, 2009.

Dados de contagem ao longo do tempo na presença de covariáveis são muito comuns em estudos na área da saúde coletiva, por exemplo; número de doenças que uma pessoa, com alguma característica especifica, adquiriu ao longo de um período de tempo; número de internações hospitalares em um período de tempo, devido a algum tipo de doença; número de doadores de órgãos em um período de tempo. Nesse trabalho são apresentados diferentes modelos estatísticos de "fragilidade" de Poisson para a análise estatística de dados de contagem longitudinais. Teoricamente, a distribuição de Poisson exige que a média seja igual à variância, quando isto não ocorre tem-se a presença de uma variabilidade extra-Poisson. Os modelos estatísticos propostos nesta dissertação incorporam a variabilidade extra-Poisson e capturam uma possível correlação entre as contagens para o mesmo indivíduo. Para cada modelo foi feito uma análise Bayesiana Hierárquica considerando os métodos MCMC (Markov Chain Monte Carlo). Utilizando bancos de dados reais, cedidos por pesquisadores auxiliados pelo CEMEQ (Centro de Métodos Quantitativos, USP/FMRP), foram discutidos alguns aspectos de discriminação Bayesiana para a escolha do melhor modelo. Um exemplo de banco de dados reais, discutido na Seção 4 dessa dissertação, que se encaixa na área da saúde coletiva, é composto de um estudo prospectivo, aberto e randomizado, realizado em pacientes infectados pelo HIV que procuraram atendimento na Unidade Especial de Terapia de Doenças Infecciosas (UETDI) do Hospital das Clínicas da Faculdade de Medicina de Ribeirão Preto da Universidade de São Paulo (HCFMRP-USP). Os esquemas terapêuticos estudados consistiam em zidovudina e lamivudina, associadas ao efavirenz ou lopinavir. Entre setembro de 2004 e maio de 2006 foram avaliados 66 pacientes, sendo 43 deles incluídos no estudo. Destes, 39 participantes alcançaram a semana 24 de acompanhamento, enquanto 27 atingiram a semana 48. Os grupos de pacientes apresentavam características basais semelhantes, quanto à idade, sexo, mediana de CD4 e carga viral. O interesse desse experimento é estudar a contagem de CD4 considerando os dois esquemas terapêuticos (efavirenz e lopinavir).

Palavras - chave: Dados de contagem, Dados longitudinais, Inferência Bayesiana 


\section{Abstract}

COELHO-BARROS, E. A. Análise estatística para dados de contagem longitudinais na presença de covariáveis: Aplicações na área médica. Dissertação (mestrado) - Faculdade de Medicina de Ribeirão Preto - USP, Ribeirão Preto - SP - Brasil, 2009.

Longitudinal counting data in the presence of covariates is very common in many applications, especially considering medical data. In this work we present different "frailty" models to analyze longitudinal Poisson data in the presence of covariates. These models incorporate the extra-Poisson variability and the possible correlation among the repeated counting data for each individual. A hierarchical Bayesian analysis is introduced for each different model considering usual MCMC (Markov Chain Monte Carlo) methods. Considering reals biological data set (obtained from CEMEQ, Medical School of Ribeirão Preto, University of São Paulo, Brazil), we also discuss some Bayesian discrimination aspects for the choice of the best model. In Section 4 is considering a data set related to an open prospective and randomized study, considering of HIV infected patients, free of treatments, which entered the Infection Diseases Therapy Special Unit (UETDI) of the Clinical Hospital of the Medical School of Ribeirão Preto, University of São Paulo (HCFMRP-USP). The therapeutic treatments consisted of the drugs Zidovudine and Lamivudine, associated to Efavirenz and Lopinavir. The data set was related to 66 patients followed from September, 2004 to may, 2006, from which, 43 were included in the study. The patients groups presented similar basal characteristics in terms of sex, age, CD4 counting median and viral load. The main goal of this study was to compare the CD4 cells counting for the two treatments, based on the drugs Efavirenz and Lopinavir, recently adopted as preferencial for the initial treatment of the disease.

Keywords: Counting data, Longitudinal data, Bayesian inference. 


\section{Siméon Denis Poisson \\ $(1781-1840)$}

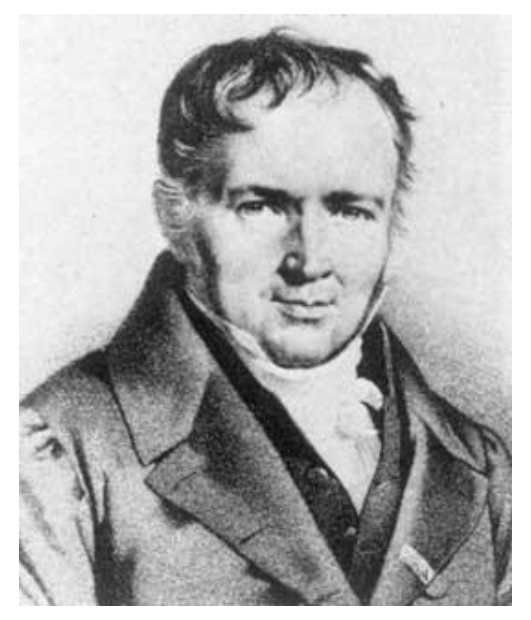

Engenheiro e matemático francês, nascido em Pithiviers, considerado o sucessor de

Laplace no estudo da mecânica celeste e da atração de esferóides. Filho de um administrador público, entrou para a École Polytechnique (1798), em Palaiseau, onde se formou, estudando com professores como Joseph Louis Lagrange, Pierre Simon

Laplace e Jean Baptiste Fourier, dos quais se tornou amigo pessoal. Ocupou cargos acadêmicos na Ecole Polytechnique e na Sorbonne e contribuiu para as teorias da eletricidade e do magnetismo e estudou também o movimento da lua. Desenvolveu pesquisas sobre mecânica, eletricidade (a constante de Poisson), elasticidade (razão de Poisson), calor, som e estudos matemáticos (integral de Poisson na teoria do potencial e

o colchete de Poisson nas equações diferenciais) com aplicação na medicina e na astronomia e produziu escritos sobre movimentos de ondas em geral e coeficientes de contração e a relação entre estes e a extensão. Publicou trabalhos (1812) que ajudaram a eletricidade e o magnetismo tornarem-se um ramo da física matemática. Ganhou o título de barão (1825). Na hidrodinâmica seu mais notável trabalho foi Mémoire sur les équations générales de l'équilibre et du mouvement des corps solides élastiques et des

fluides (1829), relacionando equilíbrio de sólidos elásticos e correntes de fluidos compressíveis. Publicou o importante tratado Traité de mécanique (1833), em dois volumes, na termodinâmica a Teoria matemática do calor (1835) e em Recherches sur la probabilité des jugements (1837) apareceu a famosa distribuição de Poisson. de intensa aplicação em estatística. Na teoria de probabilidades descobriu a forma limitada da distribuição binomial que posteriormente recebeu o seu nome e hoje considerada uma das mais importantes distribuições na probabilidade, sendo o método de Poisson um processo randômico de importância fundamental. Publicou cerca de quatrocentos trabalhos e morreu em Sceaux, próximo a Paris, França.

Informações obtidas no site: http://www.dec.ufcg.edu.br/biografias/SimeonDe.html

Figura obtida no site TURNBULL WWW SERVER: http://www-history.mcs.st-andrews.ac.uk/ 


\section{Índice de Figuras}

1 Contagem média dos comportamentos de autolimpeza. . . . . . . . . . 24

2 Gráficos dos sumários a posteriori para o modelo 1. . . . . . . . . . . . . 52

3 Gráficos dos sumários a posteriori para o modelo 2. . . . . . . . . . . . . 52

4 Gráficos dos sumários a posteriori para o modelo 3. . . . . . . . . . . . . 53

5 Estimativas Bayesianas para as variâncias dos dados de contagem em cada tempo. . . . . . . . . . . . . . . . . 53

6 Gráficos dos valores observados versus valores preditos. . . . . . . . . . . 65 


\section{Índice de Tabelas}

1 Contagem dos comportamentos de autolimpeza em ratos Wistar machos, injetados com salina e depois com ocitocina. . . . . . . . . . . . . . . 23

2 Contagem dos comportamentos de autolimpeza em ratos Wistar machos, injetados com ocitocina e depois com salina. . . . . . . . . . . . . . . . . . 24

3 Estimativas dos parâmetros do modelo via método Bayesiano. . . . . . . . . 33

4 Estimativas das taxas médias de autolimpeza via método Bayesiano. . . . . 34

5 Estimativas dos parâmetros do modelo via método Clássico. . . . . . . . . 35

6 Estimativas das taxas médias de autolimpeza via método Clássico. . . . . . 36

7 Contagem dos comportamentos de autolimpeza (grooming) em ratos Wistar machos, injetados com salina e ocitocina. . . . . . . . . . . . 38

8 Contagem dos comportamentos de autolimpeza (grooming) em ratos War machos, injetados com salina e ocitocina. . . . . . . . . . . . . . . . 39

9 Critério DIC. . . . . . . . . . . . . . . . . . 51

10 Soma dos quadrados das diferenças entre as variâncias estimadas e as variâncias amostrais. . . . . . . . . . . . . . . . . . . . 51

11 Médias a posteriori considerando o modelo 3. . . . . . . . . . . . . . 54

12 Contagem de CD4 em pacientes infectados pelo vírus HIV (COLARES, 2007). 58

13 Média a posteriori e intervalos de credibilidade para os parâmetros do modelo 1 (ausência de $w_{i}$ ) . . . . . . . . . . . . . . . . . . 61

14 Média a posteriori e intervalos de credibilidade para os parâmetros do modelo 1 (presença de $\left.w_{i}\right) \ldots \ldots \ldots$. . . . . . . . . . . . . 61

15 Média a posteriori e intervalos de credibilidade para os parâmetros do modelo 2. . . . . . . . . . . . . . . . . . . . . 62

16 Média a posteriori e intervalos de credibilidade para os parâmetros do

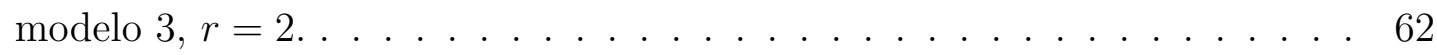

17 Média a posteriori e intervalos de credibilidade para os parâmetros do modelo $3, r=3 \ldots \ldots \ldots \ldots \ldots$. . . . . . . . . . . . . . . . . . .

18 Média a posteriori e intervalos de credibilidade para os parâmetros do modelo $3, r=4 \ldots \ldots \ldots \ldots$. . . . . . . . . . . 64

19 Critério DIC . . . . . . . . . . . . . . . . . 66

20 Soma do quadrado das diferenças entre os valores observados e os valores preditos. . . . . . . . . . . . . . . . . . . 


\section{Índice}

1 Introdução 14

1.1 Distribuição de Poisson . . . . . . . . . . . . . . . . . . . . . . . . . . 15

1.2 Algumas Características da Distribuição de Poisson . . . . . . . . . . . . . 15

1.2.1 Esperança e Variância . . . . . . . . . . . . . . . . . . . 17

1.2.2 Função de Verossimilhança . . . . . . . . . . . . . . . . . . . . . 18

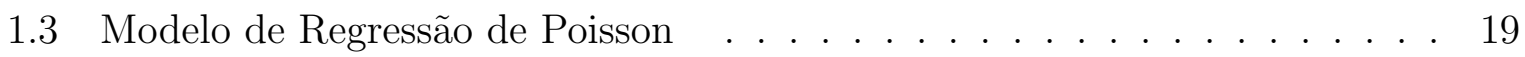

2 Métodos Bayesianos e Clássicos Para Analisar Dados Clínicos $\begin{array}{ll}\text { Longitudinais de Poisson } & 21\end{array}$

2.1 Análise de Dados de Contagem . . . . . . . . . . . . . . . . . 21

2.2 Apresentação dos Dados . . . . . . . . . . . . . . . . . . . . 23

2.3 Modelagem Estatística dos Dados . . . . . . . . . . . . . . . 25

2.3.1 Análise Bayesiana . . . . . . . . . . . . . . . . . . . . . . 27

2.4 Algumas Notas Conclusivas . . . . . . . . . . . . . . . . . . . . 31

3 Análise de Dados Longitudinais de Contagem Utilizando Diferentes $\begin{array}{ll}\text { Modelos de "Fragilidade" } & 37\end{array}$

3.1 Formulação do Modelo . . . . . . . . . . . . . . . . . . . . . . . . 40

3.1 .1 Modelo $1 \ldots \ldots \ldots$. . . . . . . . . . . . . . . . 41

3.1 .2 Modelo $2 \ldots \ldots$. . . . . . . . . . . . . . . . . . . 42

3.1 .3 Modelo 3 . . . . . . . . . . . . . . . . . . . . . . 44

3.2 Análise Bayesiana . . . . . . . . . . . . . . . . . . 46

3.2.1 Análise Bayesiana Para o Modelo 1 . . . . . . . . . . . . . . . . . 47

3.2.2 Análise Bayesiana Para o Modelo 2 . . . . . . . . . . . . . . . . . . 48

3.2.3 Análise Bayesiana Para o Modelo 3 Assumindo $r=2$. . . . . . . . 49

3.3 Análise dos Dados de Contagem de Grooming . . . . . . . . . . . . . . . 50

3.4 Algumas Conclusões e Discussão dos Resultados . . . . . . . . . . . . 55

4 Uma Aplicação Com Dados de Pacientes Infectados Pelo Vírus HIV 57

4.1 Análise Bayesiana Dos Dados . . . . . . . . . . . . . . . 59

4.2 Algumas Conclusões e Discussão dos Resultados . . . . . . . . . . . 66

$\begin{array}{ll}\text { A Ferramentas Computacionais } & 73\end{array}$

A.1 PROC NLMIXED do Software SAS f . . . . . . . . . . 73

A.2 Software Winbugs . . . . . . . . . . . . . . 74 
$\begin{array}{lr}\text { B Programas } & 75\end{array}$

B.1 Seção 2 . . . . . . . . . . . . . . . . . . . . . . . . . 75

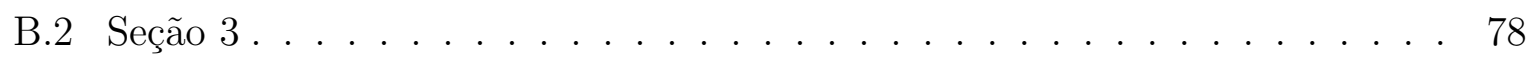

B.2.1 Modelo $1 \ldots \ldots \ldots \ldots$. . . . . . . . . . . . . . . . . . . . . . . .

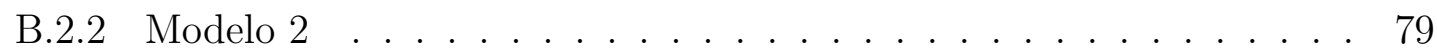

B.2.3 Modelo $3 \ldots \ldots \ldots \ldots$. . . . . . . . . . . . . 80

C Distribuições a Posteriori Condicionais $\quad 83$

C.1 Seção $3 \ldots \ldots$. . . . . . . . . . . . . . . . . . . . . . 83

C.1.1 Modelo $1 \ldots \ldots \ldots$. . . . . . . . . . . . 83

C.1.2 Modelo $2 \ldots \ldots \ldots \ldots \ldots$. . . . . . . . . . . . 84

C.1.3 Modelo $3 \ldots \ldots \ldots \ldots$. . . . . . . . . . . . 85 


\section{Introdução}

Nessa dissertação de mestrado em saúde coletiva, são introduzidos diferentes modelos estatísticos para analisar dados de contagem longitudinais na presença de uma ou mais covariáveis. Os novos modelos e a metodologia estatística são estudados utilizando banco de dados médicos reais, fornecidos pelo Centro de Métodos Quantitativos (CEMEQ) da Faculdade de Medicina da Universidade de São Paulo, campus de Ribeirão Preto.

Utilizando o enfoque Bayesiano e métodos computacionais de simulação de amostras das distribuições a posteriori de interesse, em especial o algoritmo Gibbs Sampling em conjunto com o algoritmo Metropolis-Hastings, são introduzidas diferentes formas de modelagem para dados de contagem longitudinais. Os resultados obtidos são comparados com as técnicas tradicionais clássicas de inferência para dados de contagem.

Os diferentes modelos propostos, capturam a correlação entre os dados de contagem medidos para um mesmo indivíduo e modelam a variabilidade extra-Poisson. $\mathrm{Na}$ modelagem de dados de contagem, usualmente considera-se a distribuição de Poisson.

Nessa seção, são introduzidos alguns conceitos e propriedades básicas da distribuição de Poisson. Na Seção 2, é apresentado a análise de um conjunto de dados médicos de contagem utilizando um modelo de regressão de Poisson. Comparações entre as metodologias Bayesiana e clássica foram feitas, mostrando as vantagens do uso de métodos Bayesianos na análise de dados médicos de contagem na presença de covariáveis.

Na Seção 3, são introduzidas diferentes formas de modelagem para dados de contagem. A análise é feita utilizando métodos Bayesianos Hierárquicos, que levam à grande

flexibilidade de ajuste a partir da introdução de variáveis latentes que capturam a correlação entre as respostas para um mesmo indivíduo e a presença de sobredispersão. Alguns aspectos de discriminação dos modelos propostos são considerados para escolher o melhor modelo a ser usado na análise dos dados.

Na Seção 4 tem-se uma aplicação da metodologia proposta na análise de dados de pacientes infectados pelo vírus HIV. Os dados são analisados utilizando a metodologia 
estatística proposta nos capítulos prévios. Trata-se de um conjunto de dados de um estudo prospectivo, aberto e aleatorizado incluindo 43 pacientes infectados, virgens de tratamento, com idade superior a 18 anos, contagem de linfócitos TCD4+ inferior a 350 células $/ \mathrm{mm}^{3}$ e carga viral superior a 5000 cópias $/ \mathrm{ml}$. Os esquemas terapêuticos utilizados estão associados as drogas Efavirenz e Lopinavir. A resposta imunológica é avaliada pela elevação dos níveis de linfócitos CD4+ nas semanas 24 e 48. O perfil de toxidade é avaliado pela freqüência de eventos adversos e alterações laboratoriais.

Essa análise estatística, ilustra a potencialidade da metodologia proposta nessa dissertação de mestrado. Esses resultados são de grande importância para encontrar inferências mais precisas na análise de dados de contagem médicos longitudinais.

\subsection{Distribuição de Poisson}

Poisson (1837), introduziu a distribuição de Poisson a partir de um estudo sobre a distribuição binomial. A distribuição de Poisson é uma das mais importantes distribuições de probabilidade com aplicações nas mais diversas áreas, em especial, na análise de dados médicos de contagem.

\subsection{Algumas Características da Distribuição de Poisson}

Uma variável aleatória $Y$ tem distribuição de Poisson com parâmetro $\lambda$, denotado por $\operatorname{Poisson}(\lambda)$, se ela recebe valores inteiros $(y=0,1,2, \ldots)$ com função de probabilidade,

$$
P(Y=y)=\frac{\lambda^{y} e^{-\lambda}}{y !}, \text { para } y=0,1,2, \ldots
$$

em que, $\lambda$ deve ser positivo.

A distribuição de Poisson é um caso particular da distribuição Binomial quando o tamanho amostral é significativamente grande. Isto pode ser facilmente demonstrado: 
considere a função distribuição de probabilidade Binomial escrita na forma,

$$
f(y \mid n, p)=\frac{n !}{(n-y) ! y !} p^{y}(1-p)^{n-y}
$$

em que, $n$ é o tamanho amostral, $y=1$ indica sucesso, $y=0$ indica fracasso e $p$ é a probabilidade de sucesso. Sabe-se que a esperança de uma variável aleatória com distribuição de Poisson, parametrizada em (1), é igual ao parâmetro $\lambda$ (ver, Seção 1.2.1); sabe-se também que a esperança de uma variável aleatória com distribuição binomial é igual a $n p$; logo pode-se considerar $\lambda=n p$, portanto (2) pode ser reescrita na forma,

$$
f(y \mid n, p)=\frac{n !}{(n-y) ! y !} \frac{\lambda^{y}}{n^{y}}\left(1-\frac{\lambda}{n}\right)^{n}\left(1-\frac{\lambda}{n}\right)^{-y}
$$

Aplicando o limite em (3) para $n \rightarrow \infty$, tem-se,

$$
\lim _{n \rightarrow \infty} f(y \mid n, p)=\lim _{n \rightarrow \infty}\left\{\frac{n !}{(n-y) ! y !} \frac{\lambda^{y}}{n^{y}}\right\} \lim _{n \rightarrow \infty}\left(1-\frac{\lambda}{n}\right)^{n} \lim _{n \rightarrow \infty}\left(1-\frac{\lambda}{n}\right)^{-y}
$$

Utilizando o resultado,

$$
\log \left(1-\frac{\lambda}{n}\right)^{n}=n \log \left(1-\frac{\lambda}{n}\right)=n\left(-\frac{\lambda}{n}-\frac{1}{2} \frac{\lambda^{2}}{n^{2}}-\cdots\right) \approx-\lambda, \text { para } n \rightarrow \infty
$$

tem-se,

$$
\begin{aligned}
\lim _{n \rightarrow \infty} f(y \mid n, p) & =\lim _{n \rightarrow \infty}\left\{\frac{n(n-1) \cdots(n-y+1)}{n^{y}}\right\} \frac{\lambda^{y}}{y !} \times e^{-\lambda} \times 1 \\
& =\frac{\lambda^{y} e^{-\lambda}}{y !} .
\end{aligned}
$$

Como (4) é a função de probabilidade de Poisson com parâmetro $\lambda(1)$, conclui-se que a distribuição de Poisson é um caso particular da distribuição Binomial quando o tamanho amostral é relativamente grande. 


\subsubsection{Esperança e Variância}

Se $Y \sim$ Poisson $(\lambda)$, sabendo que a distribuição de Poisson é uma distribuição que acomoda dados discretos, tem-se,

$$
\begin{aligned}
E(Y) & =\sum_{y=0}^{\infty} y P(Y=y) \\
& =\sum_{y=0}^{\infty} y \frac{\lambda^{y} e^{-\lambda}}{y !}
\end{aligned}
$$

Como,

$$
\sum_{y=a}^{\infty} \frac{\lambda^{y-a}}{(y-a) !}=e^{\lambda}
$$

em que, a é uma constante, logo,

$$
\begin{aligned}
E(Y) & =e^{-\lambda} \lambda \sum_{y=1}^{\infty} \frac{\lambda^{y-1}}{(y-1) !} \\
& =e^{-\lambda} \lambda e^{\lambda} \\
& =\lambda
\end{aligned}
$$

A variância de $Y$ pode ser particionada por,

$$
\operatorname{Var}(Y)=E\left(Y^{2}\right)-[E(Y)]^{2}=E\left(Y^{2}-Y\right)+E(Y)-[E(Y)]^{2}
$$

Como,

$$
\begin{aligned}
E\left(Y^{2}-Y\right) & =\sum_{y=0}^{\infty} y(y-1) P(Y=y) \\
& =e^{-\lambda} \lambda^{2} \sum_{y=2}^{\infty} \frac{\lambda^{y-2}}{(y-2) !}
\end{aligned}
$$

utilizando o resultado (5), tem-se, $E\left(Y^{2}-Y\right)=\lambda^{2}$, logo, de (6), tem-se,

$$
\operatorname{Var}(Y)=\lambda \text {. }
$$


Portanto a esperança e a variância para dados que seguem distribuição de Poisson são dadas, respectivamente, por,

$$
E(Y)=\lambda \quad \text { e } \operatorname{Var}(Y)=\lambda
$$

Assim, pode-se observar que a esperança e a variância, para dados que seguem distribuição de Poisson, são iguais. Na prática, quando isto não é observado, tem-se um problema de sobredispersão ou de variabilidade extra-Poisson. Breslow (1984), Brillinger (1986), Lawless (1987), McCullagh e Nelder (1983) discutem as análises de dados de contagem na presença de variabilidade extra-Poisson.

\subsubsection{Função de Verossimilhança}

Assumindo uma amostra aleatória $\left(Y_{1}, \ldots, Y_{n}\right)$ de uma distribuição de Poisson com média $\lambda$, a função de verossimilhança para $\lambda$, é dada por,

$$
\begin{aligned}
L(\lambda \mid y) & =\prod_{i=1}^{n} \frac{\lambda^{y_{i}} e^{-\lambda}}{y_{i} !} \\
& \propto e^{-n \lambda} \prod_{i=1}^{n} \lambda^{y_{i}}
\end{aligned}
$$

em que, $y_{i}$ representa a $i$-ésima observação e $\lambda>0$. Aplicando o logaritmo em (7), tem-se a função de log-verossimilhança dada por,

$$
l(\lambda \mid y)=-n \lambda+\sum_{i=1}^{n} y_{i} \log (\lambda)
$$

Logo, o estimador de máxima verossimilhança para $\lambda$ é obtido resolvendo a equação,

$$
\frac{\partial l(\lambda \mid y)}{\partial \lambda}=0 .
$$


Isto é,

$$
\hat{\lambda}=\frac{1}{n} \sum_{i=1}^{n} y_{i}
$$

ou seja, o estimador de máxima verossimilhança para $\lambda$ é dado por, $\hat{\lambda}=\bar{y}$, em que $\bar{y}$ é a média amostral dos dados observados. Intervalos de confiança ou testes de hipóteses para $\lambda$ podem ser obtidos da distribuição normal assintótica $\hat{\lambda} \sim N\left(\lambda ; I^{-1}\right)$, em que $I$ é a informação de Fisher, dada por,

$$
I=E\left(-\frac{\partial^{2} l}{\partial \lambda^{2}}\right)
$$

\subsection{Modelo de Regressão de Poisson}

Seja $\left(y_{1}, \ldots, y_{n}\right)$, uma amostra aleatória de tamanho $n$, em que $Y_{i} \sim \operatorname{Poisson}\left(\lambda_{i}\right)$, $i=1, \ldots, n$; suponha o interesse em verificar se a média $\lambda_{i}$ está relacionada com um vetor de variáveis explicativas $\mathbf{x}_{i}=\left(x_{i 1}, \ldots, x_{i p}\right)^{\prime}$. Um modelo linear simples, é dado por,

$$
\lambda_{i}=\mathbf{x}_{i}^{\prime} \boldsymbol{\beta}
$$

em que, $\boldsymbol{\beta}=\left(\beta_{1}, \ldots, \beta_{p}\right)$ é o vetor de parâmetros de regressão. Percebe-se, porém, que o preditor linear desse modelo pode assumir qualquer valor real; no entanto a média de Poisson $\lambda_{i}$, que representa o número esperado de contagem, não pode ser negativa.

Uma alternativa direta para esse problema é modelar o logaritmo da média usando um modelo linear, ou seja, aplicar o logaritmo na média $\eta_{i}=\log \left(\lambda_{i}\right)$ e assumir que a média transformada segue um modelo linear $\eta_{i}=\mathbf{x}_{i}^{\prime} \boldsymbol{\beta}$. Ou seja, considera-se um modelo linear generalizado com função de ligação logarítmica. Portanto, assume-se o seguinte modelo log-linear,

$$
\log \left(\lambda_{i}\right)=\mathbf{x}_{i}^{\prime} \boldsymbol{\beta}
$$

observa-se que o coeficiente de regressão $\beta_{j}$ representa a mudança esperada no logaritmo da média por unidade mudada do preditor $x_{j}, j=1 \ldots p$. Em outras palavras, o acréscimo de uma unidade em $x_{j}$ implica no acréscimo de $\beta_{j}$ unidades em relação ao logaritmo da 
média.

De (8), tem-se o seguinte modelo multiplicativo para a média,

$$
\lambda_{i}=\exp \left(\mathbf{x}_{i}^{\prime} \boldsymbol{\beta}\right)
$$

A partir de (9), é possível fazer análise de regressão para dados de contagem que seguem distribuição de Poisson. A seguir são apresentados exemplos de aplicação desse tipo de modelo considerando dados reais de contagem. 


\section{Métodos Bayesianos e Clássicos Para Analisar Dados Clínicos Longitudinais de Poisson}

Nesta seção é apresentado um exemplo prático, considerando dados médicos reais de contagem ao longo do tempo. Para a análise dos dados e resolução do problema é utilizado um modelo de Poisson com efeitos fixos e aleatórios. Os resultados apresentados aqui podem ser vistos também em Coelho-Barros et al. (2006).

O presente estudo apresenta, como motivação, um banco de dados obtido através de um projeto de pesquisa realizado no Laboratório de Neurofisiologia e Neuroetologia Experimental (LNNE) e analisado pelo Centro de Métodos Quantitativos da Faculdade de Medicina de Ribeirão Preto da Universidade de São Paulo (CEMEQ). Esse estudo consiste em apresentar uma análise Bayesiana para verificar os comportamentos de autolimpeza (grooming), em ratos Wistar machos, quando nestes foram injetados solução salina (controle) e ocitocina. Como os dados são apresentados em forma de contagem, a análise é realizada utilizando um modelo de Poisson. Também é feita uma análise comparativa considerando as metodologias Clássica e Bayesiana.

\subsection{Análise de Dados de Contagem}

Muitos modelos são propostos na literatura para a análise de dados discretos sob uma abordagem clássica (GOURIEROUX et al., 1984; SANTNER; DUFFY, 1989; STUKEL, 1988). Uma alternativa, ou muitas vezes a solução mais viável a essa metodologia, é a utilização de modelos Bayesianos, dada a possível dificuldade na obtenção de estimadores de máxima verossimilhança e resultados assintóticos confiáveis. Recentemente, as técnicas Bayesianas vêm sendo utilizadas em larga escala, principalmente na área médica (BERRY, 2006; BERRY; STANGL, 1996). Este fato se verifica, pois, o uso de métodos Bayesianos levam a resultados que não são dependentes de resultados assintóticos e ainda permitem a incorporação de informações de especialistas a partir da escolha de distribuições a priori para os parâmetros do modelo. Além disso, há uma maior simplicidade em estruturar a 
correlação dos dados discretos longitudinais a partir de uma análise Bayesiana hierárquica.

O banco de dados utilizado no presente estudo foi obtido a partir da contagem dos comportamentos de autolimpeza (grooming), observados em ratos Wistar machos, injetados com salina (controle) e ocitocina. Em cada animal, injetou-se salina e 24 horas depois ocitocina, sendo que durante o período de uma hora foram feitas contagens dos comportamentos de autolimpeza. Para a contagem, foi anotado a presença de qualquer um dos ítens comportamentais contidos na categoria chamada de autolimpeza. Esta categoria pode compreender: limpeza de cabeça, de focinho, de garras, autolimpeza do corpo, de genitais, coçar, entre outros, sem discriminação alguma de que tipo específico foi observado, apenas se esteve presente ou não. O registro foi feito em intervalos de 15 segundos, sendo obtido um banco de dados com as contagens totais de autolimpeza de 5 em 5 minutos. Para verificar se a seqüência de tratamento influencia na contagem de autolimpeza, um grupo de animais foi injetado primeiro com salina e depois com ocitocina e, um outro grupo de animais foi injetado primeiro com ocitocina e depois com salina. É importante frisar que o período de aplicação entre uma substância e outra foi de um dia, garantindo, assim, que o local de injeção no sistema nervoso central do rato tenha depurado a substância aplicada anteriormente.

Estudos deste tipo são conhecidos na literatura como estudos cross-over, (SENN, 1993; HILLS; ARMITAGE, 1979). O estudo cross-over é um planejamento de blocos aleatorizados modificados, nos quais cada bloco recebe mais de uma formulação de uma mesma droga, em períodos diferentes. Um bloco pode ser um individuo ou um grupo de indivíduos. Os indivíduos em cada bloco recebem uma seqüência diferente de formulações. 


\subsection{Apresentação dos Dados}

Os dados fornecidos podem ser visualizados nas Tabelas 1 e 2 , juntamente com a contagem média dos comportamentos de autolimpeza para cada tempo. Estas médias também estão expostas na forma gráfica (Figura 1).

Tabela 1: Contagem dos comportamentos de autolimpeza em ratos Wistar machos, injetados com salina e depois com ocitocina.

\begin{tabular}{|c|c|c|c|c|c|c|c|c|c|c|c|c|}
\hline \multirow[b]{3}{*}{$\mathrm{t}(\min )$} & \multicolumn{9}{|c|}{ Ratos } & \multirow[b]{3}{*}{ Média } & \multirow{3}{*}{$\begin{array}{l}\text { Desvio } \\
\text { Padrão }\end{array}$} & \multirow[b]{3}{*}{ Variância } \\
\hline & 1 & 2 & 3 & 4 & 5 & 6 & 7 & 8 & 9 & & & \\
\hline & \multicolumn{9}{|c|}{ Salina } & & & \\
\hline 5 & 3 & 1 & 3 & 0 & 3 & 1 & 1 & 1 & 1 & 1,556 & 1,130 & 1,278 \\
\hline 10 & 5 & 3 & 6 & 4 & 1 & 5 & 0 & 10 & 3 & 4,111 & 2,934 & 8,611 \\
\hline 15 & 7 & 3 & 6 & 6 & 8 & 4 & 0 & 7 & 5 & 5,111 & 2,472 & 6,111 \\
\hline 20 & 0 & 0 & 12 & 2 & 5 & 0 & 6 & 4 & 0 & 3,222 & 4,055 & 16,444 \\
\hline 25 & 11 & 0 & 10 & 1 & 12 & 0 & 1 & 0 & 4 & 4,333 & 5,172 & 26,750 \\
\hline 30 & 1 & 0 & 11 & 0 & 0 & 0 & 0 & 0 & 0 & 1,333 & 3,640 & 13,250 \\
\hline 35 & 5 & 0 & 1 & 0 & 0 & 0 & 0 & 0 & 4 & 1,111 & 1,965 & 3,861 \\
\hline 40 & 2 & 0 & 0 & 9 & 0 & 0 & 1 & 0 & 0 & 1,333 & 2,958 & 8,750 \\
\hline 45 & 1 & 0 & 0 & 7 & 0 & 0 & 0 & 1 & 0 & 1,000 & 2,291 & 5,250 \\
\hline 50 & 0 & 0 & 0 & 0 & 0 & 0 & 0 & 0 & 1 & 0,111 & 0,333 & 0,111 \\
\hline 55 & 0 & 0 & 0 & 7 & 9 & 0 & 0 & 0 & 0 & 1,778 & 3,563 & 12,694 \\
\hline \multirow[t]{2}{*}{60} & 0 & 0 & 0 & 0 & 0 & 2 & 0 & 1 & 6 & 1,000 & 2,000 & 4,000 \\
\hline & \multicolumn{9}{|c|}{ Ocitocina } & & & \\
\hline 5 & 10 & 2 & 5 & 2 & 7 & 8 & 0 & 6 & 5 & 5,000 & 3,202 & 10,250 \\
\hline 10 & 13 & 6 & 1 & 6 & 1 & 3 & 5 & 11 & 0 & 5,111 & 4,512 & 20,361 \\
\hline 15 & 13 & 12 & 9 & 13 & 12 & 0 & 0 & 0 & 5 & 7,111 & 5,883 & 34,611 \\
\hline 20 & 11 & 5 & 6 & 3 & 9 & 1 & 0 & 0 & 0 & 3,889 & 4,137 & 17,111 \\
\hline 25 & 16 & 13 & 14 & 0 & 1 & 0 & 0 & 0 & 10 & 6,000 & 7,053 & 49,750 \\
\hline 30 & 9 & 10 & 13 & 15 & 0 & 1 & 0 & 8 & 0 & 6,222 & 6,037 & 36,444 \\
\hline 35 & 10 & 16 & 10 & 8 & 16 & 0 & 0 & 9 & 0 & 7,667 & 6,403 & 41,000 \\
\hline 40 & 9 & 14 & 17 & 1 & 16 & 0 & 0 & 2 & 0 & 6,556 & 7,418 & 55,028 \\
\hline 45 & 4 & 9 & 14 & 0 & 0 & 0 & 0 & 1 & 0 & 3,111 & 5,085 & 25,861 \\
\hline 50 & 18 & 15 & 0 & 0 & 0 & 0 & 4 & 0 & 7 & 4,889 & 7,061 & 49,861 \\
\hline 55 & 0 & 8 & 0 & 0 & 6 & 0 & 2 & 0 & 0 & 1,778 & 3,073 & 9,444 \\
\hline 60 & 0 & 0 & 0 & 0 & 15 & 0 & 0 & 0 & 0 & 1,667 & 5,000 & 25,000 \\
\hline
\end{tabular}


Tabela 2: Contagem dos comportamentos de autolimpeza em ratos Wistar machos, injetados com ocitocina e depois com salina.

\begin{tabular}{|c|c|c|c|c|c|c|c|c|c|c|}
\hline \multirow[b]{3}{*}{$t(\min )$} & \multicolumn{7}{|c|}{ Ratos } & \multirow[b]{3}{*}{ Média } & \multirow{3}{*}{$\begin{array}{l}\text { Desvio } \\
\text { Padrão }\end{array}$} & \multirow[b]{3}{*}{ Variância } \\
\hline & 1 & 2 & 3 & 4 & 5 & 6 & 7 & & & \\
\hline & \multicolumn{7}{|c|}{ Ocitocina } & & & \\
\hline 5 & 1 & 1 & 3 & 2 & 6 & 2 & 0 & 2,143 & 1,952 & 3,810 \\
\hline 10 & 6 & 4 & 9 & 0 & 11 & 1 & 5 & 5,143 & 3,976 & 15,810 \\
\hline 15 & 11 & 0 & 1 & 7 & 10 & 4 & 0 & 4,714 & 4,680 & 21,905 \\
\hline 20 & 8 & 6 & 8 & 1 & 11 & 9 & 5 & 6,857 & 3,237 & 10,476 \\
\hline 25 & 13 & 8 & 11 & 0 & 8 & 6 & 7 & 7,571 & 4,117 & 16,952 \\
\hline 30 & 9 & 10 & 3 & 0 & 9 & 18 & 14 & 9,000 & 6,110 & 37,333 \\
\hline 35 & 0 & 7 & 12 & 0 & 15 & 2 & 18 & 7,714 & 7,410 & 54,905 \\
\hline 40 & 0 & 0 & 9 & 0 & 7 & 18 & 14 & 6,857 & 7,313 & 53,476 \\
\hline 45 & 0 & 0 & 6 & 6 & 5 & 8 & 4 & 4,143 & 3,078 & 9,476 \\
\hline 50 & 0 & 0 & 7 & 6 & 5 & 0 & 0 & 2,571 & 3,259 & 10,619 \\
\hline 55 & 0 & 0 & 0 & 11 & 7 & 1 & 0 & 2,714 & 4,461 & 19,905 \\
\hline \multirow[t]{2}{*}{60} & 0 & 0 & 1 & 0 & 6 & 0 & 0 & 1,000 & 2,236 & 5,000 \\
\hline & \multicolumn{7}{|c|}{ Salina } & & & \\
\hline 5 & 2 & 3 & 10 & 1 & 3 & 3 & 1 & 3,286 & 3,094 & 9,571 \\
\hline 10 & 0 & 5 & 1 & 1 & 5 & 7 & 7 & 3,714 & 2,984 & 8,905 \\
\hline 15 & 0 & 9 & 0 & 4 & 7 & 12 & 2 & 4,857 & 4,634 & 21,476 \\
\hline 20 & 0 & 0 & 8 & 0 & 0 & 11 & 4 & 3,286 & 4,572 & 20,905 \\
\hline 25 & 0 & 0 & 1 & 0 & 0 & 0 & 0 & 0,143 & 0,378 & 0,143 \\
\hline 30 & 0 & 1 & 12 & 0 & 0 & 0 & 0 & 1,857 & 4,488 & 20,143 \\
\hline 35 & 1 & 0 & 8 & 1 & 0 & 0 & 0 & 1,429 & 2,936 & 8,619 \\
\hline 40 & 0 & 0 & 0 & 0 & 1 & 0 & 0 & 0,143 & 0,378 & 0,143 \\
\hline 45 & 0 & 0 & 0 & 7 & 0 & 0 & 0 & 1,000 & 2,646 & 7,000 \\
\hline 50 & 0 & 5 & 0 & 1 & 0 & 0 & 0 & 0,857 & 1,864 & 3,476 \\
\hline 55 & 0 & 0 & 0 & 2 & 0 & 0 & 0 & 0,286 & 0,756 & 0,571 \\
\hline 60 & 0 & 0 & 0 & 0 & 0 & 0 & 0 & 0,000 & 0,000 & 0,000 \\
\hline
\end{tabular}

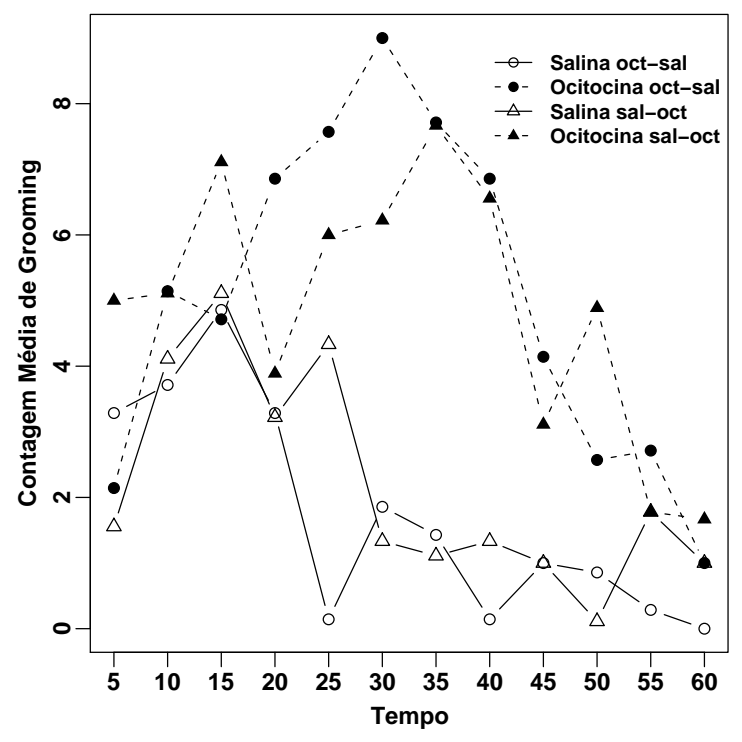

Figura 1: Contagem média dos comportamentos de autolimpeza. 
Dos resultados das Tabelas 1 e 2, observa-se que as contagens médias para cada tempo em cada tratamento são diferentes das variâncias para a maioria dos casos, indicando a presença de uma variabilidade extra-Poisson.

Observando a Figura 1, é possível perceber que, aparentemente, a ocitocina retornou um estimulo maior aos ratos quando comparada com a salina, pois a contagem média dos comportamentos de autolimpeza para os ratos que receberam ocitocina é maior para os ratos que receberam salina. Pela Figura 1 também é possível perceber que, aparentemente, a seqüência do tratamento não influencia na contagem de autolimpeza, pois a contagem média dos comportamentos de autolimpeza para os ratos injetados com salina, quando os mesmos foram injetados primeiramente com salina e depois com ocitocina, não parece diferir para os ratos que foram injetados primeiro com ocitocina e depois com salina. $\mathrm{O}$ mesmo é observado para a substância ocitocina.

\subsection{Modelagem Estatística dos Dados}

Para a análise dos dados é proposto um modelo de Poisson, pois a variável dependente é uma contagem. Logo, tem-se uma variável aleatória $Y_{i j}$ que representa o número de vezes que o $i$-ésimo animal manifestou algum comportamento de autolimpeza no j-ésimo tempo $(i=1, \ldots, 16$ e $j=1, \ldots, 24)$. Assim, $Y_{i j} \sim \operatorname{Poisson}\left(\lambda_{i j}\right)$, com função de probabilidade escrita na forma,

$$
P\left(Y_{i j}=y_{i j}\right)=\frac{e^{-\lambda_{i j}} \lambda_{i j}^{y_{i j}}}{y_{i j} !}, \quad y_{i j}=0,1,2, \ldots
$$

em que,

$$
\lambda_{i j}=\alpha_{j} \exp \left(\beta_{j} X_{i j}+w_{i}\right)
$$

$X_{i j}$ é uma variável dummy, em que $X_{i j}=0$ indica que o rato recebe inicialmente a solução salina e depois a solução ocitocina e $X_{i j}=1$ indica que o reto recebe inicialmente a solução ocitocina e depois a solução salina. Portanto, $\alpha_{j}$ é a taxa média de autolimpeza, no j-ésimo tempo, para os ratos que recebem primeiro a solução salina e depois a solução ocitocina, $\alpha_{j} e^{\beta_{j}}$ é a taxa média de autolimpeza, no j-ésimo tempo, para os ratos que 
recebem primeiro a solução ocitocina e depois a solução salina e $\beta_{j}$ é o parâmetro que indica se há ou não efeito de seqüência de tratamento. Além disso, é incorporado ao modelo um efeito aleatório $w_{i}$ que captura a possível correlação entre as contagens para os mesmos animais e também a variabilidade extra-Poisson. Considera-se que estes efeitos são variáveis aleatórias identicamente distribuídas com distribuição normal de média zero e variância $\tau^{2}$, isto é, $w_{i} \sim N\left(0, \tau^{2}\right)$.

Observa-se que $E\left(y_{i j} \mid \lambda_{i j}\right)=\lambda_{i j}$ e $\operatorname{Var}\left(y_{i j} \mid \lambda_{i j}\right)=\lambda_{i j}$; portanto,

$$
\begin{aligned}
& E\left(y_{i j} \mid \alpha_{j}, \beta_{j}, w_{i}, X_{i j}\right)=\alpha_{j} \exp \left(\beta_{j} X_{i j}+w_{i}\right) ; \\
& \operatorname{Var}\left(y_{i j} \mid \alpha_{j}, \beta_{j}, w_{i}, X_{i j}\right)=\alpha_{j} \exp \left(\beta_{j} X_{i j}+w_{i}\right) .
\end{aligned}
$$

Como,

$$
E\left(y_{i j} \mid \alpha_{j}, \beta_{j}, X_{i j}\right)=E\left[E\left(y_{i j} \mid \alpha_{j}, \beta_{j}, w_{i}, X_{i j}\right)\right]
$$

tem-se, por (11),

$$
E\left(y_{i j} \mid \alpha_{j}, \beta_{j}, X_{i j}\right)=\alpha_{j} e^{\beta_{j} X_{i j}} E\left(e^{w_{i}}\right)
$$

Se $w_{i} \sim N\left(0, \tau^{2}\right)$, então $e^{w_{i}}$ tem uma distribuição log-normal com média $E\left(e^{w_{i}}\right)=$ $e^{\tau^{2} / 2}$ e variância $\operatorname{Var}\left(e^{w_{i}}\right)=\left(e^{\tau^{2}}-1\right) e^{\tau^{2}}$, assim,

$$
E\left(y_{i j} \mid \alpha_{j}, \beta_{j}, X_{i j}\right)=\alpha_{j} e^{\beta_{j} X_{i j}} e^{\tau^{2} / 2}
$$

Da mesma forma, como,

$$
\operatorname{Var}\left(y_{i j} \mid \alpha_{j}, \beta_{j}, X_{i j}\right)=\operatorname{Var}\left[E\left(y_{i j} \mid \alpha_{j}, \beta_{j}, w_{i}, X_{i j}\right)\right]+E\left[\operatorname{Var}\left(y_{i j} \mid \alpha_{j}, \beta_{j}, w_{i}, X_{i j}\right)\right]
$$

tem-se, por (11),

$$
\operatorname{Var}\left(y_{i j} \mid \alpha_{j}, \beta_{j}, X_{i j}\right)=\alpha_{j}^{2} e^{2 \beta_{j} X_{i j}} \operatorname{Var}\left(e^{w_{i}}\right)+\alpha_{j} e^{\beta_{j} X_{i j}} E\left(e^{w_{i}}\right)
$$


Assim,

$$
\operatorname{Var}\left(y_{i j} \mid \alpha_{j}, \beta_{j}, X_{i j}\right)=\alpha_{j}^{2} e^{2 \beta_{j} X_{i j}}\left(e^{\tau^{2}}-1\right) e^{\tau^{2}}+\alpha_{j} e^{\beta_{j} X_{i j}} e^{\tau^{2} / 2}
$$

De (12) e (13), observa-se que a média e a variância de $y_{i j}$ dado $\alpha_{j}, \beta_{j}$ e $X_{i j}$ são diferentes, isto é, há a presença da variabilidade extra-Poisson, dada por $\alpha_{j}^{2} e^{2 \beta_{j} X_{i j}}\left(e^{\tau^{2}}-1\right) e^{\tau^{2}}$, incorporada ao modelo (10).

Considerando o modelo (10), a função de verossimilhança para $\boldsymbol{\alpha}=\left(\alpha_{1}, \ldots, \alpha_{24}\right)$ e $\boldsymbol{\beta}=\left(\beta_{1}, \ldots, \beta_{24}\right)$ dado os dados observados $y_{i j}$, as variáveis latentes não-observadas $w_{i}$ e as covariáveis $X_{i j}, i=1, \ldots, 16 ; j=1, \ldots, 24$, é dada por,

$$
\begin{aligned}
L(\boldsymbol{\alpha}, \boldsymbol{\beta}) & =\prod_{i=1}^{n} \prod_{j=1}^{t} \frac{e^{-\lambda_{i j}} \lambda_{i j}^{y_{i j}}}{y_{i j} !} \\
& \propto \exp \left(-\sum_{i=1}^{n} \sum_{j=1}^{t} \lambda_{i j}\right) \prod_{i=1}^{n} \prod_{j=1}^{t} \lambda_{i j}^{y_{i j}}
\end{aligned}
$$

em que, $\lambda_{i j}$ é dado em (10).

\subsubsection{Análise Bayesiana}

Considerando uma análise Bayesiana hierárquica dos dados das Tabelas 1 e 2, observase que os efeitos aleatórios ou fragilidades $w_{i}$ são parâmetros do modelo (PAULINO et al., 2003). Assim, para o primeiro estágio da análise Bayesiana hierárquica, as seguintes distribuições a priori para $\alpha_{j}, \beta_{j}$ e $w_{i}$ são consideradas,

$$
\begin{aligned}
& \alpha_{j} \sim \operatorname{Gama}(a ; b) ; a, b \text { conhecidos; } \\
& \beta_{j} \sim N\left(c ; d^{2}\right) ; c, d \text { conhecidos; } \\
& w_{i} \sim N\left(0 ; \tau^{2}\right)
\end{aligned}
$$


em que, $i=1, \ldots, 16 ; j=1, \ldots, 24 ; \operatorname{Gama}(a ; b)$ denota uma distribuição gama com média $a / b$ e variância $a / b^{2}$ e $N\left(c ; d^{2}\right)$ denota uma distribuição normal com média $c$ e variância $d^{2}$.

Para o segundo estágio da análise Bayesiana é considerado uma distribuição gama inversa para $\tau^{2}$, isto é,

$$
\tau^{2} \sim I G(f ; g)
$$

em que, $f$ e $g$ são conhecidos.

Além disso, foi assumido independência a priori entre os parâmetros. Assim, a distribuição a priori conjunta é dada por,

$$
\begin{aligned}
\pi\left(\boldsymbol{\alpha}, \boldsymbol{\beta}, \mathbf{w}, \tau^{2}\right) \propto & \prod_{j=1}^{t} \alpha_{j}^{a-1} e^{-b \alpha_{j}} \times \prod_{j=1}^{t} \exp \left[-\frac{1}{2 d^{2}}\left(\beta_{j}-c\right)^{2}\right] \times \\
& \times \prod_{i=1}^{n} \frac{1}{\sqrt{2 \pi \tau^{2}}} \exp \left(-\frac{w_{i}^{2}}{2 \tau^{2}}\right) \times\left(\tau^{2}\right)^{-(f+1)} \exp \left(-\frac{g}{\tau^{2}}\right) .
\end{aligned}
$$

A partir da fórmula de Bayes é possível obter a distribuição a posteriori conjunta para os parâmetros, combinando a distribuição a priori (17) com a função de verossimilhança (14).

As distribuições a posteriori condicionais utilizadas no amostrador de Gibbs (GELFAND; SMITH, 1990), são dadas por:

(i) Para $\alpha_{j}$, em que $j=1, \ldots, 24$,

$$
\begin{aligned}
\pi\left(\alpha_{j} \mid \boldsymbol{\alpha}_{(j)}, \boldsymbol{\beta}, \mathbf{w}, \tau^{2}, \mathbf{y}, \mathbf{x}\right) & \propto \alpha_{j}^{a-1} e^{-b \alpha_{j}} \times \exp \left(-\alpha_{j} \sum_{i=1}^{n} e^{w_{i}} e^{\beta_{j} X_{i j}}\right)\left(\prod_{i=1}^{n} \alpha_{j}^{y_{i j}}\right) \\
& \propto \alpha_{j}^{a+\sum_{i=1}^{n} y_{i j}-1} \exp \left[-\alpha_{j}\left(b+\sum_{i=1}^{n} e^{w_{i}} e^{\beta_{j} X_{i j}}\right)\right], \quad \alpha_{j} \geq 0
\end{aligned}
$$

em que, $\boldsymbol{\alpha}_{(j)}=\left(\alpha_{1}, \ldots, \alpha_{j-1}, \alpha_{j+1}, \ldots, \alpha_{t}\right)$; y é o vetor dos dados e $\mathbf{x}$ é o vetor das covariáveis.

Logo,

$$
\alpha_{j} \mid \boldsymbol{\alpha}_{(j)}, \boldsymbol{\beta}, \mathbf{w}, \mathbf{y}, \mathbf{x} \sim \operatorname{Gama}\left(a+\sum_{i=1}^{n} y_{i j}, b+\sum_{i=1}^{n} e^{w_{i}} e^{\beta_{j} X_{i j}}\right)
$$


(ii) Para $\beta_{j}$, em que $j=1, \ldots, 24$,

$$
\begin{aligned}
\pi\left(\beta_{j} \mid \boldsymbol{\alpha}, \boldsymbol{\beta}_{(j)}, \mathbf{w}, \tau^{2}, \mathbf{y}, \mathbf{x}\right) \propto & \exp \left[-\frac{1}{2 d^{2}}\left(\beta_{j}-c\right)^{2}\right] \times \exp \left(-\alpha_{j} \sum_{i=1}^{n} e^{w_{i}} e^{\beta_{j} X_{i j}}\right) \times \\
& \times \exp \left[\sum_{i=1}^{n} y_{i j}\left(\beta_{j} X_{i j}+w_{i}\right)\right], \quad-\infty<\beta_{j}<\infty
\end{aligned}
$$

em que, $\boldsymbol{\beta}_{(j)}=\left(\beta_{1}, \ldots, \beta_{j-1}, \beta_{j+1}, \ldots, \beta_{t}\right)$.

Logo,

$$
\pi\left(\beta_{j} \mid \boldsymbol{\alpha}, \boldsymbol{\beta}_{(j)}, \mathbf{w}, \tau^{2}, \mathbf{y}, \mathbf{x}\right) \propto N\left(c, d^{2}\right) \psi_{1}(\boldsymbol{\alpha}, \boldsymbol{\beta}, \mathbf{w} \mid \mathbf{y}, \mathbf{x})
$$

em que,

$$
\psi_{1}(\boldsymbol{\alpha}, \boldsymbol{\beta}, \mathbf{w} \mid \mathbf{y}, \mathbf{x})=\exp \left(-\alpha_{j} \sum_{i=1}^{n} e^{w_{i}} e^{\beta_{j} X_{i j}}+\sum_{i=1}^{n} y_{i j}\left(\beta_{j} X_{i j}+w_{i}\right)\right)
$$

(iii) Para $w_{i}$, em que $i=1, \ldots, 16$,

$$
\begin{aligned}
\pi\left(w_{i} \mid \boldsymbol{\alpha}, \boldsymbol{\beta}, \mathbf{w}_{(i)}, \tau^{2}, \mathbf{y}, \mathbf{x}\right) \propto & \exp \left(-\frac{w_{i}^{2}}{2 \tau^{2}}\right) \times \exp \left(-e^{w_{i}} \sum_{j=1}^{t} \alpha_{j} e^{\beta_{j} X_{i j}}\right) \times \\
& \times \exp \left[\sum_{j=1}^{t} y_{i j}\left(\beta_{j} X_{i j}+w_{i}\right)\right], \quad-\infty<w_{i}<\infty
\end{aligned}
$$

em que, $\mathbf{w}_{(i)}=\left(w_{1}, \ldots, w_{i-1}, w_{i+1}, \ldots, w_{n}\right)$.

Logo,

$$
\pi\left(w_{i} \mid \boldsymbol{\alpha}, \boldsymbol{\beta}, \mathbf{w}_{(i)}, \tau^{2}, \mathbf{y}, \mathbf{x}\right) \propto N\left(0, \tau^{2}\right) \psi_{2}(\boldsymbol{\alpha}, \boldsymbol{\beta}, \mathbf{w} \mid \mathbf{y}, \mathbf{x})
$$

em que,

$$
\psi_{2}(\boldsymbol{\alpha}, \boldsymbol{\beta}, \mathbf{w} \mid \mathbf{y}, \mathbf{x})=\exp \left[-e^{w_{i}} \sum_{j=1}^{t} \alpha_{j} e^{\beta_{j} X_{i j}}+\sum_{j=1}^{t} y_{i j}\left(\beta_{j} X_{i j}+w_{i}\right)\right]
$$


(iv) Para $\tau^{2}$

$$
\begin{aligned}
\pi\left(\tau^{2} \mid \boldsymbol{\alpha}, \boldsymbol{\beta}, \mathbf{w}, \mathbf{y}, \mathbf{x}\right) & \propto \prod_{i=1}^{n} \frac{1}{\sqrt{2 \pi \tau^{2}}} \exp \left(-\frac{w_{i}^{2}}{2 \tau^{2}}\right) \times\left(\tau^{2}\right)^{-(f+1)} \exp \left(-\frac{g}{\tau^{2}}\right) \\
& \propto\left(\tau^{2}\right)^{-n / 2} \exp \left(-\frac{1}{2 \tau^{2}} \sum_{i=1}^{n} w_{i}^{2}\right) \times\left(\tau^{2}\right)^{-(f+1)} \exp \left(-\frac{g}{\tau^{2}}\right) \\
& \propto\left(\tau^{2}\right)^{-(f+n / 2+1)} \exp \left[-\frac{1}{\tau^{2}}\left(g+\frac{1}{2} \sum_{i=1}^{n} w_{i}^{2}\right)\right], \quad \tau^{2} \geq 0
\end{aligned}
$$

$\log \mathrm{O}$

$$
\tau^{2} \mid \boldsymbol{\alpha}, \boldsymbol{\beta}, \mathbf{w}, \mathbf{y}, \mathbf{x} \sim I G\left(f+\frac{n}{2}, g+\frac{1}{2} \sum_{i=1}^{n} w_{i}^{2}\right)
$$

Para a análise Bayesiana dos dados das Tabelas 1 e 2, considera-se $a=b=0,01$; $c=0 ; d^{2}=1000 ; f=g=0,1$ para as distribuições a priori (15) e (16). Essas escolhas dos hiperparâmetros são motivadas para se ter distribuições a priori aproximadamente nãoinformativas e tal que a convergência do algoritmo de simulação (Gibbs com MetropolisHastings) seja observada.

Para obtenção das estimativas dos parâmetros do modelo (10), baseado no método Bayesiano via amostrador de Gibbs, o Software Winbugs é utilizado (ver, Apêndice A), o programa desenvolvido esta disponível no Apêndice B. Os parâmetros são estimados via algoritmos Gibbs-Sampling e Metropolis-Hastings. São geradas 1.005.000 amostras, das quais as 5.000 primeiras são descartadas ("burn-in-samples") com a finalidade de eliminar o efeito dos valores iniciais usados no algoritmo de simulação. Para se ter uma amostra de Gibbs aproximadamente não correlacionada, considera-se as iterações $100^{a}, 200^{a}, 300^{a}, \ldots$, resultando em uma amostra final de 10.000 observações para cada parâmetro. A convergência do algoritmo foi verificada através de gráficos temporais das amostras geradas e utilizando técnicas usuais existentes na literatura (GELMAN; RUBIN, 1992). Nas Tabelas 3 e 4, tem-se os sumários a posteriori obtidos para os parâmetros do modelo.

Para verificar o efeito de tratamento para os ratos que receberam primeiro a solução salina e depois a solução ocitocina estima-se um parâmetro $\theta_{k}$ dado por $\theta_{k}=\alpha_{k+12}-\alpha_{k}$, 
para $k=1,2, \ldots, 12$; para verificar o efeito de tratamento para os ratos que receberam primeiro a solução ocitocina e depois a solução salina, foi estimado um parâmetro $\eta_{k}$ dado por $\eta_{k}=\alpha_{k+12} e^{\beta_{k+12}}-\alpha_{k} e^{\beta_{k}}$ para $k=1, \ldots, 12$. Essas estimativas Bayesianas também são dadas nas Tabelas 3 e 4 .

Com propósito comparativo, uma análise clássica dos dados das Tabelas 1 e 2 é feita. Para a obtenção dos estimadores de máxima verossimilhança para os parâmetros do modelo (10), a rotina PROC NLMIXED (ver, Apêndice A) do software SAS é utilizada. O programa utilizado esta disponível no Apêndice B.

Os erros padrão das estimativas para os parâmetros $\theta_{k}$ e $\eta_{k}$ são encontrados utilizando o método delta. O método Delta, (RAO; TOUTENBURG, 1999) calcula a $\widehat{\operatorname{Var}}\left(\hat{\theta}_{k}\right)$, por exemplo, a partir da matriz de variâncias-covariâncias de $\alpha_{j}$ e $\beta_{j}$, estimada pela inversa da matriz de segundas derivadas da função de log-verossimilhança.

Os intervalos de confiança são construídos a partir da estatística $t$ de Wald, com graus de liberdade igual ao número de indivíduos menos o número de efeitos aleatórios. As estimativas dos parâmetros com seus respectivos intervalos de confiança encontram-se nas Tabelas 5 e 6.

Para os modelos clássico e Bayesiano, observa-se que os valores preditos se aproximam dos valores observados e as suposições residuais são atendidas.

\subsection{Algumas Notas Conclusivas}

Dos resultados das Tabelas 3 e 5, percebe-se que muitos intervalos de confiança e de credibilidade para o parâmetro $\beta_{j}$ contem o valor zero, logo, a partir dessa amostra, não há evidências de que exista diferença na contagem média de autolimpeza em aplicar primeiro a solução salina e depois a solução ocitocina, e aplicar primeiro a solução ocitocina e depois a solução salina (não há efeito de seqüência). Percebe-se, também, que um grande número de intervalos de confiança e de credibilidade para os parâmetros $\theta_{k}$ e $\eta_{k}$ não contem o valor zero, ou seja, a partir dessa amostra existem evidências de que há diferença na contagem média de autolimpeza entre o grupo que recebeu a solução salina e o grupo que recebeu 
a solução ocitocina.

Observa-se que as estimativas Bayesianas apresentam melhores resultados se comparado com as estimativas clássicas, pois a maioria dos desvios padrão para as estimativas dos parâmetros do modelo via método Bayesiano e a maioria das amplitudes dos intervalos de credibilidade, são menores se comparados com o método clássico. Percebe-se, também, que na estimativa clássica o parâmetro $\beta_{12}$ retorna um desvio padrão muito alto, tornando sua estimativa e intervalo de confiança não muito confiáveis. Como na modelagem Bayesiana utilizou-se distribuição a priori não-informativas, esperase que as estimativas dos parâmetros do modelo sejam semelhantes às estimativas obtidas pela modelagem clássica, porem percebe-se que as estimativas via modelagem Bayesiana retornam melhores resultados, por esse motivo é muito importante a comparação entre as inferências clássica e Bayesiana.

É importante salientar que os resultados da inferência Bayesiana são muito mais sensíveis na captura de efeitos de fatores que muitas vezes não são observados utilizando inferência clássica, isto é observado nas informações por intervalo para os parâmetros $\eta_{4}$ e $\eta_{10}$ (ver, Tabelas 3 e 5) onde o método Bayesiano mostra efeito significativo.

O modelo Bayesiano apresenta melhores resultados, visto que visa a estimação de quantidades desconhecidas utilizando outras informações além da amostra expressa, através da verossimilhança. Essas informações adicionais são consideradas subjetivas, pois expressam a incerteza sobre o parâmetro antes da observação dos dados e são representadas através da distribuição a priori. Além disso, os métodos clássicos são baseados em resultados assintóticos nem sempre de boa precisão, especialmente para situações de amostras pequenas. 
Tabela 3: Estimativas dos parâmetros do modelo via método Bayesiano.

\begin{tabular}{|c|c|c|c|c|}
\hline Parâmetro & $\begin{array}{c}\text { Média a } \\
\text { Posteriori }\end{array}$ & $\begin{array}{l}\text { Desvio } \\
\text { Padrão }\end{array}$ & $\begin{array}{c}\text { Intervalo de } \\
\text { Credibilidade } 95 \%\end{array}$ & $\begin{array}{l}\text { Amplitude do } \\
\text { Intervalo }\end{array}$ \\
\hline$\beta_{1}$ & 0,9054 & 0,4720 & $(-0,0021 ; 1,8630)$ & 1,8651 \\
\hline$\beta_{2}$ & 0,0446 & 0,4123 & $(-0,7495 ; 0,8655)$ & 1,6150 \\
\hline$\beta_{3}$ & 0,0966 & 0,3898 & $(-0,6557 ; 0,8638)$ & 1,5195 \\
\hline$\beta_{4}$ & 0,1681 & 0,4237 & $(-0,6532 ; 0,9972)$ & 1,6504 \\
\hline$\beta_{5}$ & $-3,8090$ & 1,3250 & $(-6,9760 ;-1,7560)$ & 5,2200 \\
\hline$\beta_{6}$ & 0,4838 & 0,5172 & $(-0,5147 ; 1,5010)$ & 2,0157 \\
\hline$\beta_{7}$ & 0,4006 & 0,5517 & $(-0,6879 ; 1,4990)$ & 2,1869 \\
\hline$\beta_{8}$ & $-2,6100$ & 1,3620 & $(-5,8810 ;-0,5395)$ & 5,3415 \\
\hline$\beta_{9}$ & 0,1283 & 0,6144 & $(-1,0840 ; 1,3070)$ & 2,3910 \\
\hline$\beta_{10}$ & 2,6970 & 1,3750 & $(0,4989 ; 5,8780)$ & 5,3791 \\
\hline$\beta_{11}$ & $-1,9030$ & 0,8935 & $(-3,8750 ;-0,3363)$ & 3,5387 \\
\hline$\beta_{12}$ & $-26,5100$ & 18,6000 & $(-70,5000 ;-2,8840)$ & 67,616 \\
\hline$\beta_{13}$ & $-0,7162$ & 0,4385 & $(-1,5840 ; 0,1430)$ & 1,7270 \\
\hline$\beta_{14}$ & 0,1545 & 0,3898 & $(-0,6104 ; 0,9281)$ & 1,5385 \\
\hline$\beta_{15}$ & $-0,2677$ & 0,3885 & $(-1,0350 ; 0,5079)$ & 1,5429 \\
\hline$\beta_{16}$ & 0,7189 & 0,3895 & $(-0,0399 ; 1,5090)$ & 1,5489 \\
\hline$\beta_{17}$ & 0,3841 & 0,3779 & $(-0,3553 ; 1,1350)$ & 1,4903 \\
\hline$\beta_{18}$ & 0,5245 & 0,3699 & $(-0,1917 ; 1,2700)$ & 1,4617 \\
\hline$\beta_{19}$ & 0,1549 & 0,3713 & $(-0,5712 ; 0,8982)$ & 1,4694 \\
\hline$\beta_{20}$ & 0,1951 & 0,3768 & $(-0,5381 ; 0,9396)$ & 1,4777 \\
\hline$\beta_{21}$ & 0,4421 & 0,4207 & $(-0,3832 ; 1,2900)$ & 1,6732 \\
\hline$\beta_{22}$ & $-0,5101$ & 0,4300 & $(-1,3560 ; 0,3431)$ & 1,6991 \\
\hline$\beta_{23}$ & 0,5854 & 0,4751 & $(-0,3278 ; 1,5550)$ & 1,8828 \\
\hline$\beta_{24}$ & $-0,3971$ & 0,5731 & $(-1,5200 ; 0,7107)$ & 2,2307 \\
\hline$\theta_{1}$ & 2,8320 & 0,9286 & $(1,2880 ; 4,9400)$ & 3,6520 \\
\hline$\theta_{2}$ & 0,8246 & 0,8768 & $(-0,8454 ; 2,6640)$ & 3,5094 \\
\hline$\theta_{3}$ & 1,6520 & 1,0310 & $(-0,1668 ; 3,9150)$ & 4,0818 \\
\hline$\theta_{4}$ & 0,5601 & 0,7596 & $(-0,9023 ; 2,1450)$ & 3,0473 \\
\hline$\theta_{5}$ & 1,3810 & 0,9614 & $(-0,3113 ; 3,4770)$ & 3,7883 \\
\hline$\theta_{6}$ & 4,0400 & 1,1570 & $(2,1560 ; 6,5950)$ & 4,4390 \\
\hline$\theta_{7}$ & 5,4240 & 1,4190 & $(3,1020 ; 8,6390)$ & 5,5370 \\
\hline$\theta_{8}$ & 4,3120 & 1,2050 & $(2,3440 ; 7,0250)$ & 4,6810 \\
\hline$\theta_{9}$ & 1,7430 & 0,6828 & $(0,6040 ; 3,3040)$ & 2,7000 \\
\hline$\theta_{10}$ & 3,9590 & 1,0400 & $(2,2830 ; 6,3140)$ & 4,0310 \\
\hline$\theta_{11}$ & 0,0025 & 0,5258 & $(-1,0260 ; 1,0650)$ & 2,0910 \\
\hline$\theta_{12}$ & 0,5590 & 0,4723 & $(-0,2931 ; 1,570)$ & 1,8631 \\
\hline$\eta_{1}$ & $-1,1040$ & 0,9170 & $(-3,0800 ; 0,5342)$ & 3,6140 \\
\hline$\eta_{2}$ & 1,3830 & 1,1730 & $(-0,7172 ; 3,9070)$ & 4,6242 \\
\hline$\eta_{3}$ & $-0,1338$ & 1,1560 & $(-2,4890 ; 2,2110)$ & 4,7000 \\
\hline$\eta_{4}$ & 3,4560 & 1,4900 & $(1,0430 ; 6,8640)$ & 5,8210 \\
\hline$\eta_{5}$ & 7,2060 & 2,0960 & $(3,9740 ; 12,0800)$ & 8,1060 \\
\hline$\eta_{6}$ & 6,9480 & 2,1170 & $(3,6600 ; 11,9100)$ & 8,2500 \\
\hline$\eta_{7}$ & 6,0940 & 1,9220 & $(3,1360 ; 10,5400)$ & 7,4040 \\
\hline$\eta_{8}$ & 6,5170 & 1,9410 & $(3,5120 ; 11,0400)$ & 7,5280 \\
\hline$\eta_{9}$ & 3,0640 & 1,1600 & $(1,2400 ; 5,8010)$ & 4,5610 \\
\hline$\eta_{10}$ & 1,6570 & 0,8103 & $(0,3667 ; 3,5130)$ & 3,1463 \\
\hline$\eta_{11}$ & 2,3650 & 0,8978 & $(1,0090 ; 4,4690)$ & 3,4600 \\
\hline$\eta_{12}$ & 0,9704 & 0,4522 & $(0,3332 ; 2,0480)$ & 1,7148 \\
\hline$\tau^{2}$ & 0,4094 & 0,1949 & $(0,1757 ; 0,9036)$ & 0,7279 \\
\hline
\end{tabular}


Tabela 4: Estimativas das taxas médias de autolimpeza via método Bayesiano.

\begin{tabular}{|c|c|c|c|c|}
\hline Parâmetro & $\begin{array}{l}\text { Média a } \\
\text { Posteriori }\end{array}$ & $\begin{array}{l}\text { Desvio } \\
\text { Padrão }\end{array}$ & $\begin{array}{c}\text { Intervalo de } \\
\text { Credibilidade } 95 \%\end{array}$ & $\begin{array}{l}\text { Amplitude do } \\
\text { Intervalo }\end{array}$ \\
\hline$\alpha_{1}$ & 1,2990 & 0,4544 & $(0,6053 ; 2,3640)$ & 1,7587 \\
\hline$\alpha_{2}$ & 3,3990 & 0,9155 & $(1,9160 ; 5,4620)$ & 3,5460 \\
\hline$\alpha_{3}$ & 4,2330 & 1,1070 & $(2,4360 ; 6,6590)$ & 4,2230 \\
\hline$\alpha_{4}$ & 2,6660 & 0,7552 & $(1,4500 ; 4,3920)$ & 2,9420 \\
\hline$\alpha_{5}$ & 3,5890 & 0,9593 & $(2,0200 ; 5,7340)$ & 3,7140 \\
\hline$\alpha_{6}$ & 1,1020 & 0,3983 & $(0,4799 ; 2,0470)$ & 1,5671 \\
\hline$\alpha_{7}$ & 0,9193 & 0,3512 & $(0,3905 ; 1,7460)$ & 1,3555 \\
\hline$\alpha_{8}$ & 1,1090 & 0,4060 & $(0,4936 ; 2,0660)$ & 1,5724 \\
\hline$\alpha_{9}$ & 0,8251 & 0,3290 & $(0,3307 ; 1,6200)$ & 1,2893 \\
\hline$\alpha_{10}$ & 0,0909 & 0,0939 & $(0,0023 ; 0,3453)$ & 0,3430 \\
\hline$\alpha_{11}$ & 1,4650 & 0,4782 & $(0,7199 ; 2,5670)$ & 1,8471 \\
\hline$\alpha_{12}$ & 0,8212 & 0,3247 & $(0,3257 ; 1,5790)$ & 1,2533 \\
\hline$\alpha_{13}$ & 4,1310 & 1,0670 & $(2,3850 ; 6,5460)$ & 4,1610 \\
\hline$\alpha_{14}$ & 4,2240 & 1,0830 & $(2,4510 ; 6,6290)$ & 4,1780 \\
\hline$\alpha_{15}$ & 5,8850 & 1,4400 & $(3,5220 ; 9,1520)$ & 5,6300 \\
\hline$\alpha_{16}$ & 3,2260 & 0,8757 & $(1,8180 ; 5,2320)$ & 3,4140 \\
\hline$\alpha_{17}$ & 4,9700 & 1,2840 & $(2,8940 ; 7,8750)$ & 4,9810 \\
\hline$\alpha_{18}$ & 5,1420 & 1,2990 & $(3,0030 ; 8,0490)$ & 5,0460 \\
\hline$\alpha_{19}$ & 6,3440 & 1,5540 & $(3,7810 ; 9,8880)$ & 6,1070 \\
\hline$\alpha_{20}$ & 5,4200 & 1,3590 & $(3,1690 ; 8,4880)$ & 5,3190 \\
\hline$\alpha_{21}$ & 2,5680 & 0,7350 & $(1,3980 ; 4,2720)$ & 2,8740 \\
\hline$\alpha_{22}$ & 4,0500 & 1,0510 & $(2,3450 ; 6,4160)$ & 4,0710 \\
\hline$\alpha_{23}$ & 1,4680 & 0,4899 & $(0,7060 ; 2,6030)$ & 1,8970 \\
\hline$\alpha_{24}$ & 1,3800 & 0,4637 & $(0,6459 ; 2,4480)$ & 1,8021 \\
\hline$\alpha_{1} e^{\beta_{1}}$ & 3,1850 & 1,0490 & $(1,6150 ; 5,6080)$ & 3,9930 \\
\hline$\alpha_{2} e^{\beta_{2}}$ & 3,6060 & 1,1700 & $(1,8230 ; 6,2190)$ & 4,3960 \\
\hline$\alpha_{3} e^{\beta_{3}}$ & 4,7150 & 1,4370 & $(2,5060 ; 8,0130)$ & 5,5070 \\
\hline$\alpha_{4} e^{\beta_{4}}$ & 3,1950 & 1,0540 & $(1,5890 ; 5,6350)$ & 4,0460 \\
\hline$\alpha_{5} e^{\beta_{5}}$ & 0,1405 & 0,1499 & $(0,0033 ; 0,5483)$ & 0,5449 \\
\hline$\alpha_{6} e^{\beta_{6}}$ & 1,7960 & 0,6834 & $(0,7872 ; 3,4010)$ & 2,6138 \\
\hline$\alpha_{7} e^{\beta_{7}}$ & 1,3850 & 0,5684 & $(0,5613 ; 2,7760)$ & 2,2147 \\
\hline$\alpha_{8} e^{\beta_{8}}$ & 0,1395 & 0,1462 & $(0,0031 ; 0,5340)$ & 0,5309 \\
\hline$\alpha_{9} e^{\beta_{9}}$ & 0,9624 & 0,4460 & $(0,3293 ; 2,0410)$ & 1,7117 \\
\hline$\alpha_{10} e^{\beta_{10}}$ & 0,8377 & 0,4145 & $(0,2638 ; 1,8360)$ & 1,5722 \\
\hline$\alpha_{11} e^{\beta_{11}}$ & 0,2800 & 0,2185 & $(0,0319 ; 0,8412)$ & 0,8093 \\
\hline$\alpha_{12} e^{\beta_{12}}$ & 0,0037 & 0,0231 & $\left(1,6666 \times 10^{-31} ; 0,0396\right)$ & 0,0396 \\
\hline$\alpha_{13} e^{\beta_{13}}$ & 2,0800 & 0,7609 & $(0,9581 ; 3,8830)$ & 2,9249 \\
\hline$\alpha_{14 e^{\beta_{14}}}$ & 4,9890 & 1,5320 & $(2,6390 ; 8,5390)$ & 5,9000 \\
\hline$\alpha_{15} e^{\beta_{15}}$ & 4,5810 & 1,4410 & $(2,3920 ; 7,9020)$ & 5,5100 \\
\hline$\alpha_{16} e^{\beta_{16}}$ & 6,6510 & 1,9410 & $(3,6170 ; 11,1800)$ & 7,5630 \\
\hline$\alpha_{17} e^{\beta_{17}}$ & 7,3460 & 2,1230 & $(4,0810 ; 12,2400)$ & 8,1590 \\
\hline$\alpha_{18} e^{\beta_{18}}$ & 8,7440 & 2,4540 & $(4,9250 ; 14,5700)$ & 9,6450 \\
\hline$\alpha_{19} e^{\beta_{19}}$ & 7,4790 & 2,1550 & $(4,1620 ; 12,4900)$ & 8,3280 \\
\hline$\alpha_{20} e^{\beta_{20}}$ & 6,6560 & 1,9670 & $(3,5980 ; 11,2000)$ & 7,6020 \\
\hline$\alpha_{21} e^{\beta_{21}}$ & 4,0260 & 1,2780 & $(2,0760 ; 7,0730)$ & 4,9970 \\
\hline$\alpha_{22} e^{\beta_{22}}$ & 2,4940 & 0,8744 & $(1,1910 ; 4,5120)$ & 3,3210 \\
\hline$\alpha_{23} e^{\beta_{23}}$ & 2,6450 & 0,9244 & $(1,2840 ; 4,8050)$ & 3,5210 \\
\hline$\alpha_{24} e^{\beta_{24}}$ & 0,9741 & 0,4523 & $(0,3400 ; 2,0560)$ & 1,7160 \\
\hline
\end{tabular}


Tabela 5: Estimativas dos parâmetros do modelo via método Clássico.

\begin{tabular}{|c|c|c|c|c|}
\hline Parâmetro & Estimativa & $\begin{array}{l}\text { Desvio } \\
\text { Padrão }\end{array}$ & $\begin{array}{c}\text { Intervalo de } \\
\text { Confiança } 95 \%\end{array}$ & $\begin{array}{l}\text { Amplitude do } \\
\text { Intervalo }\end{array}$ \\
\hline$\beta_{1}$ & 0,7410 & 0,4647 & $(-0,2068 ; 1,6888)$ & 1,8956 \\
\hline$\beta_{2}$ & $-0,1082$ & 0,4081 & $(-0,9406 ; 0,7242)$ & 1,6648 \\
\hline$\beta_{3}$ & $-0,0575$ & 0,3902 & $(-0,8532 ; 0,7382)$ & 1,5914 \\
\hline$\beta_{4}$ & 0,0129 & 0,4231 & $(-0,8500 ; 0,8759)$ & 1,7259 \\
\hline$\beta_{5}$ & $-3,4184$ & 1,0613 & $(-5,5828 ;-1,2539)$ & 4,3289 \\
\hline$\beta_{6}$ & 0,3248 & 0,5112 & $(-0,7178 ; 1,3674)$ & 2,0852 \\
\hline$\beta_{7}$ & 0,2447 & 0,5487 & $(-0,8744 ; 1,3638)$ & 2,2382 \\
\hline$\beta_{8}$ & $-2,2401$ & 1,0883 & $(-4,4597 ;-0,0205)$ & 4,4392 \\
\hline$\beta_{9}$ & $-0,0067$ & 0,5958 & $(-1,2219 ; 1,2085)$ & 2,4304 \\
\hline$\beta_{10}$ & 2,0353 & 1,1255 & $(-0,2602 ; 4,3309)$ & 4,5911 \\
\hline$\beta_{11}$ & $-1,8349$ & 0,8147 & $(-3,4964 ;-0,1734)$ & 3,3230 \\
\hline$\beta_{12}$ & $-11,9777$ & 150,31 & $(-318,54 ; 294,58)$ & 613,12 \\
\hline$\beta_{13}$ & $-0,6600$ & 0,4336 & $(-1,5444 ; 0,2244)$ & 1,7688 \\
\hline$\beta_{14}$ & 0,1935 & 0,3856 & $(-0,5929 ; 0,9799)$ & 1,5728 \\
\hline$\beta_{15}$ & $-0,2240$ & 0,3809 & $(-1,0009 ; 0,5529)$ & 1,5538 \\
\hline$\beta_{16}$ & 0,7544 & 0,3854 & $(-0,0317 ; 1,5406)$ & 1,5723 \\
\hline$\beta_{17}$ & 0,4199 & 0,3695 & $(-0,3338 ; 1,1736)$ & 1,5074 \\
\hline$\beta_{18}$ & 0,5564 & 0,3645 & $(-0,1871 ; 1,2998)$ & 1,4869 \\
\hline$\beta_{19}$ & 0,1935 & 0,3635 & $(-0,5479 ; 0,9350)$ & 1,4829 \\
\hline$\beta_{20}$ & 0,2322 & 0,3701 & $(-0,5226 ; 0,9869)$ & 1,5095 \\
\hline$\beta_{21}$ & 0,4736 & 0,4115 & $(-0,3657 ; 1,3130)$ & 1,6787 \\
\hline$\beta_{22}$ & $-0,4552$ & 0,4212 & $(-1,3143 ; 0,4039)$ & 1,7182 \\
\hline$\beta_{23}$ & 0,6106 & 0,4629 & $(-0,3335 ; 1,5547)$ & 1,8882 \\
\hline$\beta_{24}$ & $-0,3235$ & 0,5556 & $(-1,4567 ; 0,8096)$ & 2,2663 \\
\hline$\theta_{1}$ & 2,5398 & 1,0927 & $(0,3112 ; 4,7685)$ & 4,4573 \\
\hline$\theta_{2}$ & 0,4430 & 1,3792 & $(-2,3699 ; 3,2559)$ & 5,6258 \\
\hline$\theta_{3}$ & 1,1377 & 1,7480 & $(-2,4275 ; 4,7028)$ & 7,1303 \\
\hline$\theta_{4}$ & 0,2568 & 1,1183 & $(-2,0241 ; 2,5377)$ & 4,5618 \\
\hline$\theta_{5}$ & 0,9415 & 1,5164 & $(-2,1512 ; 4,0341)$ & 6,1853 \\
\hline$\theta_{6}$ & 3,6750 & 1,2640 & $(1,0971 ; 6,2528)$ & 5,1557 \\
\hline$\theta_{7}$ & 4,9821 & 1,4788 & $(1,9660 ; 7,9982)$ & 6,0322 \\
\hline$\theta_{8}$ & 3,9335 & 1,3163 & $(1,2490 ; 6,6180)$ & 5,3690 \\
\hline$\theta_{9}$ & 1,5531 & 0,7581 & $(0,0070 ; 3,0992)$ & 3,0922 \\
\hline$\theta_{10}$ & 3,6874 & 0,9820 & $(1,6845 ; 5,6903)$ & 4,0058 \\
\hline$\theta_{11}$ & $-0,1431$ & 0,6684 & $(-1,5063 ; 1,2202)$ & 2,7265 \\
\hline$\theta_{12}$ & 0,4355 & 0,5449 & $(-0,6758 ; 1,5468)$ & 2,2226 \\
\hline$\eta_{1}$ & $-0,7880$ & 1,1268 & $(-3,0860 ; 1,5101)$ & 4,5961 \\
\hline$\eta_{2}$ & 1,6473 & 1,6910 & $(-1,8016 ; 5,0962)$ & 6,8978 \\
\hline$\eta_{3}$ & 0,2775 & 1,7677 & $(-3,3277 ; 3,8827)$ & 7,2104 \\
\hline$\eta_{4}$ & 3,6101 & 1,9731 & $(-0,4140 ; 7,6343)$ & 8,0483 \\
\hline$\eta_{5}$ & 6,9433 & 1,9263 & $(3,0146 ; 10,8719)$ & 7,8573 \\
\hline$\eta_{6}$ & 6,8208 & 2,3111 & $(2,1073 ; 11,5343)$ & 9,4270 \\
\hline$\eta_{7}$ & 5,9856 & 2,0120 & $(1,8822 ; 10,0890)$ & 8,2068 \\
\hline$\eta_{8}$ & 6,2763 & 1,7681 & $(2,6702 ; 9,8823)$ & 7,2121 \\
\hline$\eta_{9}$ & 3,0171 & 1,2179 & $(0,5331 ; 5,5010)$ & 4,9679 \\
\hline$\eta_{10}$ & 1,6721 & 0,8693 & $(-0,1008 ; 3,4450)$ & 3,5458 \\
\hline$\eta_{11}$ & 2,2902 & 0,8510 & $(0,5547 ; 4,0258)$ & 3,4711 \\
\hline$\eta_{12}$ & 0,9329 & 0,4152 & $(0,0862 ; 1,7797)$ & 1,6935 \\
\hline$\tau^{2}$ & 0,3840 & 0,1117 & $(0,1561 ; 0,6118)$ & 0,4557 \\
\hline
\end{tabular}


Tabela 6: Estimativas das taxas médias de autolimpeza via método Clássico.

\begin{tabular}{|c|c|c|c|c|}
\hline Parâmetro & Estimativa & $\begin{array}{l}\text { Desvio } \\
\text { Padrão }\end{array}$ & $\begin{array}{c}\text { Intervalo de } \\
\text { Confiança } 95 \%\end{array}$ & $\begin{array}{l}\text { Amplitude do } \\
\text { Intervalo }\end{array}$ \\
\hline$\alpha_{1}$ & 1,3285 & 0,4516 & $(0,4074 ; 2,2497)$ & 1,8423 \\
\hline$\alpha_{2}$ & 3,5111 & 0,9368 & $(1,6005 ; 5,4218)$ & 3,8213 \\
\hline$\alpha_{3}$ & 4,3648 & 1,1205 & $(2,0796 ; 6,6501)$ & 4,5705 \\
\hline$\alpha_{4}$ & 2,7519 & 0,7718 & $(1,1779 ; 4,3260)$ & 3,1481 \\
\hline$\alpha_{5}$ & 3,7007 & 0,9777 & $(1,7066 ; 5,6947)$ & 3,9881 \\
\hline$\alpha_{6}$ & 1,1387 & 0,4066 & $(0,3094 ; 1,9680)$ & 1,6586 \\
\hline$\alpha_{7}$ & 0,9489 & 0,3603 & $(0,2141 ; 1,6838)$ & 1,4697 \\
\hline$\alpha_{8}$ & 1,1386 & 0,4065 & $(0,3095 ; 1,9677)$ & 1,6582 \\
\hline$\alpha_{9}$ & 0,8539 & 0,3364 & $(0,1678 ; 1,5401)$ & 1,3723 \\
\hline$\alpha_{10}$ & 0,0950 & 0,0970 & $(-0,1029 ; 0,2928)$ & 0,3957 \\
\hline$\alpha_{11}$ & 1,5183 & 0,4959 & $(0,5070 ; 2,5296)$ & 2,0226 \\
\hline$\alpha_{12}$ & 0,8539 & 0,3364 & $(0,1677 ; 1,5400)$ & 1,3723 \\
\hline$\alpha_{13}$ & 3,8684 & 0,9957 & $(1,8376 ; 5,8992)$ & 4,0616 \\
\hline$\alpha_{14}$ & 3,9541 & 1,0141 & $(1,8860 ; 6,0223)$ & 4,1363 \\
\hline$\alpha_{15}$ & 5,5025 & 1,3441 & $(2,7612 ; 8,2438)$ & 5,4826 \\
\hline$\alpha_{16}$ & 3,0087 & 0,8107 & $(1,3553 ; 4,6622)$ & 3,3069 \\
\hline$\alpha_{17}$ & 4,6422 & 1,1611 & $(2,2741 ; 7,0102)$ & 4,7361 \\
\hline$\alpha_{18}$ & 4,8137 & 1,1974 & $(2,3716 ; 7,2558)$ & 4,8842 \\
\hline$\alpha_{19}$ & 5,9311 & 1,4348 & $(3,0048 ; 8,8573)$ & 5,8525 \\
\hline$\alpha_{20}$ & 5,0721 & 1,2525 & $(2,5175 ; 7,6266)$ & 5,1091 \\
\hline$\alpha_{21}$ & 2,4070 & 0,6797 & $(1,0207 ; 3,7933)$ & 2,7726 \\
\hline$\alpha_{22}$ & 3,7824 & 0,9773 & $(1,7892 ; 5,7756)$ & 3,9864 \\
\hline$\alpha_{23}$ & 1,3752 & 0,4489 & $(0,4598 ; 2,2907)$ & 1,8309 \\
\hline$\alpha_{24}$ & 1,2893 & 0,4290 & $(0,4145 ; 2,1642)$ & 1,7497 \\
\hline$\alpha_{1} e^{\beta_{1}}$ & 2,7874 & 0,8848 & $(0,9828 ; 4,5919)$ & 3,6091 \\
\hline$\alpha_{2} e^{\beta_{2}}$ & 3,1511 & 0,9750 & $(1,1625 ; 5,1397)$ & 3,9772 \\
\hline$\alpha_{3} e^{\beta_{3}}$ & 4,1209 & 1,2133 & $(1,6463 ; 6,5955)$ & 4,9492 \\
\hline$\alpha_{4} e^{\beta_{4}}$ & 2,7877 & 0,8849 & $(0,9830 ; 4,5925)$ & 3,6095 \\
\hline$\alpha_{5} e^{\beta_{5}}$ & 0,1213 & 0,1247 & $(-0,1330 ; 0,3755)$ & 0,5085 \\
\hline$\alpha_{6} e^{\beta_{6}}$ & 1,5757 & 0,5772 & $(0,3984 ; 2,7529)$ & 2,3545 \\
\hline$\alpha_{7} e^{\beta_{7}}$ & 1,2120 & 0,4807 & $(0,2317 ; 2,1924)$ & 1,9607 \\
\hline$\alpha_{8} e^{\beta_{8}}$ & 0,1212 & 0,1246 & $(-0,1330 ; 0,3754)$ & 0,5084 \\
\hline$\alpha_{9} e^{\beta_{9}}$ & 0,8482 & 0,3795 & $(0,0742 ; 1,6222)$ & 1,5480 \\
\hline$\alpha_{10} e^{\beta_{10}}$ & 0,7271 & 0,3441 & $(0,0253 ; 1,4289)$ & 1,4036 \\
\hline$\alpha_{11} e^{\beta_{11}}$ & 0,2424 & 0,1809 & $(-0,1267 ; 0,6114)$ & 0,7381 \\
\hline$\alpha_{12} e^{\beta_{12}}$ & 0,000005 & 0,0008 & $(-0,0016 ; 0,0017)$ & 0,0033 \\
\hline$\alpha_{13} e^{\beta_{13}}$ & 1,9994 & 0,6979 & $(0,5761 ; 3,4228)$ & 2,8467 \\
\hline$\alpha_{14} e^{\beta_{14}}$ & 4,7984 & 1,3820 & $(1,9798 ; 7,6169)$ & 5,6371 \\
\hline$\alpha_{15} e^{\beta_{15}}$ & 4,3984 & 1,2859 & $(1,7758 ; 7,0210)$ & 5,2452 \\
\hline$\alpha_{16} e^{\beta_{16}}$ & 6,3979 & 1,7638 & $(2,8006 ; 9,9952)$ & 7,1946 \\
\hline$\alpha_{17} e^{\beta_{17}}$ & 7,0645 & 1,9222 & $(3,1441 ; 10,9850)$ & 7,8409 \\
\hline$\alpha_{18} e^{\beta_{18}}$ & 8,3965 & 2,2380 & $(3,8320 ; 12,9609)$ & 9,1289 \\
\hline$\alpha_{19} e^{\beta_{19}}$ & 7,1976 & 1,9538 & $(3,2128 ; 11,1825)$ & 7,9697 \\
\hline$\alpha_{20} e^{\beta_{20}}$ & 6,3975 & 1,7637 & $(2,8004 ; 9,9946)$ & 7,1942 \\
\hline$\alpha_{21} e^{\beta_{21}}$ & 3,8653 & 1,1574 & $(1,5049 ; 6,2257)$ & 4,7208 \\
\hline$\alpha_{22} e^{\beta_{22}}$ & 2,3992 & 0,7983 & $(0,7710 ; 4,0274)$ & 3,2564 \\
\hline$\alpha_{23} e^{\beta_{23}}$ & 2,5326 & 0,8315 & $(0,8367 ; 4,2285)$ & 3,3918 \\
\hline$\alpha_{24} e^{\beta_{24}}$ & 0,9329 & 0,4152 & $(0,0862 ; 1,7797)$ & 1,6935 \\
\hline
\end{tabular}




\section{Análise de Dados Longitudinais de Contagem Utilizando Diferentes Modelos de "Fragilidade"}

Nesta seção é apresentado outra aplicação utilizando dados longitudinais de contagem na presença de covariáveis. O experimento é semelhante ao apresentado na Seção 2, sendo a variável resposta a contagem de grooming. Diferente do caso anterior, o interesse desse experimento não é estudar o efeito de seqüência entre as substâncias injetadas, mas sim, verificar a diferença da contagem média de grooming entre as espécies de ratos (Wistar e War). Os resultados aqui apresentados podem ser vistos em Achcar et al. (2008).

Nessa seção são apresentados diferentes modelos de "fragilidade" para a análise de dados longitudinais de Poisson na presença de uma covariável. Esses modelos incorporam a variabilidade extra-Poisson e a possível correlação entre as medidas repetidas para cada indivíduo. Considerando o método MCMC (Markov Chain Monte Carlo), é utilizada uma análise Bayesiana Hierárquica para analisar os dados de contagem na presença de covariáveis. Alguns aspectos de discriminação Bayesiana para a escolha do melhor modelo são apresentados. Dados de contagem longitudinal na presença de uma ou mais covariáveis são muito comuns, especialmente em estudos médicos. Para a análise deste tipo de dados, normalmente é necessário utilizar modelos que capturam a correlação entre os dados de contagem e a presença de sobredispersão. Diferentes modelos de "fragilidade" são introduzidos na literatura para analisar dados de contagem de Poisson, e o uso de métodos Bayesianos Hierárquicos são muito utilizados na analise deste tipo de dados.

Sejam os dados da Tabela 7, onde tem-se a contagem de grooming de 8 ratos Wistar machos em diferentes tempos, recebendo salina e ocitocina (os dados foram cedidos pelo CEMEQ, Faculdade de Medicina de Ribeirão Preto, Universidade de São Paulo, Brasil). Nesse experimento, realizado no Laboratório de Neurofisiologia e Neuroetologia Experimental (LNNE, Faculdade de Medicina de Ribeirão Preto, Universidade de São Paulo, Brasil), a variável resposta de interesse é mensurada em 24 tempos com intervalos de 5 minutos cada, depois da aplicação de dois tratamentos. Primeiramente o animal recebe a solução salina (Tratamento 1) onde são medidas 12 contagens de grooming 
(de 5 em 5 minutos); o experimento é repetido com os mesmos animais recebendo ocitocina (Tratamento 2), totalizando 24 contagens para cada rato. Da mesma maneira, o experimento é repetido com 6 ratos War (os dados são apresentados na Tabela 8). O interesse dessa pesquisa é verificar a diferença das contagens médias de grooming entre as espécies de ratos (Wistar e War).

Tabela 7: Contagem dos comportamentos de autolimpeza (grooming) em ratos Wistar machos, injetados com salina e ocitocina.

\begin{tabular}{|c|c|c|c|c|c|c|c|c|c|c|c|}
\hline \multirow[b]{3}{*}{$\mathrm{t}(\min )$} & \multicolumn{8}{|c|}{ Ratos } & \multirow[b]{3}{*}{ Média } & \multirow{3}{*}{$\begin{array}{l}\text { Desvio } \\
\text { Padrão }\end{array}$} & \multirow[b]{3}{*}{ Variância } \\
\hline & 1 & 2 & 3 & 4 & 5 & 6 & 7 & 8 & & & \\
\hline & \multicolumn{8}{|c|}{ Salina } & & & \\
\hline 5 & 0 & 3 & 2 & 2 & 4 & 0 & 5 & 8 & 3,000 & 2,673 & 7,143 \\
\hline 10 & 9 & 3 & 9 & 6 & 6 & 0 & 9 & 0 & 5,250 & 3,845 & 14,786 \\
\hline 15 & 6 & 10 & 8 & 8 & 8 & 7 & 8 & 0 & 6,875 & 2,997 & 8,982 \\
\hline 20 & 0 & 0 & 0 & 5 & 5 & 1 & 7 & 6 & 3,000 & 3,024 & 9,143 \\
\hline 25 & 9 & 0 & 6 & 2 & 14 & 4 & 0 & 1 & 4,500 & 4,957 & 24,571 \\
\hline 30 & 11 & 0 & 0 & 0 & 4 & 0 & 0 & 0 & 1,875 & 3,944 & 15,554 \\
\hline 35 & 16 & 10 & 4 & 0 & 2 & 0 & 0 & 0 & 4,000 & 5,952 & 35,429 \\
\hline 40 & 0 & 0 & 10 & 2 & 5 & 0 & 0 & 0 & 2,125 & 3,643 & 13,268 \\
\hline 45 & 0 & 0 & 0 & 0 & 1 & 0 & 0 & 0 & 0,125 & 0,354 & 0,125 \\
\hline 50 & 0 & 0 & 4 & 0 & 0 & 0 & 0 & 0 & 0,500 & 1,414 & 2,000 \\
\hline 55 & 0 & 0 & 12 & 0 & 4 & 0 & 0 & 0 & 2,000 & 4,276 & 18,286 \\
\hline \multirow[t]{2}{*}{60} & 0 & 0 & 2 & 0 & 0 & 0 & 0 & 0 & 0,250 & 0,707 & 0,500 \\
\hline & \multicolumn{8}{|c|}{ Ocitocina } & & & \\
\hline 5 & 9 & 0 & 15 & 0 & 2 & 2 & 1 & 5 & 4,250 & 5,285 & 27,929 \\
\hline 10 & 16 & 13 & 19 & 0 & 7 & 0 & 8 & 6 & 8,625 & 6,968 & 48,554 \\
\hline 15 & 16 & 9 & 18 & 2 & 17 & 3 & 11 & 0 & 9,500 & 7,191 & 51,714 \\
\hline 20 & 13 & 0 & 14 & 11 & 18 & 10 & 14 & 1 & 10,125 & 6,402 & 40,982 \\
\hline 25 & 17 & 1 & 9 & 14 & 19 & 11 & 19 & 9 & 12,375 & 6,163 & 37,982 \\
\hline 30 & 18 & 5 & 13 & 16 & 6 & 14 & 15 & 11 & 12,250 & 4,652 & 21,643 \\
\hline 35 & 18 & 6 & 1 & 7 & 16 & 9 & 14 & 10 & 10,125 & 5,643 & 31,839 \\
\hline 40 & 15 & 2 & 16 & 11 & 13 & 0 & 9 & 8 & 9,250 & 5,800 & 33,643 \\
\hline 45 & 13 & 3 & 15 & 0 & 7 & 1 & 19 & 1 & 7,375 & 7,367 & 54,268 \\
\hline 50 & 11 & 0 & 4 & 0 & 8 & 8 & 8 & 10 & 6,125 & 4,291 & 18,411 \\
\hline 55 & 8 & 0 & 13 & 7 & 9 & 3 & 7 & 0 & 5,875 & 4,549 & 20,696 \\
\hline 60 & 5 & 0 & 0 & 0 & 0 & 7 & 1 & 7 & 2,500 & 3,251 & 10,571 \\
\hline
\end{tabular}


Tabela 8: Contagem dos comportamentos de autolimpeza (grooming) em ratos War machos, injetados com salina e ocitocina.

\begin{tabular}{|c|c|c|c|c|c|c|c|c|c|}
\hline \multirow[b]{3}{*}{$\mathrm{t}(\min )$} & \multicolumn{6}{|c|}{ Ratos } & \multirow[b]{3}{*}{ Média } & \multirow{3}{*}{$\begin{array}{l}\text { Desvio } \\
\text { Padrão }\end{array}$} & \multirow[b]{3}{*}{ Variância } \\
\hline & 1 & 2 & 3 & 4 & 5 & 6 & & & \\
\hline & \multicolumn{6}{|c|}{ Salina } & & & \\
\hline 5 & 2 & 2 & 6 & 2 & 6 & 4 & 3,667 & 1,966 & 3,867 \\
\hline 10 & 3 & 3 & 0 & 2 & 1 & 2 & 1,833 & 1,169 & 1,367 \\
\hline 15 & 3 & 0 & 6 & 10 & 7 & 0 & 4,333 & 4,033 & 16,267 \\
\hline 20 & 11 & 7 & 8 & 7 & 0 & 9 & 7,000 & 3,742 & 14,000 \\
\hline 25 & 1 & 0 & 13 & 0 & 8 & 1 & 3,833 & 5,419 & 29,367 \\
\hline 30 & 3 & 0 & 1 & 3 & 0 & 0 & 1,167 & 1,472 & 2,167 \\
\hline 35 & 2 & 1 & 0 & 3 & 0 & 0 & 1,000 & 1,265 & 1,600 \\
\hline 40 & 0 & 0 & 0 & 0 & 0 & 0 & 0,000 & 0,000 & 0,000 \\
\hline 45 & 5 & 6 & 0 & 0 & 0 & 0 & 1,833 & 2,858 & 8,167 \\
\hline 50 & 0 & 1 & 0 & 0 & 0 & 0 & 0,167 & 0,408 & 0,167 \\
\hline 55 & 0 & 0 & 0 & 0 & 3 & 0 & 0,500 & 1,225 & 1,500 \\
\hline \multirow[t]{2}{*}{60} & 0 & 0 & 4 & 11 & 10 & 0 & 4,167 & 5,154 & 26,567 \\
\hline & \multicolumn{6}{|c|}{ Ocitocina } & & & \\
\hline 5 & 4 & 6 & 1 & 9 & 0 & 7 & 4,500 & 3,507 & 12,300 \\
\hline 10 & 1 & 13 & 0 & 13 & 5 & 8 & 6,667 & 5,680 & 32,267 \\
\hline 15 & 9 & 19 & 6 & 1 & 10 & 10 & 9,167 & 5,913 & 34,967 \\
\hline 20 & 11 & 12 & 6 & 14 & 3 & 5 & 8,500 & 4,416 & 19,500 \\
\hline 25 & 4 & 15 & 8 & 16 & 13 & 14 & 11,667 & 4,676 & 21,867 \\
\hline 30 & 17 & 15 & 2 & 12 & 0 & 12 & 9,667 & 7,005 & 49,067 \\
\hline 35 & 20 & 8 & 12 & 16 & 0 & 5 & 10,167 & 7,333 & 53,767 \\
\hline 40 & 1 & 10 & 7 & 6 & 16 & 8 & 8,000 & 4,940 & 24,400 \\
\hline 45 & 0 & 6 & 0 & 0 & 5 & 9 & 3,333 & 3,882 & 15,067 \\
\hline 50 & 1 & 17 & 2 & 12 & 0 & 8 & 6,667 & 6,861 & 47,067 \\
\hline 55 & 0 & 5 & 5 & 0 & 8 & 14 & 5,333 & 5,279 & 27,867 \\
\hline 60 & 1 & 14 & 3 & 8 & 12 & 4 & 7,000 & 5,215 & 27,200 \\
\hline
\end{tabular}

Nas Tabelas 7 e 8, tem-se as médias e as variâncias amostrais para cada combinação tempo $\times$ tratamento. Pelos resultados das Tabelas 7 e 8 , observa-se que as médias amostrais são diferentes das variâncias amostrais para quase todas as combinações tempo $\times$ tratamento, isto indica a presença de uma variabilidade extra-Poisson.

Para a análise dos dados das Tabelas 7 e 8, assume-se que as contagens, na presença de covariáveis, seguem distribuição de Poisson. Para incorporar a dependência entre os dados de contagem e a variabilidade extra-Poisson, é introduzido um efeito aleatório ou "fragilidade" nos diferentes modelos de regressão para o parâmetro da distribuição de Poisson. O uso do efeito aleatório ou "fragilidade" na análise de dados discretos longitudinais é considerado por vários autores (ALBERT; CHIB, 1993; CROUCHLEY; DAVIES, 1999; DUNSON, 2000, 2003; JøRGENSEN et al., 1999; HENDERSON; SHIMAKURA, 2003; 
DUNSON; HERRING, 2005). Modelos mistos normalmente distribuídos são considerados por muitos autores (MOUSTAKI, 1996; SAMMEL et al., 1997; MOUSTAKI; KNOTT, 2000; DUNSON, 2000, 2003).

Em aplicações na área de bioestatística, várias alternativas aos modelos de Poisson com variável latente são propostos na literatura, motivados por estudos de malformação (LEGLER; RYAN, 1997) e tumorgênese (YAKOVLEV; TSODIKOV, 1996; DUNSON; BAIRD, 2002). Modelos Poisson-Gamma para dados longitudinais de contagem são propostos por Crouchley e Davies (1999), Jørgensen et al. (1999), Henderson e Shimakura (2003) e modelos de fragilidade gama para dados de sobrevivência são introduzidos por Clayton (1991).

Nessa seção, é desenvolvido um estudo comparativo considerando diferentes estruturas de "fragilidade" para um modelo de Poisson. Métodos Bayesianos hierárquicos baseados no algoritmo Gibbs Sampling (GELFAND; SMITH, 1990; CHIB; GREENBERG, 1995) são utilizados. A seção é organizado da seguinte maneira: na Seção 3.1, é apresentado a formulação do modelo considerando três modelos de "fragilidade" diferentes para analisar dados longitudinais de Poisson; na Seção 3.2, é introduzido uma análise Bayesiana para cada modelo considerando o uso de métodos MCMC (Markov Chain Monte Carlo); na Seção 3.3, é feito a análise de um banco de dados real, apresentado nas Tabelas 7 e 8; para finalizar, na Seção 3.4, é apresentado as conclusões e algumas discussões dos resultados obtidos.

\subsection{Formulação do Modelo}

Seja $Y_{i j}$ uma variável aleatória com distribuição de Poisson (ver, (10)), isto é,

$$
P\left(Y_{i j}=y_{i j}\right)=\frac{e^{-\lambda_{i j}} \lambda_{i j}^{y_{i j}}}{y_{i j} !},
$$

em que, $y_{i j}=0,1,2, \ldots ; i=1, \ldots, n$ (tamanho amostral) e $j=1, \ldots, k$ (número de tempos). Associado a cada combinação tempo $\times$ indivíduo, assume-se a presença de uma 
covariável $x_{i j}, i=1, \ldots, n ; j=1, \ldots, k$.

Como os dados são longitudinais, é introduzido um efeito aleatório ou "fragilidade" no qual captura uma possível correlação entre as medidas repetidas para cada indivíduo e a variabilidade extra-Poisson. Diferentes modelos são considerados na análise dos dados longitudinais de contagem.

\subsubsection{Modelo 1}

Assumindo que os dados de contagem seguem distribuição de Poisson (18) com parâmetro $\lambda_{i j}$, o seguinte modelo de regressão pode ser utilizado,

$$
\lambda_{i j}=\alpha_{j} \exp \left(\beta_{j} x_{i j}+w_{i}\right)
$$

em que, $x_{i j}$ é uma variável dummy que assume os valores $x_{i j}=0$ indicando que o rato pertence ao grupo Wistar e $x_{i j}=1$ indicando que o rato pertence ao grupo War. Nesse caso, $\alpha_{j}$ mede o grooming médio no $j^{\text {th }}$ tempo para os ratos Wistar; $\alpha_{j} e^{\beta_{j}}$ mede o grooming médio no $j^{\text {th }}$ tempo para os ratos $W a r ; \beta_{j}$ é o parâmetro de regressão que indica o efeito de espécie. No modelo (19), tem-se a presença de um efeito aleatório ou "fragilidade" $w_{i}$ que captura a possível correlação entre as medidas repetidas para cada indivíduo e a variabilidade extra-Poisson, assume-se que esse efeito aleatório segue distribuição normal, ou seja,

$$
w_{i} \stackrel{i i d}{\sim} N\left(0, \tau^{2}\right)
$$

para $i=1, \ldots, n$.

Como $Y_{i j}$ segue distribuição de Poisson, tem-se $E\left(Y_{i j} \mid \lambda_{i j}\right)=\lambda_{i j}$ e $\operatorname{Var}\left(Y_{i j} \mid \lambda_{i j}\right)=\lambda_{i j}$. Isto é,

$$
\begin{aligned}
& E\left(Y_{i j} \mid \alpha_{j}, \beta_{j}, w_{i}, x_{i j}\right)=\alpha_{j} \exp \left(\beta_{j} x_{i j}+w_{i}\right) ; \\
& \operatorname{Var}\left(Y_{i j} \mid \alpha_{j}, \beta_{j}, w_{i}, x_{i j}\right)=\alpha_{j} \exp \left(\beta_{j} x_{i j}+w_{i}\right) .
\end{aligned}
$$


De,

$$
E\left(Y_{i j} \mid \alpha_{j}, \beta_{j}, x_{i j}\right)=E\left[E\left(Y_{i j} \mid \alpha_{j}, \beta_{j}, w_{i}, x_{i j}\right)\right]
$$

tem-se por (21) que,

$$
E\left(Y_{i j} \mid \alpha_{j}, \beta_{j}, x_{i j}\right)=\alpha_{j} e^{\beta_{j} x_{i j}} E\left(e^{w_{i}}\right)
$$

Da normalidade dos efeitos aleatórios $w_{i}(20)$, tem-se que $e^{w_{i}}$ segue distribuição lognormal com média $E\left(e^{w_{i}}\right)=e^{\tau^{2} / 2}$ e variância $\operatorname{Var}\left(e^{w_{i}}\right)=\left(e^{\tau^{2}}-1\right) e^{\tau^{2}}$. Isto é,

$$
E\left(Y_{i j} \mid \alpha_{j}, \beta_{j}, x_{i j}\right)=\alpha_{j} e^{\beta_{j} x_{i j}} e^{\tau^{2} / 2}
$$

De,

$$
\operatorname{Var}\left(Y_{i j} \mid \alpha_{j}, \beta_{j}, x_{i j}\right)=\operatorname{Var}\left[E\left(Y_{i j} \mid \alpha_{j}, \beta_{j}, w_{i}, x_{i j}\right)\right]+E\left[\operatorname{Var}\left(Y_{i j} \mid \alpha_{j}, \beta_{j}, w_{i}, x_{i j}\right)\right],
$$

tem-se por (21) que,

$$
\operatorname{Var}\left(Y_{i j} \mid \alpha_{j}, \beta_{j}, x_{i j}\right)=\alpha_{j}^{2} e^{2 \beta_{j} x_{i j}} \operatorname{Var}\left(e^{w_{i}}\right)+\alpha_{j} e^{\beta_{j} x_{i j}} E\left(e^{w_{i}}\right)
$$

isto é,

$$
\operatorname{Var}\left(Y_{i j} \mid \alpha_{j}, \beta_{j}, x_{i j}\right)=\alpha_{j}^{2} e^{2 \beta_{j} x_{i j}}\left(e^{\tau^{2}}-1\right) e^{\tau^{2}}+\alpha_{j} e^{\beta_{j} x_{i j}} e^{\tau^{2} / 2}
$$

De (22) e (23), é possível observar que a média e a variância de $Y_{i j}$ dado $\alpha_{j}, \beta_{j}$ e $x_{i j}$ são diferentes, ou seja, tem-se a presença da variabilidade extra-Poisson dada pelo termo $\alpha_{j}^{2} e^{2 \beta_{j} x_{i j}}\left(e^{\tau^{2}}-1\right) e^{\tau^{2}}$, incorporada ao modelo (19).

\subsubsection{Modelo 2}

Pode-se assumir que os dados de contagem seguem distribuição de Poisson (18) com $\lambda_{i j}$ dado por,

$$
\lambda_{i j}=w_{i} \alpha_{j} \exp \left(\beta_{j} x_{i j}\right)
$$


em que, $x_{i j}$ é definido no modelo $1, w_{i}$ é um efeito aleatório ou "fragilidade" seguindo distribuição gama, isto é,

$$
w_{i} \stackrel{i i d}{\sim} \operatorname{Gamma}\left(\phi^{-1} ; \phi^{-1}\right)
$$

para $i=1, \ldots, n$.

O efeito aleatório ou "fragilidade" $w_{i}$ é estruturado para acomodar a correlação entre as medidas repetidas e a variabilidade extra-Poisson. Observa-se que $E\left(w_{i}\right)=1$ e $\operatorname{Var}\left(w_{i}\right)=$ $\phi$. Essa estrutura de "fragilidade" esta relacionada aos modelos de "fragilidades" gama aditivos introduzidos na literatura por Korsgaard e Andersen (1998), Petersen (1998), Li (2002).

Do resultado,

$$
E\left(Y_{i j} \mid \alpha_{j}, \beta_{j}, x_{i j}\right)=E\left[E\left(Y_{i j} \mid \alpha_{j}, \beta_{j}, w_{i}, x_{i j}\right)\right]
$$

tem-se,

$$
E\left(Y_{i j} \mid \alpha_{j}, \beta_{j}, x_{i j}\right)=\alpha_{j} e^{\beta_{j} x_{i j}} E\left(w_{i}\right)
$$

isto é,

$$
E\left(Y_{i j} \mid \alpha_{j}, \beta_{j}, x_{i j}\right)=\alpha_{j} e^{\beta_{j} x_{i j}}
$$

pois, $E\left(w_{i}\right)=1$ para $i=1, \ldots, n$. Do resultado,

$$
\operatorname{Var}\left(Y_{i j} \mid \alpha_{j}, \beta_{j}, x_{i j}\right)=\operatorname{Var}\left[E\left(Y_{i j} \mid \alpha_{j}, \beta_{j}, w_{i}, x_{i j}\right)\right]+E\left[\operatorname{Var}\left(Y_{i j} \mid \alpha_{j}, \beta_{j}, w_{i}, x_{i j}\right)\right]
$$

tem-se,

$$
\operatorname{Var}\left(Y_{i j} \mid \alpha_{j}, \beta_{j}, x_{i j}\right)=\alpha_{j}^{2} e^{2 \beta_{j} x_{i j}} \operatorname{Var}\left(w_{i}\right)+\alpha_{j} e^{\beta_{j} x_{i j}} E\left(w_{i}\right)
$$

isto é,

$$
\operatorname{Var}\left(Y_{i j} \mid \alpha_{j}, \beta_{j}, x_{i j}\right)=\phi \alpha_{j}^{2} e^{2 \beta_{j} x_{i j}}+\alpha_{j} e^{\beta_{j} x_{i j}}
$$

De (26) e (27), observa-se que a variabilidade extra-Poisson é dada por $\phi \alpha_{j}^{2} e^{2 \beta_{j} x_{i j}}$, em que o parâmetro $\phi$ esta relacionado a variabilidade extra-Poisson. 
É possível observar que o modelo 2, uma mistura de uma distribuição de Poisson com uma Gama, resulta em uma generalização de uma distribuição binomial negativa (BERNARDO; SMITH, 1994) para a distribuição incondicional de $y_{i j}, i=1, \ldots, n ; j=$ $1, \ldots, k$.

Para o modelo 1, a distribuição incondicional de $Y_{i j}$ é obtida de uma mistura de distribuição de Poisson com log-normal, sendo assim, a distribuição incondicional para $Y_{i j}$ é obtida de forma diferente da obtida assumindo o modelo 2.

\subsubsection{Modelo 3}

Uma generalização do modelo visto em (24) é dado por,

$$
\lambda_{i j}=\left(\sum_{l=1}^{r} \alpha_{l} w_{l i}\right) \exp \left(\beta_{1 j}+\beta_{2 j} x_{i j}\right)
$$

em que, $i=1, \ldots, n ; j=1, \ldots, k$. Nesse caso tem-se que $\sum_{l=1}^{r} \alpha_{l} \exp \left(\beta_{1 j}\right)$ mede o grooming médio no $j^{\text {th }}$ tempo para os ratos Wistar $; \sum_{l=1}^{r} \alpha_{l} \exp \left(\beta_{1 j}+\beta_{2 j}\right)$ mede o grooming médio no $j^{\text {th }}$ tempo para os ratos War; $\beta_{2 j}$ é um parâmetro de regressão que indica o efeito de espécie, esse modelo é um modelo de "fragilidade" gama aditivo.

Um caso especial do modelo (28) é dado considerando $r=2$, isto é,

$$
\lambda_{i j}=\left(\alpha_{1} w_{1 i}+\alpha_{2} w_{2 i}\right) \exp \left(\beta_{1 j}+\beta_{2 j} x_{i j}\right)
$$

em que, assume-se que $w_{1 i}$ e $w_{2 i}$ são efeitos aleatórios ou "fragilidades" independentes com distribuição gama,

$$
\begin{aligned}
& w_{1 i} \stackrel{i i d}{\sim} \operatorname{Gamma}\left(\phi_{1}^{-1} ; \phi_{1}^{-1}\right) \\
& w_{2 i} \stackrel{i i d}{\sim} \operatorname{Gamma}\left(\phi_{2}^{-1} ; \phi_{2}^{-1}\right)
\end{aligned}
$$

para $i=1,2, \ldots, n$. 
De,

$$
E\left(Y_{i j} \mid \alpha_{1 j}, \alpha_{2 j}, \beta_{j}, x_{i j}\right)=E\left[E\left(Y_{i j} \mid \alpha_{1 j}, \alpha_{2 j}, \beta_{j}, x_{i j}, w_{1 i}, w_{2 i}\right)\right],
$$

tem-se,

$$
E\left(Y_{i j} \mid \alpha_{1 j}, \alpha_{2 j}, \beta_{j}, x_{i j}\right)=\alpha_{1} e^{\beta_{1 j}+\beta_{2 j} x_{i j}} E\left(w_{1 i}\right)+\alpha_{2} e^{\beta_{1 j}+\beta_{2 j} x_{i j}} E\left(w_{2 i}\right) .
$$

Como $E\left(w_{1 i}\right)=1$ e $E\left(w_{2 i}\right)=1$, tem-se,

$$
E\left(Y_{i j} \mid \alpha_{1 j}, \alpha_{2 j}, \beta_{j}, x_{i j}\right)=\left(\alpha_{1}+\alpha_{2}\right) e^{\beta_{1 j}+\beta_{2 j} x_{i j}} .
$$

Considerando, também, o resultado,

$$
\begin{aligned}
\operatorname{Var}\left(Y_{i j} \mid \alpha_{1 j}, \alpha_{2 j}, \beta_{j}, x_{i j}\right)= & \operatorname{Var}\left[E\left(Y_{i j} \mid \alpha_{1 j}, \alpha_{2 j}, \beta_{j}, x_{i j}, w_{1 i}, w_{2 i}\right)\right]+ \\
& +E\left[\operatorname{Var}\left(Y_{i j} \mid \alpha_{1 j}, \alpha_{2 j}, \beta_{j}, x_{i j}, w_{1 i}, w_{2 i}\right)\right],
\end{aligned}
$$

tem-se,

$$
\begin{aligned}
\operatorname{Var}\left(Y_{i j} \mid \alpha_{1 j}, \alpha_{2 j}, \beta_{j}, x_{i j}\right)= & \operatorname{Var}\left(\alpha_{1} e^{\beta_{1 j}+\beta_{2 j} x_{i j}} w_{1 i}+\alpha_{2} e^{\beta_{1 j}+\beta_{2 j} x_{i j}} w_{2 i}\right)+ \\
& +E\left(\alpha_{1} e^{\beta_{1 j}+\beta_{2 j} x_{i j}} w_{1 i}+\alpha_{2} e^{\beta_{1 j}+\beta_{2 j} x_{i j}} w_{2 i}\right) .
\end{aligned}
$$

Como, $\operatorname{Var}\left(w_{1 i}\right)=\phi_{1}$ e $\operatorname{Var}\left(w_{2 i}\right)=\phi_{2}$, tem-se,

$$
\begin{aligned}
\operatorname{Var}\left(Y_{i j} \mid \alpha_{1 j}, \alpha_{2 j}, \beta_{j}, x_{i j}\right)= & \phi_{1} \alpha_{1}^{2} e^{2\left(\beta_{1 j}+\beta_{2 j} x_{i j}\right)}+\phi_{2} \alpha_{2}^{2} e^{2\left(\beta_{1 j}+\beta_{2 j} x_{i j}\right)}+ \\
& \left(\alpha_{1}+\alpha_{2}\right) e^{\beta_{1 j}+\beta_{2 j} x_{i j}} .
\end{aligned}
$$

De (31) e (32), observa-se que a variabilidade extra-Poisson é dada pelo termo,

$$
\phi_{1} \alpha_{1}^{2} e^{2\left(\beta_{1 j}+\beta_{2 j} x_{i j}\right)}+\phi_{2} \alpha_{2}^{2} e^{2\left(\beta_{1 j}+\beta_{2 j} x_{i j}\right)},
$$


para $i=1, \ldots, n$ e $j=1, \ldots, k$.

Assumindo o modelo 3, a distribuição incondicional para $Y_{i j}$ é resultante de uma mistura de distribuição de Poisson com uma combinação linear de distribuições Gama. Esta é uma nova estrutura de modelagem, e pode dar mais flexibilidade ou melhorar o ajuste quando se tem problemas que envolvem dados de contagem longitudinais na presença de covariáveis.

Percebe-se um problema de identificabilidade no modelo 3, alguns parâmetros $\alpha_{l}$ devem ser estudados; para resolver o problema de identificabilidade pode-se utilizar distribuições a priori informativas apropriadas. Usualmente, a escolha de $\alpha_{l}$ é baseado na interpretação biológica (DUNSON; HERRING, 2005); em algumas aplicações essa escolha não é tão simples.

Os modelos 1 e 2 não têm problema de identificabilidade e é relativamente simples obter as medidas a posteriori de interesse, usando métodos usuais de MCMC. No entanto, será explorado o uso do modelo 3 como alternativa para se ter melhores ajustes aos dados das Tabelas 7 e 8. Outros modelos com variáveis latentes também são usados para analisar dados de contagem (CHIB et al., 1998).

\subsection{Análise Bayesiana}

Assumindo o modelo de Poisson visto em (18), a função de verossimilhança para $\boldsymbol{\alpha}=\left(\alpha_{1}, \ldots, \alpha_{k}\right)$ e $\boldsymbol{\beta}=\left(\beta_{1}, \ldots, \beta_{k}\right)$ dado os dados observados $Y_{i j}$, as variáveis nãoobserváveis $w_{i}$ e as covariáveis $x_{i j}, i=1, \ldots, n ; j=1, \ldots, k$, é dada por,

$$
L(\boldsymbol{\alpha}, \boldsymbol{\beta})=\prod_{i=1}^{n} \prod_{j=1}^{k} \frac{e^{-\lambda_{i j}} \lambda_{i j}^{y_{i j}}}{y_{i j} !}
$$

em que, $\lambda_{i j}$, dependendo do modelo, é dado em (19), (24) ou (29). Isto é,

$$
L(\boldsymbol{\alpha}, \boldsymbol{\beta}) \propto \exp \left(-\sum_{i=1}^{n} \sum_{j=1}^{k} \lambda_{i j}\right) \prod_{i=1}^{n} \prod_{j=1}^{k} \lambda_{i j}^{y_{i j}}
$$




\subsubsection{Análise Bayesiana Para o Modelo 1}

Para o primeiro estágio da análise Bayesiana hierárquica considerando o Modelo 1, assume-se as seguintes distribuições a priori para os parâmetros $\alpha_{j}$ e $\beta_{j}$,

$$
\begin{aligned}
& \alpha_{j} \sim \operatorname{Gamma}(a ; b) ; a, b \text { conhecidos; } \\
& \beta_{j} \sim N\left(c ; d^{2}\right) ; c, d \text { conhecidos; }
\end{aligned}
$$

para $j=1, \ldots, k$; assume-se que a "fragilidade" $w_{i}$ é uma variável aleatória independente com distribuição normal $N\left(0, \tau^{2}\right)$. Para o segundo estágio da análise Bayesiana hierárquica, assume-se uma distribuição gama inversa para $\tau^{2}$, isto é,

$$
\tau^{2} \sim I G(f, g) ; f, g \text { conhecidos. }
$$

Assume-se independência a priori entre os parâmetros. A distribuição a posteriori conjunta para $\boldsymbol{\alpha}, \boldsymbol{\beta}, \mathbf{w}$ e $\tau^{2}$ é dada por,

$$
\begin{aligned}
\pi\left(\boldsymbol{\alpha}, \boldsymbol{\beta}, \mathbf{w}, \tau^{2} \mid \mathbf{y}, \mathbf{x}\right) \propto & \prod_{j=1}^{k} \alpha_{j}^{a-1} e^{-b \alpha_{j}} \times \prod_{j=1}^{k} \exp \left[-\frac{1}{2 d^{2}}\left(\beta_{j}-c\right)^{2}\right] \times \\
& \times \prod_{i=1}^{n} \frac{1}{\sqrt{2 \pi \tau^{2}}} \exp \left(-\frac{w_{i}^{2}}{2 \tau^{2}}\right) \times\left(\tau^{2}\right)^{-(f+1)} \exp \left(-\frac{g}{\tau^{2}}\right) \times \\
& \times \exp \left(-\sum_{i=1}^{n} \sum_{j=1}^{k} \lambda_{i j}\right) \prod_{i=1}^{n} \prod_{j=1}^{k} \lambda_{i j}^{y_{i j}}
\end{aligned}
$$

em que, $\lambda_{i j}$ é dado em $(19), \mathbf{w}=\left(w_{1}, \ldots, w_{n}\right), \boldsymbol{\alpha}=\left(\alpha_{1}, \ldots, \alpha_{k}\right), \boldsymbol{\beta}=\left(\beta_{1}, \ldots, \beta_{k}\right), \mathbf{y}$ é o vetor de dados de contagem e $\mathbf{x}$ é o vetor de covariáveis.

Amostras simuladas da distribuição a posteriori (37) são obtidas utilizando métodos MCMC (GELFAND; SMITH, 1990; SMITH; ROBERTS, 1993). As distribuições a posteriori condicionais necessárias para o algoritmo Gibbs sampling podem ser vistas no Apêndice C. Uma grande simplificação é obtida utilizando o Software Winbugs (SPIEGELHALTER et al., 1995) no qual é preciso somente especificar a distribuição dos dados e as distribuições a priori para os parâmetros (ver, Apêndice A). 
É importante comentar que pode-se incorporar a dependência de $\beta_{j}$ assumindo outras distribuições a priori; nesse caso, pode-se modelar $\beta_{j}$ por um processo de séries temporais.

\subsubsection{Análise Bayesiana Para o Modelo 2}

Para o primeiro estágio da análise Bayesiana hierárquica considerando o Modelo 2, assume-se as mesmas distribuições a priori (35) para $\alpha_{j}$ e $\beta_{j}, j=1, \ldots, k$. Para o modelo 2, assume-se que a "fragilidade" $w_{i}$ é uma variável aleatória independente com distribuição gama Gamma $\left(\phi^{-1} ; \phi^{-1}\right)$. Para o segundo estágio da análise Bayesiana hierárquica, assume-se uma distribuição gama para $\phi$, isto é,

$$
\phi \sim \operatorname{Gamma}(f ; g) ; f, g \text { conhecidos. }
$$

Assume-se também independência a priori entre os parâmetros. A distribuição a posteriori conjunta para $\boldsymbol{\alpha}, \boldsymbol{\beta}, \mathbf{w}$ e $\phi$ é dada por,

$$
\begin{aligned}
\pi(\boldsymbol{\alpha}, \boldsymbol{\beta}, \mathbf{w}, \phi \mid \mathbf{y}, \mathbf{x}) & \propto \prod_{j=1}^{k} \alpha_{j}^{a-1} e^{-b \alpha_{j}} \times \prod_{j=1}^{k} \exp \left[-\frac{1}{2 d^{2}}\left(\beta_{j}-c\right)^{2}\right] \times \\
& \times \prod_{i=1}^{n} \frac{\phi^{-\phi^{-1}}}{\Gamma\left(\phi^{-1}\right)} w_{i}^{\phi^{-1}-1} \exp \left(-\phi^{-1} w_{i}\right) \times \phi^{f-1} \exp (-g \phi) \times \\
& \times \exp \left(-\sum_{i=1}^{n} \sum_{j=1}^{k} \lambda_{i j}\right) \prod_{i=1}^{n} \prod_{j=1}^{k} \lambda_{i j}^{y_{i j}} .
\end{aligned}
$$

em que, $\lambda_{i j}$ é dado em (24) para $i=1, \ldots, n ; j=1, \ldots, k$. As distribuições a posteriori condicionais necessárias para o algoritmo Gibbs sampling podem se vistas no Apêndice C. 


\subsubsection{Análise Bayesiana Para o Modelo 3 Assumindo $r=2$}

Assumindo um caso especial para o modelo 3, com $r=2$, em que $\lambda_{i j}$ é dado em (29), assume-se distribuição a priori normal para $\beta_{1 j}$ e $\beta_{2 j}$, isto é,

$$
\begin{aligned}
& \beta_{1 j} \sim N\left(\beta_{1 j}^{*}, d_{1}^{2}\right) \\
& \beta_{2 j} \sim N\left(\beta_{2 j}^{*}, d_{2}^{2}\right) ;
\end{aligned}
$$

com $d_{1}$ e $d_{2}$ conhecidos.

Como tem-se problema de identificabilidade no modelo 3 para os parâmetros $\alpha_{l}$, $l=1,2$, a análise Bayesiana é feita em dois passos: No primeiro passo, assume-se o modelo 2 para os dados de contagem; No segundo passo, assume-se distribuições a priori informativas (Análise Bayesiana Empírica) para a escolha dos hiperparâmetros $\beta_{1 j}^{*}$ e $\beta_{2 j}^{*}$ dados em (40), utilizando as médias a posteriori de $\alpha_{j}$ e $\beta_{j}$ do modelo 2 , obtidas no primeiro passo. Ou seja, denotando $\hat{\alpha}_{j}$ e $\hat{\beta}_{j}$ as médias a posteriori estimadas para $\alpha_{j}$ e $\beta_{j}$ do modelo 2 , assume-se $\beta_{1 j}^{*}=e^{\hat{\alpha}_{j}}$ e $\beta_{2 j}^{*}=\hat{\beta}_{j}$.

Diferentes distribuições a priori podem ser assumidas para os parâmetros $\alpha_{l}, l=1,2$. Foi assumido uma distribuição a priori beta, ou seja,

$$
\begin{aligned}
& \alpha_{1} \sim \operatorname{Beta}\left(a_{1} ; b_{1}\right) ; a_{1}, b_{1} \text { Conhecido; } \\
& \alpha_{2} \sim \operatorname{Beta}\left(a_{2} ; b_{2}\right) ; a_{2}, b_{2} \text { Conhecido; }
\end{aligned}
$$

considerando o modelo 3 , assume-se que as "fragilidades" $w_{1 i}$ e $w_{2 i}$ são variáveis aleatórias independentes com distribuição $\operatorname{Gamma}\left(\phi_{l}^{-1} ; \phi_{l}^{-1}\right)(30)$ para $l=1,2$. Para o segundo estágio de análise Bayesiana hierárquica, assume-se uma distribuição a priori gama para $\phi_{l}$, isto é,

$$
\phi_{l} \sim \operatorname{Gamma}\left(f_{l} ; g_{l}\right) ; f_{l}, g_{l} \text { conhecidos; } l=1,2 .
$$

Assume-se independência a priori entre os parâmetros. A distribuição a posteriori 
conjunta para $\alpha_{1}, \alpha_{2}, \boldsymbol{\beta}_{1}, \boldsymbol{\beta}_{2}, \phi_{1}, \phi_{2}, \mathbf{w}_{1}$ e $\mathbf{w}_{2}$ é dada por,

$$
\begin{aligned}
\pi\left(\alpha_{1}, \alpha_{2}, \boldsymbol{\beta}_{1}, \boldsymbol{\beta}_{2}, \mathbf{w}_{1}, \mathbf{w}_{2},\right. & \left.\phi_{1}, \phi_{2} \mid \mathbf{y}, \mathbf{x}\right) \propto \frac{\Gamma\left(a_{1}+b_{1}\right)}{\Gamma\left(a_{1}\right) \Gamma\left(b_{1}\right)} \alpha_{1}^{a_{1}-1}\left(1-\alpha_{1}\right)^{b_{1}-1} \\
& \times \frac{\Gamma\left(a_{2}+b_{2}\right)}{\Gamma\left(a_{2}\right) \Gamma\left(b_{2}\right)} \alpha_{2}^{a_{2}-1}\left(1-\alpha_{2}\right)^{b_{2}-1} \times \prod_{j=1}^{k} \exp \left[-\frac{1}{2 d_{1}^{2}}\left(\beta_{1 j}-\beta_{1 j}^{*}\right)^{2}\right] \\
& \times \prod_{j=1}^{k} \exp \left[-\frac{1}{2 d_{2}^{2}}\left(\beta_{2 j}-\beta_{2 j}^{*}\right)^{2}\right] \times \prod_{i=1}^{n} \frac{\phi_{1}^{-\phi_{1}^{-1}}}{\Gamma\left(\phi_{1}^{-1}\right)} w_{1 i}^{\phi_{1}^{-1}-1} \exp \left(-\phi_{1}^{-1} w_{1 i}\right) \\
& \times \prod_{i=1}^{n} \frac{\phi_{2}^{-\phi_{2}^{-1}}}{\Gamma\left(\phi_{2}^{-1}\right)} w_{2 i}^{\phi_{2}^{-1}-1} \exp \left(-\phi_{2}^{-1} w_{2 i}\right) \times \phi_{1}^{f_{1}-1} \exp \left(-g_{1} \phi_{1}\right) \\
& \times \phi_{2}^{f_{2}-1} \exp \left(-g_{2} \phi_{2}\right) \times \exp \left(-\sum_{i=1}^{n} \sum_{j=1}^{k} \lambda_{i j}\right) \prod_{i=1}^{n} \prod_{j=1}^{k} \lambda_{i j}^{y_{i j}}
\end{aligned}
$$

em que, $\lambda_{i j}$ é dado em (29) para $i=1, \ldots, n ; j=1, \ldots, k$. As distribuições a posteriori condicionais necessárias para o algoritmo Gibbs sampling podem se vistas no Apêndice C.

Resultados similares podem ser obtidos considerando $r>2$ em (28); desse modo, pode-se considerar valores fixos para $r$ e escolher o melhor modelo usando alguns critérios de discriminação Bayesianos (ver, Seção 4).

\subsection{Análise dos Dados de Contagem de Grooming}

Para a análise Bayesiana dos dados das Tabelas 7 e 8, são considerados para os modelos 1 e 2, os seguintes valores para os hiperparâmetros das distribuições a priori (35), (36) e (38): $a=b=0,01 ; c=0 ; d^{2}=1000 ; f=g=0,1$. Para o modelo 3 , é considerado $a_{1}=a_{2}=b_{1}=b_{2}=1,0 ; d_{1}^{2}=d_{2}^{2}=1,0 ; f_{1}=f_{2}=g_{1}=g_{2}=1,0$ para os hiperparâmetros das distribuições a priori (40), (41) e (42). A escolha desses hiperparâmetros é feita para se ter distribuições a priori aproximadamente não-informativas e tal que a convergência dos algoritmos MCMC usados para a simulação de Gibbs sampling para a distribuição a posteriori de interesse utilizando o Software Winbugs (SPIEGELHALTER et al., 1995) seja observada. Os códigos de programa do Software Winbugs podem ser vistos no Apêndice B. Para os modelos 1, 2, e 3, são simuladas 1.005.000 amostras, onde as primeiras 5000 amostras ("burn-in-samples") são descartadas para eliminar os efeitos dos valores iniciais do algoritmo de Gibbs sampling. Para se ter uma amostra de Gibbs aproximadamente não-correlacionada, considera-se a amostra $100^{a}, 200^{a}, 300^{a}, \ldots$, no qual resulta em uma 
amostra final de tamanho 10.000 para cada parâmetro. A convergência do algoritmo de Gibbs sampling é observada por gráficos usuais de séries temporais para as amostras simuladas e também utilizando alguns métodos de convergência existentes (GELMAN; RUBIN, 1992).

Os resultados a posteriori para os parâmetros dos modelos 1, 2, e 3 são vistos nas Figuras 2 a 4. Na Figura 5, tem-se a variância amostral para os dados de contagem em cada combinação tempo $\times$ tratamento e as estimativas Monte Carlo para as variâncias das médias a posteriori em cada combinação tempo $\times$ tratamento considerando os modelos 1 , 2 e 3. Dos resultados da Figura 5, observa-se, em geral, um melhor ajuste ao modelo 3, pois as variâncias estimadas desse modelo estão mais próximas das variâncias amostrais, se comparadas com as dos modelos 1 e 2 .

Para a seleção do melhor modelo, pode-se utilizar algumas medidas de discriminação de modelos, como por exemplo o Deviance Information Criterion (DIC) (SPIEGELHALTER et al., 2000). O menor valor de DIC indica o melhor modelo. Na Tabela 9, pode-se observar os DIC estimados para cada modelo, obtidos utilizando o Software Winbugs. Observa-se que o modelo 3 se ajusta melhor aos dados de contagem das Tabelas 7 e 8 (menor valor de DIC). Observa-se que a diferença entre as variâncias estimadas e as variâncias amostrais são, em geral, menores se considerado o modelo 3. Na Tabela 10, pode-se observar as somas de quadrados destas diferenças assumindo cada um dos modelos propostos. Dos resultados da Tabela 10, observa-se um menor valor para a soma dos quadrados das diferenças para o modelo 3 , especialmente para os ratos Wistar $(x=0)$.

\begin{tabular}{ccc} 
& Tabela 9: & Critério DIC. \\
\hline Modelo & DIC & Número de Parâmetros \\
\hline Modelo 1 & 2016,790 & 49 \\
Modelo 2 & 2016,360 & 49 \\
Modelo 3 & 2011,480 & 52 \\
\hline
\end{tabular}

Tabela 10: Soma dos quadrados das diferenças entre as variâncias estimadas e as variâncias amostrais.

\begin{tabular}{cccc}
\hline $\mathrm{X}$ & Modelo 1 & Modelo 2 & Modelo 3 \\
\hline 0 & 5073,575 & 5907,703 & 4982,026 \\
1 & 3354,934 & 4398,451 & 3452,206 \\
\hline
\end{tabular}




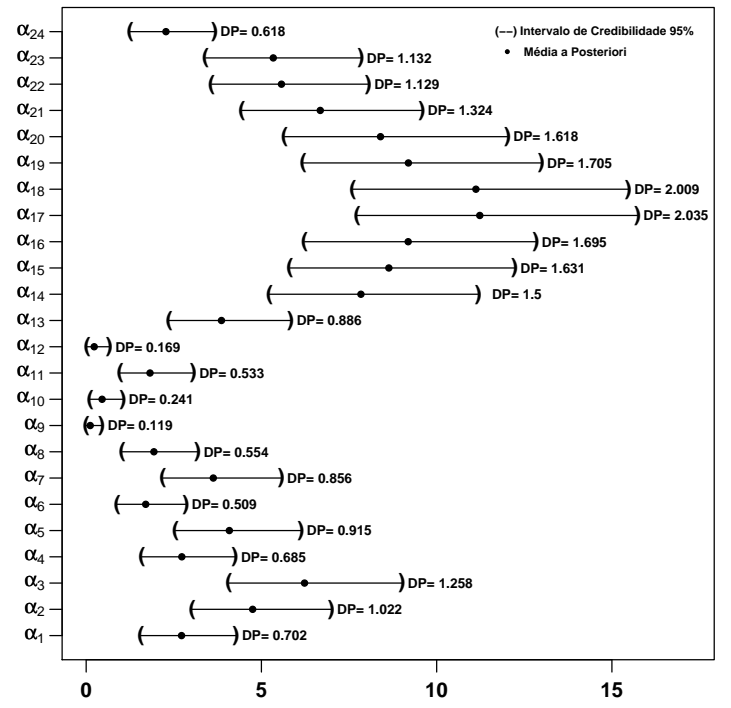

(a) $\alpha_{j}$

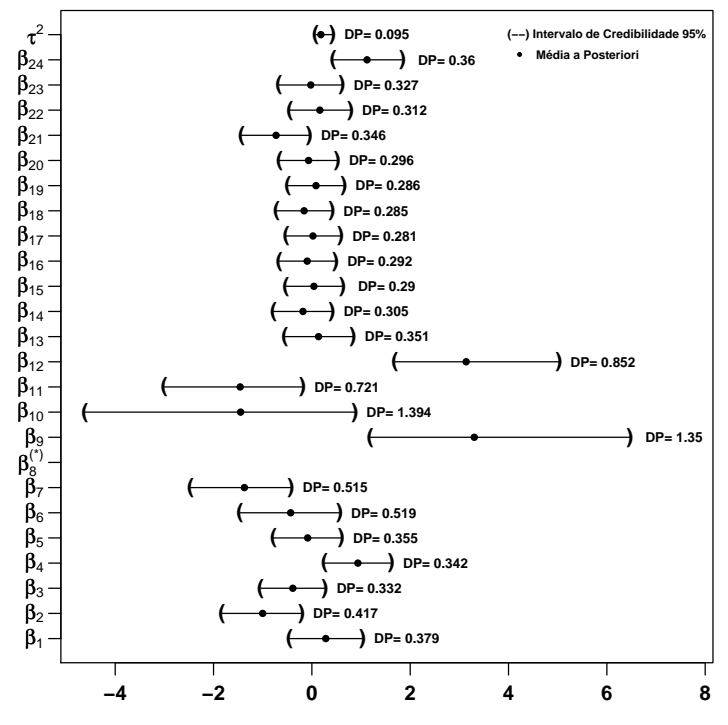

(b) $\beta_{j}$ e $\tau^{2}$

*Média a Posteriori, Intervalo de Credibilidade $95 \%$ e DP para $\beta_{8}$ são dados, respectivamente, por $-27.280,(-73.69 ;-3.539)$ e 18.78

Figura 2: Gráficos dos sumários a posteriori para o modelo 1.

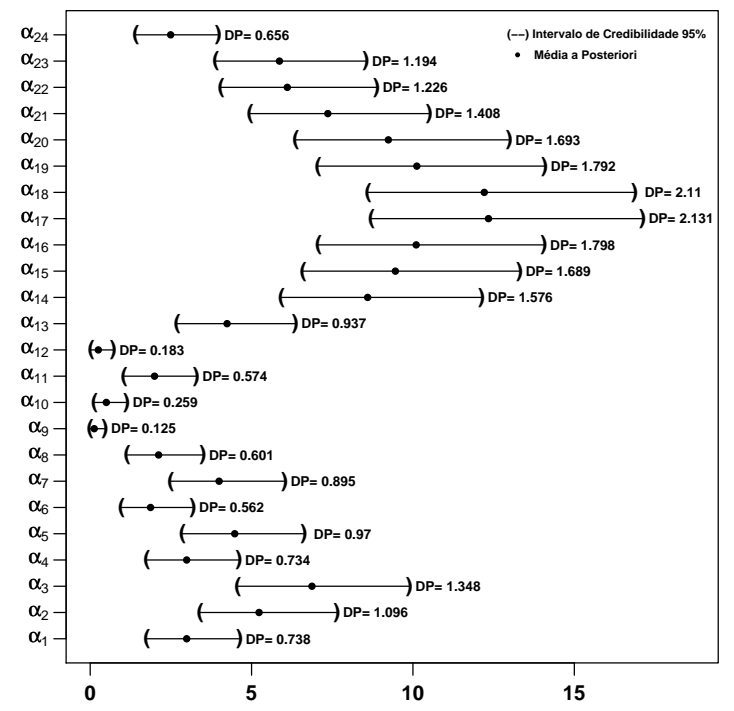

(a) $\alpha_{j}$

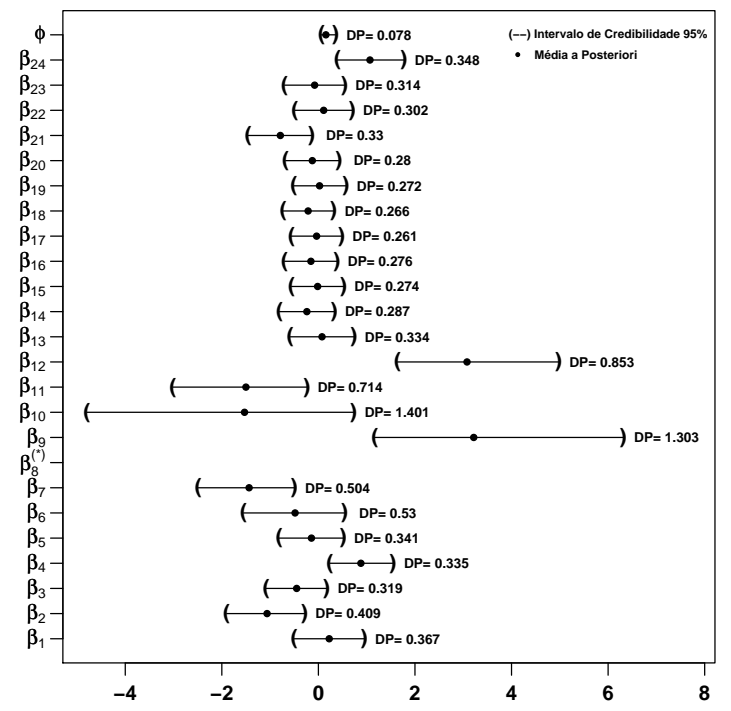

(b) $\beta_{j}$ e $\phi$

*Média a Posteriori, Intervalo de Credibilidade $95 \%$ e DP para $\beta_{8}$ são dados, respectivamente, por $-27.15,(-72.16 ;-3.688)$ e 18.51

Figura 3: Gráficos dos sumários a posteriori para o modelo 2. 


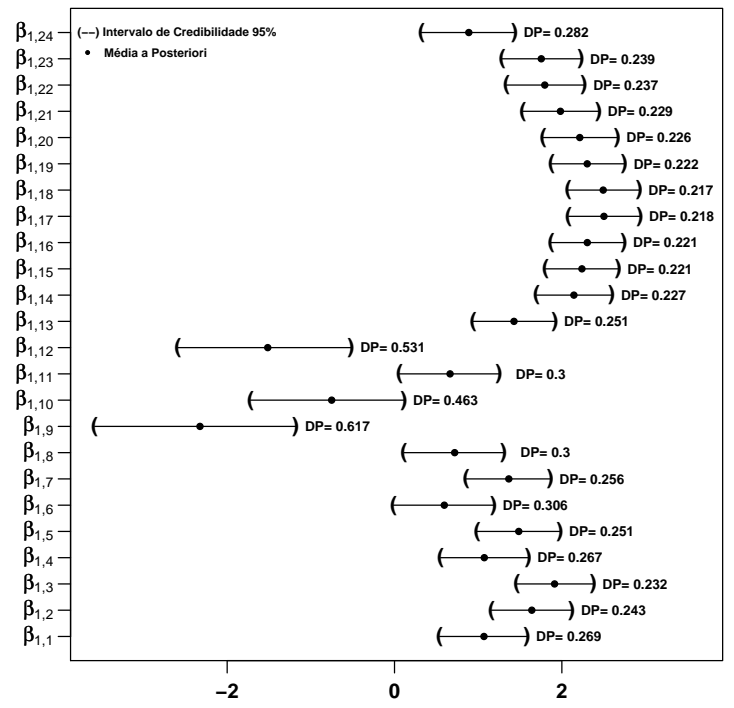

(a) $\beta_{1, j}$

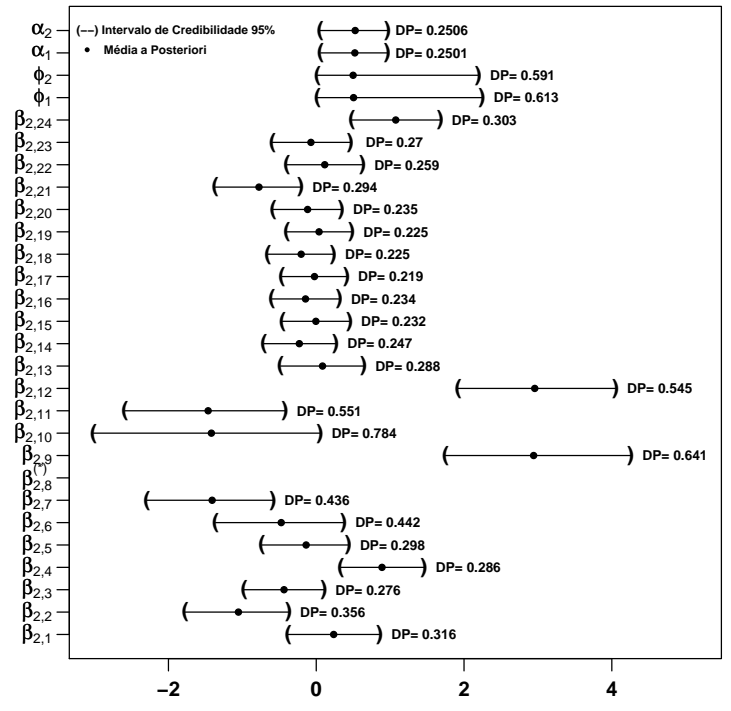

(b) $\beta_{2, j} ; \phi_{l}$ e $\alpha_{l}$

* Média a Posteriori, Intervalo de Credibilidade $95 \%$ e DP para $\beta_{2,8}$ são dados, respectivamente, por $-27.15,(-29.09 ;-25.20)$ e 0.989

Figura 4: Gráficos dos sumários a posteriori para o modelo 3.

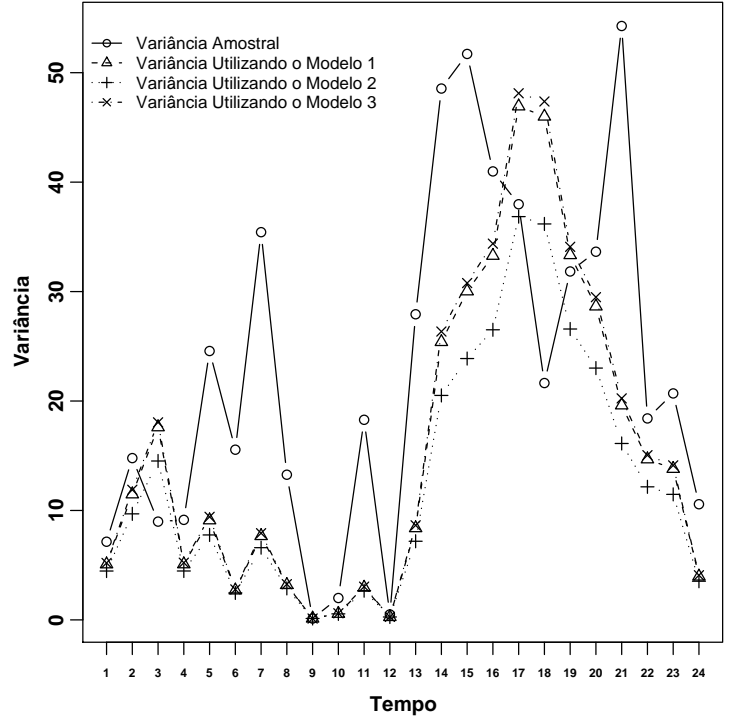

(a) $x=0$

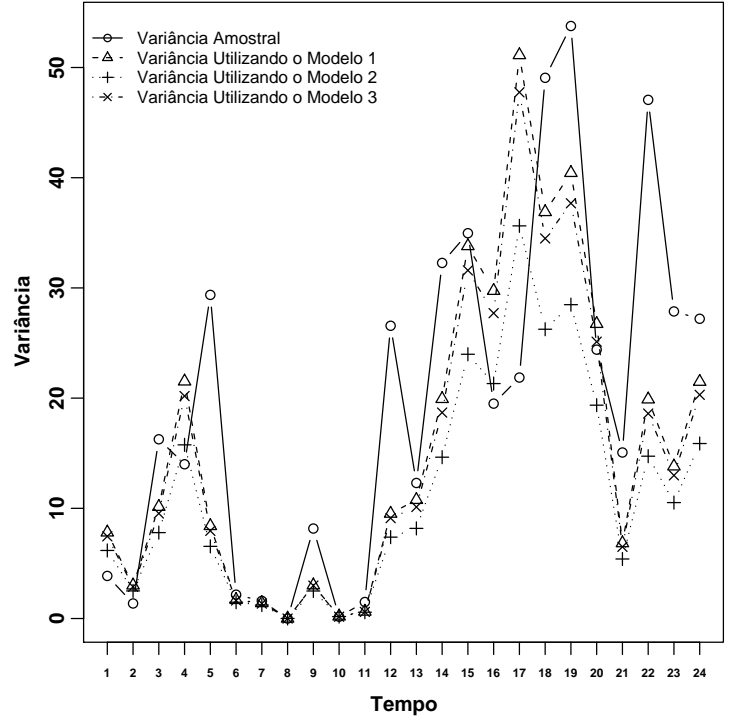

(b) $x=1$

Figura 5: Estimativas Bayesianas para as variâncias dos dados de contagem em cada tempo. 
Portanto, o modelo 3 é utilizado para obter outras inferências Bayesianas de interesse para os dados de contagem das Tabelas 7 e 8. Para verificar o efeito de tratamento para os ratos Wistar, em cada tempo, são considerados os seguintes parâmetros,

$$
\theta_{k}=\left(\alpha_{1}+\alpha_{2}\right) e^{\beta_{1, k+12}}-\left(\alpha_{1}+\alpha_{2}\right) e^{\beta_{1, k}}
$$

em que, $k=1, \ldots, 12$; o modelo 3 também é utilizado para verificar o efeito de tratamento dos ratos War, considerando os parâmetros,

$$
\eta_{k}=\left(\alpha_{1}+\alpha_{2}\right) e^{\beta_{1, k+12}+\beta_{2, k+12}}-\left(\alpha_{1}+\alpha_{2}\right) e^{\beta_{1, k}+\beta_{2, k}}
$$

em que, $k=1, \ldots, 12$.

Estimativas Monte Carlo para $\theta_{k}$ e $\eta_{k}, k=1, \ldots, 12$ considerando as 10.000 amostras geradas utilizando o algoritmo Gibbs samples são mostradas na Tabela 11. Observa-se que o efeito de tratamento é significante para os tempos $k=2,4,5,6,7,8,9,10,11,12$ considerando os ratos Wistar, pois o valor zero não esta incluído no intervalo de credibilidade $95 \%$ para cada um desses $\theta_{k}$. Considerando os ratos War, observa-se o efeito de tratamento significativo para os tempos $k=2,3,5,6,7,8,10,11,12$.

Tabela 11: Médias a posteriori considerando o modelo 3.

\begin{tabular}{cccccccc}
\hline Parâmetro & Média & DP & $\begin{array}{c}\text { 95\% Intervalo de } \\
\text { Credibilidade }\end{array}$ & Parâmetro & Média & DP & $\begin{array}{c}95 \% \text { Intervalo de } \\
\text { Credibilidade }\end{array}$ \\
\hline$\theta_{1}$ & 1,300 & 0,964 & $(-0,524 ; 3,302)$ & $\eta_{1}$ & 0,889 & 1,252 & $(-1,506 ; 3,448)$ \\
$\theta_{2}$ & 3,486 & 1,423 & $(0,824 ; 6,472)$ & $\eta_{2}$ & 5,171 & 1,507 & $(2,604 ; 8,513)$ \\
$\theta_{3}$ & 2,713 & 1,528 & $(-0,160 ; 5,841)$ & $\eta_{3}$ & 5,166 & 1,818 & $(2,041 ; 9,158)$ \\
$\theta_{4}$ & 7,347 & 1,677 & $(4,455 ; 11,050)$ & $\eta_{4}$ & 1,601 & 1,726 & $(-1,671 ; 5,126)$ \\
$\theta_{5}$ & 8,078 & 1,868 & $(4,836 ; 12,160)$ & $\eta_{5}$ & 8,384 & 2,196 & $(4,690 ; 13,320)$ \\
$\theta_{6}$ & 10,660 & 2,017 & $(7,274 ; 15,150)$ & $\eta_{6}$ & 9,076 & 2,048 & $(5,764 ; 13,700)$ \\
$\theta_{7}$ & 6,287 & 1,587 & $(3,511 ; 9,704)$ & $\eta_{7}$ & 9,794 & 2,146 & $(6,319 ; 14,630)$ \\
$\theta_{8}$ & 7,343 & 1,582 & $(4,620 ; 10,880)$ & $\eta_{8}$ & 8,531 & 1,827 & $(5,588 ; 12,680)$ \\
$\theta_{9}$ & 7,456 & 1,421 & $(5,105 ; 10,550)$ & $\eta_{9}$ & 1,546 & 1,014 & $(-0,313 ; 3,745)$ \\
$\theta_{10}$ & 5,762 & 1,214 & $(3,742 ; 8,451)$ & $\eta_{10}$ & 6,945 & 1,589 & $(4,379 ; 10,510)$ \\
$\theta_{11}$ & 3,975 & 1,143 & $(1,973 ; 6,419)$ & $\eta_{11}$ & 5,135 & 1,312 & $(2,986 ; 8,113)$ \\
$\theta_{12}$ & 2,316 & 0,658 & $(1,234 ; 3,802)$ & $\eta_{12}$ & 3,016 & 1,551 & $(0,237 ; 6,405)$ \\
\hline
\end{tabular}




\subsection{Algumas Conclusões e Discussão dos Resultados}

É muito comum encontrar dados de contagem longitudinais na presença de uma ou mais covariáveis, especialmente em estudos médicos. Para a análise deste tipo de dados é necessário utilizar modelos que capturam a correlação entre os dados de contagem e a presença de sobredispersão. Diferentes modelos de "fragilidade" são introduzidos na literatura para a análise de dados de contagem de Poisson. O uso de métodos Bayesianos hierárquicos é uma forma confiável de analisar dados longitudinais de Poisson, especialmente se forem utilizados softwares recentes de simulação para as distribuições a posteriori conjuntas de interesse. Dessa forma, softwares como o Winbugs fornecem uma grande simplificação na obtenção dos valores a posteriori de interesse.

Para a análise dos dados de contagem dados nas Tabelas 7 e 8, considera-se três modelos com diferentes estruturas de "fragilidade". Assumindo os modelos 1 e 2, dados nas Seções 3.1.1 e 3.1.2, respectivamente, observa-se um valor de DIC muito similar (perto de 2016). Ou seja, usando este critério de discriminação, não se pode dizer que um desses dois modelos tem melhor ajuste aos dados. Porem, se for feito uma análise considerando a variância dos dados de contagem, o modelo 1 se ajusta melhor aos dados (ver, Tabela $10)$.

Pelo critério DIC, é observado que o modelo 3 se ajusta melhor aos dados, pois a estimativa do DIC é dado por 2011.48 (menor do que o valor de DIC para os modelos 1 e 2). Observa-se, também, que em termos da estimativa da variância, o modelo 3 leva a resultados similares se comparado com o modelo 1 (ver, Tabela 10), considerando $X=0$ ou $X=1$. Outros critérios de discriminação podem ser utilizados para comparar esses três modelos (GELFAND; GHOSH, 1998).

$\mathrm{Na}$ análise de dados considerada como exemplo, observa-se um melhor ajuste ao modelo 3 (um modelo de "fragilidade" aditivo) introduzido na Seção 3.1 assumindo $r=2$. Possivelmente, melhores ajustes podem ser obtidos considerando o modelo 3 com $r>2$. É importante mencionar que a opinião de um especialista pode ser utilizada na escolha dos hiperparâmetros das distribuições a priori (40) e (41), assumindo o conhecimento 
biológico (DUNSON; HERRING, 2005). Outra possibilidade é utilizar distribuições a priori informativas para fixar um dos $\alpha_{l}, l=1,2$ (ver (41)) na análise Bayesiana (ou um dos $\phi_{l}$, $l=1,2$ dados em (42)). Desta forma, é possível obter melhores resultados na inferência dos parâmetros.

Outro aspecto positivo da metodologia Bayesiana está relacionada com a discriminação do modelo proposto, e o possível uso de distribuições a priori informativas considerando a opinião de um especialista, o que é comum em estudos médicos. 


\section{Uma Aplicação Com Dados de Pacientes Infectados Pelo Vírus HIV}

Nessa seção, á apresentado um conjunto de dados relacionado a um estudo prospectivo, aberto e aleatorizado, que inclui pacientes infectados pelo vírus HIV, virgens de tratamento, idade superior a 18 anos, contagem de linfócitos T CD4+ inferior a 350 células $/ \mathrm{mm}^{3}$ e carga viral superior a 5000 cópias $/ \mathrm{ml}$. Os esquemas terapêuticos consistem em zidovudina e lamivudina, associados ao efavirenz ou lopinavir. A resposta virológica é avaliada pela proporção de pacientes que obteve carga viral inferior a 400 cópias/ml na $24^{a}$ semana de tratamento e inferior a 50 cópias/ml na semana 48. Avalia-se a resposta imunológica considerando a elevação dos níveis de linfócitos CD4+ nas semanas 24 e 48. O perfil de toxicidade é medido pela freqüência de eventos adversos e alterações laboratoriais. Entre setembro de 2004 e maio de 2006 foram avaliados 66 pacientes, sendo 43 deles incluídos no estudo. Os grupos de pacientes apresentam características basais semelhantes, quanto à idade, sexo, mediana de CD4 e carga viral.

A amostra é composta de pacientes infectados pelo vírus HIV que procuraram atendimento na Unidade Especial de Terapia de Doenças Infecciosas (UETDI) do Hospital das Clínicas da Faculdade de Medicina de Ribeirão Preto da Universidade de São Paulo (HCFMRP-USP). A equipe responsável pela pesquisa é formada por um médico assistente, responsável pela avaliação clínica dos pacientes, e dois enfermeiros, responsáveis pelas orientações pós-consulta, mais detalhes a respeito do experimento podem ser vistos em Colares (2007).

Esse estudo tem como objetivo comparar a contagem média de células CD4 para dois esquemas terapêuticos, baseados nas drogas efavirenz e lopinavir, atualmente consideradas preferenciais para o tratamento inicial da doença. O conjunto de dados pode ser visto na Tabela 12 . 
Tabela 12: Contagem de CD4 em pacientes infectados pelo vírus HIV (COLARES, 2007).

\begin{tabular}{|c|c|c|c|c|c|c|c|c|c|c|c|c|c|c|c|}
\hline Ind & Droga & Tempo & CD4 & Ind & Droga & Tempo & CD4 & Ind & Droga & Tempo & CD4 & Ind & Droga & Tempo & CD4 \\
\hline 1 & LPV & 1 & 202 & 12 & EFV & 1 & 2 & 23 & LPV & 1 & 301 & 34 & LPV & 1 & 87 \\
\hline 1 & LPV & 2 & 284 & 12 & EFV & 2 & 41 & 23 & LPV & 2 & $N A$ & 34 & LPV & 2 & 188 \\
\hline 1 & LPV & 3 & 300 & 12 & EFV & 3 & 57 & 23 & LPV & 3 & 399 & 34 & LPV & 3 & 254 \\
\hline 1 & LPV & 4 & 443 & 12 & EFV & 4 & 64 & 23 & LPV & 4 & 390 & 34 & LPV & 4 & 285 \\
\hline 1 & LPV & 5 & 557 & 12 & EFV & 5 & 107 & 23 & LPV & 5 & 380 & 34 & LPV & 5 & 303 \\
\hline 1 & LPV & 6 & 532 & 12 & EFV & 6 & 87 & 23 & LPV & 6 & 523 & 34 & LPV & 6 & 298 \\
\hline 2 & LPV & 1 & 296 & 13 & EFV & 1 & 159 & 24 & LPV & 1 & 26 & 35 & EFV & 1 & 118 \\
\hline 2 & LPV & 2 & 550 & 13 & EFV & 2 & 195 & 24 & LPV & 2 & 194 & 35 & EFV & 2 & 175 \\
\hline 2 & LPV & 3 & 499 & 13 & EFV & 3 & 195 & 24 & LPV & 3 & 117 & 35 & EFV & 3 & 214 \\
\hline 2 & LPV & 4 & 584 & 13 & EFV & 4 & 212 & 24 & LPV & 4 & 149 & 35 & EFV & 4 & 194 \\
\hline 2 & LPV & 5 & 723 & 13 & EFV & 5 & $N A$ & 24 & LPV & 5 & 170 & 35 & EFV & 5 & 239 \\
\hline 2 & LPV & 6 & 617 & 13 & EFV & 6 & $N A$ & 24 & LPV & 6 & 222 & 35 & EFV & 6 & 295 \\
\hline 3 & EFV & 1 & 33 & 14 & LPV & 1 & 240 & 25 & LPV & 1 & 35 & 36 & EFV & 1 & 174 \\
\hline 3 & EFV & 2 & 65 & 14 & LPV & 2 & 413 & 25 & LPV & 2 & 113 & 36 & EFV & 2 & 366 \\
\hline 3 & EFV & 3 & 61 & 14 & LPV & 3 & 404 & 25 & LPV & 3 & 120 & 36 & EFV & 3 & 363 \\
\hline 3 & EFV & 4 & 58 & 14 & LPV & 4 & 504 & 25 & LPV & 4 & 120 & 36 & EFV & 4 & 375 \\
\hline 3 & EFV & 5 & 85 & 14 & LPV & 5 & 484 & 25 & LPV & 5 & 300 & 36 & EFV & 5 & 351 \\
\hline 3 & EFV & 6 & 136 & 14 & LPV & 6 & 391 & 25 & LPV & 6 & 223 & 36 & EFV & 6 & 345 \\
\hline 4 & EFV & 1 & 206 & 15 & LPV & 1 & 4 & 26 & EFV & 1 & 109 & 37 & LPV & 1 & 201 \\
\hline 4 & EFV & 2 & 373 & 15 & LPV & 2 & 173 & 26 & $\mathrm{EFV}$ & 2 & 167 & 37 & LPV & 2 & 386 \\
\hline 4 & EFV & 3 & 272 & 15 & LPV & 3 & 147 & 26 & $\mathrm{EFV}$ & 3 & 163 & 37 & LPV & 3 & 532 \\
\hline 4 & EFV & 4 & 571 & 15 & LPV & 4 & 133 & 26 & EFV & 4 & 170 & 37 & LPV & 4 & 453 \\
\hline 4 & EFV & 5 & 663 & 15 & LPV & 5 & 160 & 26 & EFV & 5 & 191 & 37 & LPV & 5 & 414 \\
\hline 4 & EFV & 6 & 669 & 15 & LPV & 6 & 264 & 26 & EFV & 6 & 188 & 37 & LPV & 6 & 603 \\
\hline 5 & LPV & 1 & 21 & 16 & LPV & 1 & 47 & 27 & EFV & 1 & 22 & 38 & EFV & 1 & 6 \\
\hline 5 & LPV & 2 & $N A$ & 16 & LPV & 2 & 125 & 27 & $\mathrm{EFV}$ & 2 & 410 & 38 & EFV & 2 & 90 \\
\hline 5 & LPV & 3 & $N A$ & 16 & LPV & 3 & 280 & 27 & $\mathrm{EFV}$ & 3 & 190 & 38 & EFV & 3 & 65 \\
\hline 5 & LPV & 4 & $N A$ & 16 & LPV & 4 & 591 & 27 & $\mathrm{EFV}$ & 4 & 138 & 38 & EFV & 4 & 56 \\
\hline 5 & LPV & 5 & $N A$ & 16 & LPV & 5 & 206 & 27 & EFV & 5 & 332 & 38 & EFV & 5 & 110 \\
\hline 5 & LPV & 6 & $N A$ & 16 & LPV & 6 & 225 & 27 & EFV & 6 & 302 & 38 & EFV & 6 & 114 \\
\hline 6 & LPV & 1 & 11 & 17 & EFV & 1 & 224 & 28 & LPV & 1 & 290 & 39 & LPV & 1 & 98 \\
\hline 6 & LPV & 2 & 83 & 17 & EFV & 2 & 346 & 28 & LPV & 2 & 421 & 39 & LPV & 2 & 220 \\
\hline 6 & LPV & 3 & 101 & 17 & EFV & 3 & 330 & 28 & LPV & 3 & 547 & 39 & LPV & 3 & 245 \\
\hline 6 & LPV & 4 & 170 & 17 & EFV & 4 & 315 & 28 & LPV & 4 & $N A$ & 39 & LPV & 4 & 110 \\
\hline 6 & LPV & 5 & 201 & 17 & EFV & 5 & 450 & 28 & LPV & 5 & $N A$ & 39 & LPV & 5 & $N A$ \\
\hline 6 & LPV & 6 & 238 & 17 & EFV & 6 & 452 & 28 & LPV & 6 & $N A$ & 39 & LPV & 6 & $N A$ \\
\hline 7 & LPV & 1 & 14 & 18 & EFV & 1 & 137 & 29 & LPV & 1 & 147 & 40 & EFV & 1 & 51 \\
\hline 7 & LPV & 2 & 148 & 18 & EFV & 2 & 270 & 29 & LPV & 2 & $N A$ & 40 & EFV & 2 & 143 \\
\hline 7 & LPV & 3 & 171 & 18 & EFV & 3 & 292 & 29 & LPV & 3 & 209 & 40 & EFV & 3 & 114 \\
\hline 7 & LPV & 4 & 143 & 18 & EFV & 4 & 244 & 29 & LPV & 4 & 221 & 40 & EFV & 4 & 215 \\
\hline 7 & LPV & 5 & 106 & 18 & EFV & 5 & 292 & 29 & LPV & 5 & 301 & 40 & EFV & 5 & 294 \\
\hline 7 & LPV & 6 & 154 & 18 & EFV & 6 & 287 & 29 & LPV & 6 & 301 & 40 & EFV & 6 & 301 \\
\hline 8 & LPV & 1 & 42 & 19 & EFV & 1 & 271 & 30 & EFV & 1 & 159 & 41 & LPV & 1 & 93 \\
\hline 8 & LPV & 2 & $N A$ & 19 & EFV & 2 & 266 & 30 & $\mathrm{EFV}$ & 2 & 175 & 41 & LPV & 2 & 137 \\
\hline 8 & LPV & 3 & $N A$ & 19 & EFV & 3 & 351 & 30 & EFV & 3 & 187 & 41 & LPV & 3 & 176 \\
\hline 8 & LPV & 4 & $N A$ & 19 & EFV & 4 & 377 & 30 & $\mathrm{EFV}$ & 4 & 227 & 41 & LPV & 4 & 215 \\
\hline 8 & LPV & 5 & $N A$ & 19 & EFV & 5 & 476 & 30 & EFV & 5 & 226 & 41 & LPV & 5 & 262 \\
\hline 8 & LPV & 6 & $N A$ & 19 & EFV & 6 & 538 & 30 & EFV & 6 & 356 & 41 & LPV & 6 & 197 \\
\hline 9 & EFV & 1 & 225 & 20 & EFV & 1 & 297 & 31 & LPV & 1 & 22 & 42 & LPV & 1 & 112 \\
\hline 9 & EFV & 2 & 211 & 20 & EFV & 2 & 467 & 31 & LPV & 2 & $N A$ & 42 & LPV & 2 & 301 \\
\hline 9 & EFV & 3 & 221 & 20 & EFV & 3 & 469 & 31 & LPV & 3 & $N A$ & 42 & LPV & 3 & 568 \\
\hline 9 & EFV & 4 & 185 & 20 & EFV & 4 & 487 & 31 & LPV & 4 & $N A$ & 42 & LPV & 4 & 306 \\
\hline 9 & EFV & 5 & 205 & 20 & EFV & 5 & 600 & 31 & LPV & 5 & $N A$ & 42 & LPV & 5 & 362 \\
\hline 9 & EFV & 6 & 183 & 20 & EFV & 6 & 677 & 31 & LPV & 6 & $N A$ & 42 & LPV & 6 & 427 \\
\hline 10 & LPV & 1 & 165 & 21 & EFV & 1 & 22 & 32 & $\mathrm{EFV}$ & 1 & 278 & 43 & EFV & 1 & 26 \\
\hline 10 & LPV & 2 & $N A$ & 21 & EFV & 2 & 306 & 32 & EFV & 2 & 318 & 43 & EFV & 2 & 93 \\
\hline 10 & LPV & 3 & $N A$ & 21 & EFV & 3 & 188 & 32 & $\mathrm{EFV}$ & 3 & 355 & 43 & EFV & 3 & 142 \\
\hline 10 & LPV & 4 & $N A$ & 21 & EFV & 4 & 277 & 32 & $\mathrm{EFV}$ & 4 & 335 & 43 & EFV & 4 & 197 \\
\hline 10 & LPV & 5 & $N A$ & 21 & EFV & 5 & 250 & 32 & $\mathrm{EFV}$ & 5 & 322 & 43 & EFV & 5 & $N A$ \\
\hline 10 & LPV & 6 & $N A$ & 21 & EFV & 6 & 247 & 32 & EFV & 6 & 452 & 43 & EFV & 6 & $N A$ \\
\hline 11 & EFV & 1 & 44 & 22 & EFV & 1 & 42 & 33 & EFV & 1 & 75 & & & & \\
\hline 11 & EFV & 2 & $N A$ & 22 & EFV & 2 & 278 & 33 & EFV & 2 & 117 & & & & \\
\hline 11 & EFV & 3 & $N A$ & 22 & EFV & 3 & 232 & 33 & EFV & 3 & 285 & & & & \\
\hline 11 & EFV & 4 & $N A$ & 22 & EFV & 4 & 286 & 33 & $\mathrm{EFV}$ & 4 & 221 & & & & \\
\hline 11 & EFV & 5 & $N A$ & 22 & EFV & 5 & 353 & 33 & $\mathrm{EFV}$ & 5 & 341 & & & & \\
\hline 11 & EFV & 6 & $N A$ & 22 & EFV & 6 & 380 & 33 & EFV & 6 & 474 & & & & \\
\hline
\end{tabular}


Fazendo uma descrição dos dados, calculando as médias e as variâncias amostrais para cada combinação tempo $\times$ tratamento, percebe-se que as médias amostrais são diferentes das variâncias amostrais para quase todas as combinações tempo $\times$ tratamento. A diferença amostral entre a média e a variância amostral, para cada combinação tempo $\times$ tratamento, indica a presença de uma variabilidade extra-Poisson.

Para a análise dos dados da Tabela 12, assume-se que os dados de contagem na presença da covariável seguem distribuição de Poisson. Para analisar os dados da Tabela 12, os modelos e a metodologia Bayesiana introduzidos nos Capítulos 2 e 3 são considerados. Duas análises utilizando o modelo 1 introduzido na Seção 2 (ver, (10)) são feitas, a primeira com a ausência do efeito aleatório $w_{i}$ e a segunda com a presença do efeito aleatório $w_{i}$. Para o modelo 3, introduzido na Seção 3 (ver, (28)), houve uma pequena modificação na estrutura do modelo,

$$
\lambda_{i j}=\left(\sum_{l=1}^{r} \alpha_{l j} w_{l i}\right) \exp \left(\beta_{j} x_{i j}\right)
$$

em que, $i=1, \ldots, n ; j=1, \ldots, k$. Nesse caso tem-se que $\sum_{l=1}^{r} \alpha_{l j}$ mede o CD4 médio no $j^{t h}$ tempo para os indivíduos que recebem o tratamento a base de efavirenz; $\sum_{l=1}^{r} \alpha_{l j} \exp \left(\beta_{j}\right)$ mede o CD4 médio no $j^{\text {th }}$ tempo para os indivíduos que recebem o tratamento a base de lopinavir; $\beta_{j}$ é um parâmetro de regressão que indica o efeito de tratamento. Diferentes valores para $r$ são considerados $(r=2,3,4)$.

Na Seção 3, uma distribuição a priori Beta é utilizada para os parâmetros $\alpha_{l}, l=1,2$; agora considera-se uma distribuição a priori uniforme para $\alpha_{l}$, isto é,

$$
\alpha_{l j} \sim U\left(a_{l} ; b_{l}\right) ; a_{l}, b_{l} \text { conhecidos } l=1, \ldots, r ; j=1, \ldots, k
$$

\subsection{Análise Bayesiana Dos Dados}

Para análise Bayesiana dos dados da Tabela 12, assume-se para os modelos 1 e 2, introduzidos na Seção 3, os seguintes valores para os hiperparâmetros das distribuições a priori (35), (36) e (38): $a=b=0,01 ; c=0 ; d^{2}=1000 ; f=g=0,1$. Para o modelo 3, 
assume-se $a_{l}=0 ; b_{l}=100 ; d_{l}^{2}=1,0 ; f_{l}=g_{l}=1,0, l=1, \ldots, r$, para os hiperparâmetros das distribuições a priori (40), (42) e (45). A escolha desses hiperparâmetros é feita para se ter distribuições a prior aproximadamente não-informativas e tal que a convergência dos algoritmos MCMC usados na simulação de Gibbs Sample para a distribuição a posteriori de interesse, utilizando o Software Winbugs (SPIEGELHALTER et al., 1995), seja observada. Os códigos de programa do Software Winbugs são similares aos códigos utilizados para resolver o problema da Seção 3 e podem ser vistos no Apêndice B. Para os modelos 1, 2, e 3, são simuladas 1.005.000 amostras, onde as primeiras 5000 amostras ("burnin-samples") são descartadas para eliminar os efeitos dos valores iniciais do algoritmo de Gibbs sampling. Para se ter uma amostra de Gibbs aproximadamente não-correlacionada, considera-se as amostras $100^{a}, 200^{a}, 300^{a}, \ldots$, no qual resulta em uma amostra final de tamanho 10.000 para cada parâmetro. A convergência do algoritmo de Gibbs sampling é observada por gráficos usuais de séries temporais das amostras simuladas e também utilizando alguns métodos de convergência existentes (GELMAN; RUBIN, 1992).

Os resultados a posteriori para os parâmetros dos modelos 1, 2, e 3 podem ser vistos nas Tabelas 13 a 18. Na Figura 6, tem-se o gráfico dos valores observados versus valores preditos pelos modelos 1, 2 e 3. Dos resultados da Figura 6, observa-se, em geral, um melhor ajuste ao modelo 3, e percebe-se que quanto maior o valor de $r$ melhor o ajuste do modelo aos dados. 
Tabela 13: Média a posteriori e intervalos de credibilidade para os parâmetros do modelo 1 (ausência de $w_{i}$ ).

\begin{tabular}{cccc}
\hline Parâmetro & $\begin{array}{c}\text { Média a } \\
\text { Posteriori }\end{array}$ & $\begin{array}{c}\text { Desvio } \\
\text { Padrão }\end{array}$ & $\begin{array}{c}\text { Intervalo de } \\
\text { Credibilidade }\end{array}$ \\
\hline$\alpha_{1}$ & 121,8 & 2,344 & $(117,3 ; 126,5)$ \\
$\alpha_{2}$ & 231,9 & 3,295 & $(225,4 ; 238,4)$ \\
$\alpha_{3}$ & 225,9 & 3,293 & $(219,5 ; 232,4)$ \\
$\alpha_{4}$ & 247,7 & 3,438 & $(240,9 ; 254,3)$ \\
$\alpha_{5}$ & 309,7 & 4,028 & $(301,8 ; 317,5)$ \\
$\alpha_{6}$ & 341,0 & 4,224 & $(332,9 ; 349,4)$ \\
$\beta_{1}$ & $-0,041$ & 0,028 & $(-0,097 ; 0,013)$ \\
$\beta_{2}$ & 0,071 & 0,021 & $(0,030 ; 0,113)$ \\
$\beta_{3}$ & 0,277 & 0,020 & $(0,237 ; 0,318)$ \\
$\beta_{4}$ & 0,195 & 0,020 & $(0,156 ; 0,234)$ \\
$\beta_{5}$ & 0,059 & 0,019 & $(0,021 ; 0,097)$ \\
$\beta_{6}$ & 0,019 & 0,018 & $(-0,017 ; 0,055)$ \\
\hline
\end{tabular}

Tabela 14: Média a posteriori e intervalos de credibilidade para os parâmetros do modelo 1 (presença de $w_{i}$ ).

\begin{tabular}{cccc}
\hline Parâmetro & $\begin{array}{c}\text { Média a } \\
\text { Posteriori }\end{array}$ & $\begin{array}{c}\text { Desvio } \\
\text { Padrão }\end{array}$ & $\begin{array}{c}\text { Intervalo de } \\
\text { Credibilidade }\end{array}$ \\
\hline$\alpha_{1}$ & 86,01 & 11,87 & $(63,44 ; 111,0)$ \\
$\alpha_{2}$ & 159,0 & 21,83 & $(117,6 ; 204,5)$ \\
$\alpha_{3}$ & 154,9 & 21,27 & $(114,1 ; 198,9)$ \\
$\alpha_{4}$ & 169,8 & 23,36 & $(124,9 ; 218,4)$ \\
$\alpha_{5}$ & 206,5 & 28,38 & $(152,3 ; 265,5)$ \\
$\alpha_{6}$ & 227,5 & 31,22 & $(167,7 ; 292,6)$ \\
$\beta_{1}$ & 0,113 & 0,207 & $(-0,276 ; 0,544)$ \\
$\beta_{2}$ & 0,168 & 0,206 & $(-0,218 ; 0,598)$ \\
$\beta_{3}$ & 0,361 & 0,206 & $(-0,022 ; 0,785)$ \\
$\beta_{4}$ & 0,333 & 0,207 & $(-0,055 ; 0,761)$ \\
$\beta_{5}$ & 0,206 & 0,206 & $(-0,184 ; 0,636)$ \\
$\beta_{6}$ & 0,165 & 0,206 & $(-0,222 ; 0,595)$ \\
\hline
\end{tabular}


Tabela 15: Média a posteriori e intervalos de credibilidade para os parâmetros do modelo 2 .

\begin{tabular}{cccc}
\hline Parâmetro & $\begin{array}{c}\text { Média a } \\
\text { Posteriori }\end{array}$ & $\begin{array}{c}\text { Desvio } \\
\text { Padrão }\end{array}$ & $\begin{array}{c}\text { Intervalo de } \\
\text { Credibilidade }\end{array}$ \\
\hline$\alpha_{1}$ & 101,7 & 13,07 & $(79,51 ; 126,8)$ \\
$\alpha_{2}$ & 188,1 & 23,95 & $(147,3 ; 233,8)$ \\
$\alpha_{3}$ & 183,2 & 23,34 & $(143,0 ; 227,8)$ \\
$\alpha_{4}$ & 200,9 & 25,62 & $(157,2 ; 250,4)$ \\
$\alpha_{5}$ & 244,4 & 31,17 & $(191,4 ; 304,3)$ \\
$\alpha_{6}$ & 269,1 & 34,27 & $(210,8 ; 334,9)$ \\
$\beta_{1}$ & 0,162 & 0,218 & $(-0,199 ; 0,545)$ \\
$\beta_{2}$ & 0,215 & 0,216 & $(-0,144 ; 0,597)$ \\
$\beta_{3}$ & 0,409 & 0,216 & $(0,0525 ; 0,795)$ \\
$\beta_{4}$ & 0,381 & 0,217 & $(0,0222 ; 0,764)$ \\
$\beta_{5}$ & 0,253 & 0,217 & $(-0,104 ; 0,634)$ \\
$\beta_{6}$ & 0,213 & 0,217 & $(-0,145 ; 0,592)$ \\
\hline
\end{tabular}

Tabela 16: Média a posteriori e intervalos de credibilidade para os parâmetros do modelo $3, r=2$.

\begin{tabular}{cccc}
\hline Parâmetro & $\begin{array}{c}\text { Média a } \\
\text { Posteriori }\end{array}$ & $\begin{array}{c}\text { Desvio } \\
\text { Padrão }\end{array}$ & $\begin{array}{c}\text { Intervalo de } \\
\text { Credibilidade }\end{array}$ \\
\hline$\alpha_{11}$ & 2,363 & 1,472 & $(0,152 ; 5,591)$ \\
$\alpha_{12}$ & 64,03 & 2,99 & $(57,9 ; 69,67)$ \\
$\alpha_{13}$ & 53,44 & 2,66 & $(48,05 ; 58,58)$ \\
$\alpha_{14}$ & 74,41 & 3,246 & $(67,67 ; 80,41)$ \\
$\alpha_{15}$ & 91,0 & 3,731 & $(83,06 ; 97,8)$ \\
$\alpha_{16}$ & 97,32 & 2,583 & $(90,38 ; 99,93)$ \\
$\alpha_{21}$ & 86,4 & 7,64 & $(70,37 ; 98,98)$ \\
$\alpha_{22}$ & 72,73 & 5,279 & $(60,96 ; 82,09)$ \\
$\alpha_{23}$ & 83,75 & 5,968 & $(70,75 ; 94,17)$ \\
$\alpha_{24}$ & 68,73 & 5,31 & $(56,8 ; 77,97)$ \\
$\alpha_{25}$ & 82,95 & 6,051 & $(69,4 ; 93,4)$ \\
$\alpha_{26}$ & 93,57 & 5,542 & $(79,46 ; 99,81)$ \\
$\beta_{1}$ & 0,203 & 0,195 & $(-0,161 ; 0,603)$ \\
$\beta_{2}$ & 0,520 & 0,148 & $(0,231 ; 0,819)$ \\
$\beta_{3}$ & 0,669 & 0,152 & $(0,370 ; 0,97)$ \\
$\beta_{4}$ & 0,704 & 0,148 & $(0,415 ; 1,003)$ \\
$\beta_{5}$ & 0,571 & 0,148 & $(0,282 ; 0,872)$ \\
$\beta_{6}$ & 0,533 & 0,147 & $(0,249 ; 0,829)$ \\
\hline
\end{tabular}


Tabela 17: Média a posteriori e intervalos de credibilidade para os parâmetros do modelo $3, r=3$.

\begin{tabular}{cccc}
\hline Parâmetro & $\begin{array}{c}\text { Média a } \\
\text { Posteriori }\end{array}$ & $\begin{array}{c}\text { Desvio } \\
\text { Padrão }\end{array}$ & $\begin{array}{c}\text { Intervalo de } \\
\text { Credibilidade }\end{array}$ \\
\hline$\alpha_{11}$ & 3,066 & 1,944 & $(0,243 ; 7,721)$ \\
$\alpha_{12}$ & 22,57 & 6,141 & $(9,1 ; 33,83)$ \\
$\alpha_{13}$ & 46,6 & 4,166 & $(37,95 ; 54,35)$ \\
$\alpha_{14}$ & 79,85 & 6,283 & $(66,65 ; 91,67)$ \\
$\alpha_{15}$ & 83,09 & 6,288 & $(69,43 ; 94,23)$ \\
$\alpha_{16}$ & 93,9 & 5,414 & $(80,04 ; 99,84)$ \\
$\alpha_{21}$ & 0,612 & 0,528 & $(0,019 ; 1,976)$ \\
$\alpha_{22}$ & 96,32 & 3,477 & $(87,2 ; 99,9)$ \\
$\alpha_{23}$ & 28,58 & 4,628 & $(19,86 ; 38,09)$ \\
$\alpha_{24}$ & 1,231 & 1,132 & $(0,036 ; 4,091)$ \\
$\alpha_{25}$ & 50,28 & 6,049 & $(38,77 ; 62,54)$ \\
$\alpha_{26}$ & 44,47 & 5,78 & $(34,0 ; 56,61)$ \\
$\alpha_{31}$ & 82,79 & 10,6 & $(59,74 ; 99,0)$ \\
$\alpha_{32}$ & 71,69 & 11,4 & $(48,47 ; 92,1)$ \\
$\alpha_{33}$ & 76,93 & 10,77 & $(54,12 ; 95,28)$ \\
$\alpha_{34}$ & 63,88 & 10,61 & $(42,58 ; 82,43)$ \\
$\alpha_{35}$ & 67,59 & 11,22 & $(44,69 ; 86,81)$ \\
$\alpha_{36}$ & 77,4 & 12,69 & $(51,06 ; 98,03)$ \\
$\beta_{1}$ & 1,401 & 0,356 & $(0,730 ; 2,124)$ \\
$\beta_{2}$ & $-0,017$ & 0,245 & $(-0,518 ; 0,439)$ \\
$\beta_{3}$ & 1,003 & 0,270 & $(0,492 ; 1,557)$ \\
$\beta_{4}$ & 1,816 & 0,326 & $(1,211 ; 2,492)$ \\
$\beta_{5}$ & 0,701 & 0,260 & $(0,198 ; 1,213)$ \\
$\beta_{6}$ & 0,797 & 0,265 & $(0,286 ; 1,326)$ \\
\hline & & &
\end{tabular}


Tabela 18: Média a posteriori e intervalos de credibilidade para os parâmetros do modelo $3, r=4$.

\begin{tabular}{|c|c|c|c|}
\hline Parâmetro & $\begin{array}{l}\text { Média a } \\
\text { Posteriori }\end{array}$ & $\begin{array}{l}\text { Desvio } \\
\text { Padrão }\end{array}$ & $\begin{array}{l}\text { Intervalo de } \\
\text { Credibilidade }\end{array}$ \\
\hline$\alpha_{11}$ & 88,12 & 7,926 & $(69,81 ; 99,37)$ \\
\hline$\alpha_{12}$ & 73,05 & 9,45 & $(53,15 ; 89,7)$ \\
\hline$\alpha_{13}$ & 86,25 & 8,51 & $(67,04 ; 98,9)$ \\
\hline$\alpha_{14}$ & 70,67 & 9,526 & $(50,28 ; 87,87)$ \\
\hline$\alpha_{15}$ & 72,37 & 9,219 & $(53,07 ; 88,39)$ \\
\hline$\alpha_{16}$ & 83,83 & 9,763 & $(62,83 ; 98,82)$ \\
\hline$\alpha_{21}$ & 4,163 & 2,444 & $(0,238 ; 9,145)$ \\
\hline$\alpha_{22}$ & 19,23 & 7,13 & $(5,569 ; 33,78)$ \\
\hline$\alpha_{23}$ & 42,13 & 8,892 & $(25,35 ; 60,13)$ \\
\hline$\alpha_{24}$ & 85,3 & 11,0 & $(59,2 ; 99,43)$ \\
\hline$\alpha_{25}$ & 24,7 & 10,35 & $(4,139 ; 44,44)$ \\
\hline$\alpha_{26}$ & 27,41 & 11,36 & $(5,232 ; 49,42)$ \\
\hline$\alpha_{31}$ & 1,415 & 1,139 & $(0,048 ; 4,2)$ \\
\hline$\alpha_{32}$ & 92,64 & 6,497 & $(76,29 ; 99,78)$ \\
\hline$\alpha_{33}$ & 53,44 & 6,893 & $(39,87 ; 67,0)$ \\
\hline$\alpha_{34}$ & 10,82 & 6,995 & $(0,630 ; 26,09)$ \\
\hline$\alpha_{35}$ & 52,48 & 12,49 & $(28,69 ; 76,63)$ \\
\hline$\alpha_{36}$ & 59,36 & 12,33 & $(36,14 ; 84,07)$ \\
\hline$\alpha_{41}$ & 1,823 & 1,456 & $(0,066 ; 5,389)$ \\
\hline$\alpha_{42}$ & 16,81 & 7,528 & $(2,493 ; 31,29)$ \\
\hline$\alpha_{43}$ & 11,59 & 5,957 & $(1,256 ; 23,67)$ \\
\hline$\alpha_{44}$ & 42,55 & 10,09 & $(23,54 ; 62,95)$ \\
\hline$\alpha_{45}$ & 90,47 & 6,078 & $(76,0 ; 99,41)$ \\
\hline$\alpha_{46}$ & 93,9 & 5,247 & $(80,51 ; 99,77)$ \\
\hline$\beta_{1}$ & 0,394 & 0,233 & $(-0,040 ; 0,877)$ \\
\hline$\beta_{2}$ & 0,157 & 0,140 & $(-0,121 ; 0,433)$ \\
\hline$\beta_{3}$ & 0,446 & 0,145 & $(0,164 ; 0,738)$ \\
\hline$\beta_{4}$ & 0,489 & 0,156 & $(0,193 ; 0,810)$ \\
\hline$\beta_{5}$ & 0,338 & 0,140 & $(0,071 ; 0,624)$ \\
\hline$\beta_{6}$ & 0,299 & 0,135 & $(0,038 ; 0,572)$ \\
\hline
\end{tabular}




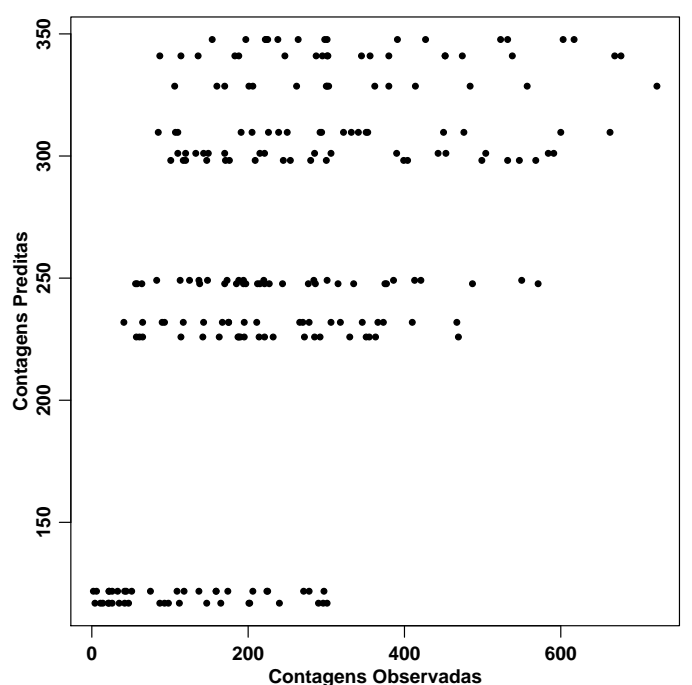

(a) Modelo 1 (ausência de $w_{i}$ )

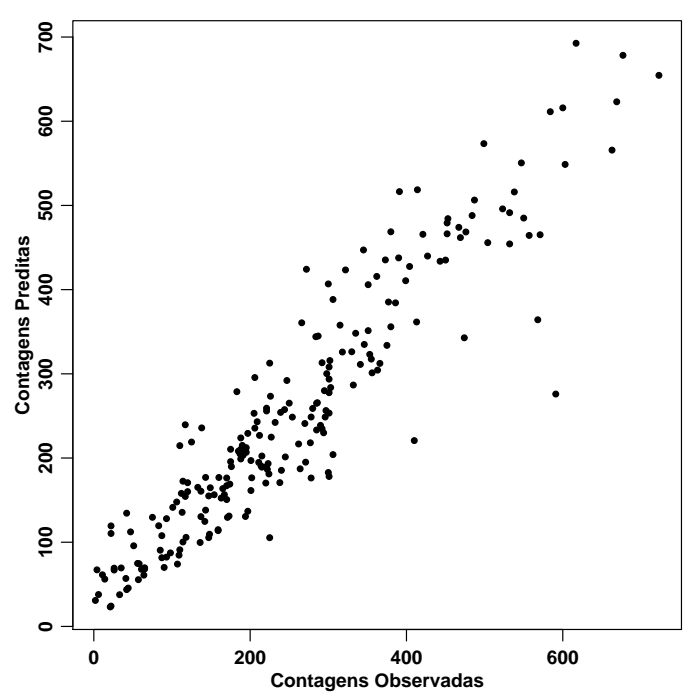

(c) Modelo 2

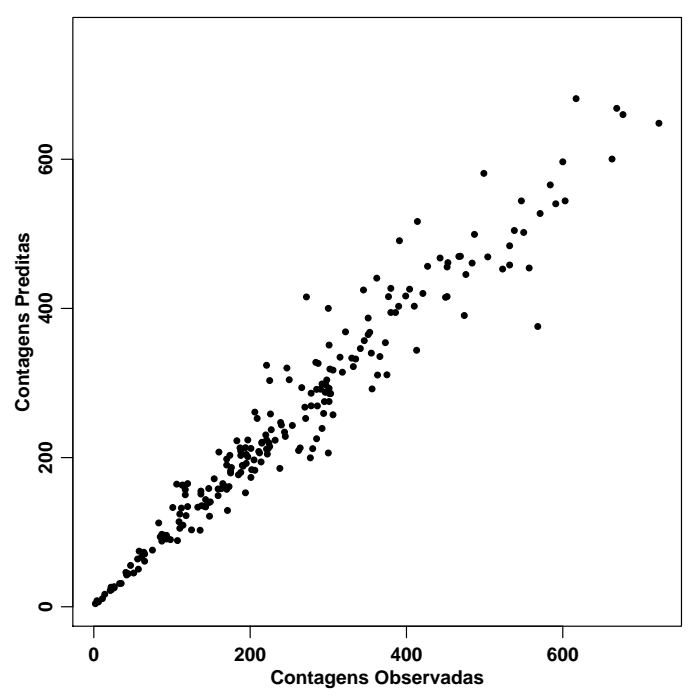

(e) Modelo $3(\mathrm{r}=3)$

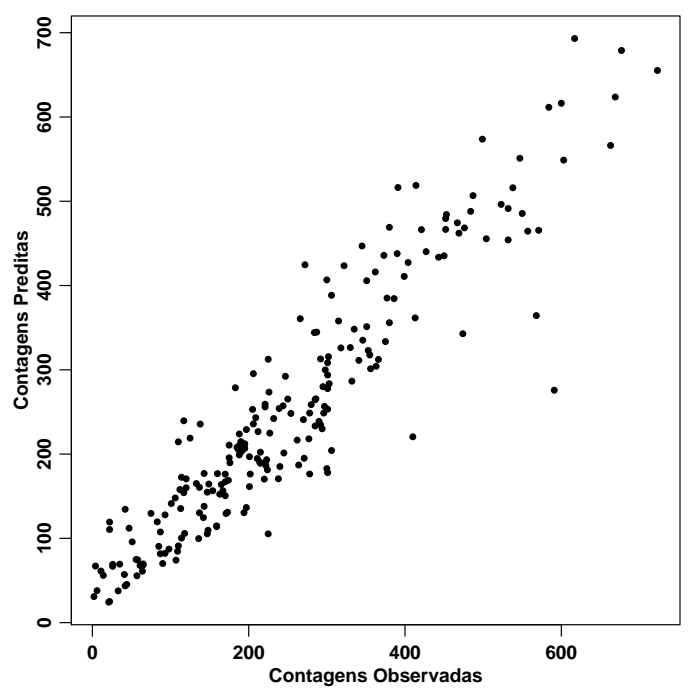

(b) Modelo 1 (presença de $w_{i}$ )

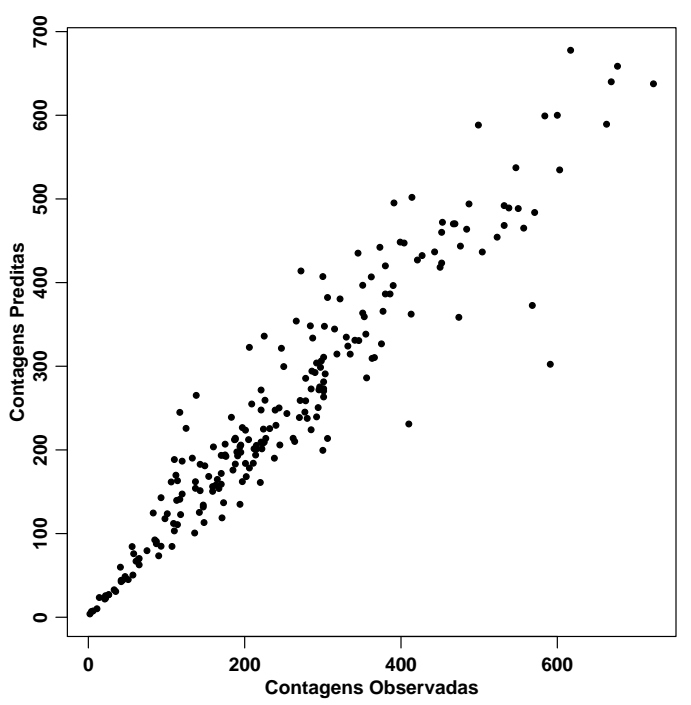

(d) Modelo 3 ( $\mathrm{r}=2$ )

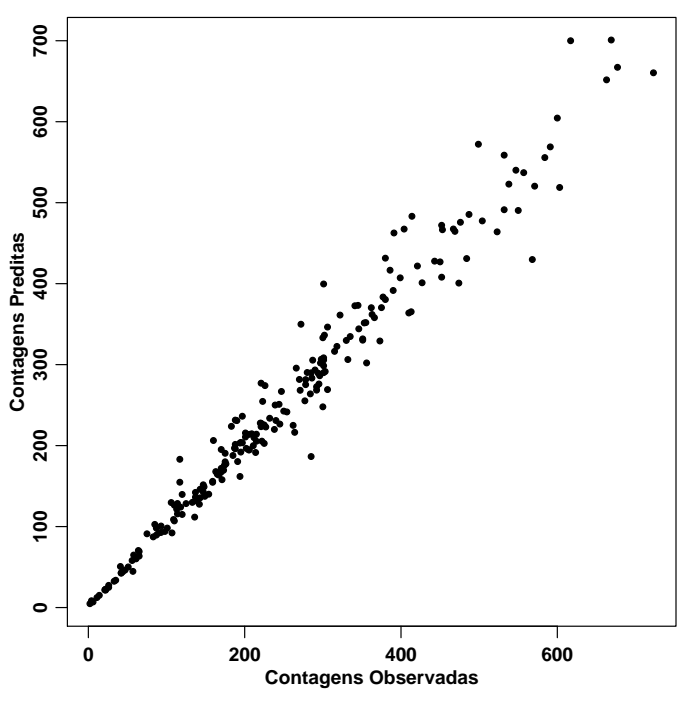

(f) Modelo $3(\mathrm{r}=4)$

Figura 6: Gráficos dos valores observados versus valores preditos. 
Para a seleção do melhor modelo, pode-se utilizar algumas medidas de discriminação de modelos como, por exemplo, o Deviance Information Criterion (DIC) (SPIEGELHALTER et al., 2000), onde o menor valor de DIC indica o melhor modelo. Na Tabela 19, pode-se observar os DIC estimados para cada modelo, obtidos utilizando o Software Winbugs. Observa-se que o modelo 3 é o melhor ajustado para os dados de contagem da Tabela 12, e quanto maior o valor de $r$ melhor o ajuste (menor valor de DIC). Observa-se também que a diferença entre os valores observados e os valores preditos pelos modelos são, em geral, menores se considerado o modelo 3. Na Tabela 20, pode-se observar as somas de quadrados destas diferenças assumindo cada um dos modelos propostos. Dos resultados da Tabela 20, observa-se um menor valor para a soma dos quadrados das diferenças para o modelo 3 , especialmente para $r=4$.

Tabela 19: Critério DIC.

\begin{tabular}{lc}
\hline Modelo & Deviance Information Criterion (DIC) \\
\hline Modelo 1 (ausência de $\left.w_{i}\right)$ & 18010,800 \\
Modelo 1 (presença $\left.w_{i}\right)$ & 4914,000 \\
Modelo 2 & 4861,450 \\
Modelo 3 $(r=2)$ & 3659,560 \\
Modelo 3 $(r=3)$ & 2783,210 \\
Modelo 3 $(r=4)$ & 2430,550 \\
\hline
\end{tabular}

Tabela 20: Soma do quadrado das diferenças entre os valores observados e os valores preditos.

\begin{tabular}{lc}
\hline Modelo & $\sum_{i=1}^{n}\left(y_{i}-\hat{y}_{i}\right)^{2}$ \\
\hline Modelo 1 (ausência $\left.w_{i}\right)$ & 4093784,0 \\
Modelo 1 (presença $\left.w_{i}\right)$ & 722850,9 \\
Modelo 2 & 722642,4 \\
Modelo 3 $(r=2)$ & 552654,9 \\
Modelo 3 $(r=3)$ & 312354,2 \\
Modelo 3 $(r=4)$ & 176012,7 \\
\hline
\end{tabular}

\subsection{Algumas Conclusões e Discussão dos Resultados}

É muito comum encontrar dados de contagem longitudinais na presença de uma ou mais covariáveis, especialmente em estudos médicos. Para a análise deste tipo de dados 
é necessário utilizar modelos que capturam a correlação entre os dados de contagem e a presença de sobredispersão. Diferentes modelos de "fragilidade" são introduzidos na literatura para a análise de dados de contagem de Poisson. O uso de métodos Bayesianos hierárquicos é uma forma confiável de analisar dados longitudinais de Poisson, especialmente se for utilizado os softwares recentes de simulação para as distribuições a posteriori conjuntas de interesse. Portanto, softwares como o Winbugs, fornecem uma grande simplificação na obtenção dos valores a posteriori de interesse.

Para a análise dos dados de contagem da Tabela 12, são considerados três modelos com diferentes estruturas de "fragilidade". Assumindo o modelo 1 com a presença de efeito aleatório e o modelo 2, observa-se um valor de DIC muito similar (perto de 4900). Ou seja, usando este critério de discriminação, não se pode dizer que um desses dois modelos tem melhor ajuste aos dados.

Pelo critério DIC, observa-se que o modelo 3 considerando $r=4$, se ajusta melhor aos dados, pois a estimativa do DIC é dada por 2430,55 (menor do que o valor de DIC para os outros modelos). Observa-se, também, que em termos de predição, o modelo 3 é o que melhor se ajusta aos dados, percebe-se também que quanto maior o valor de $r$ melhor é a predição (ver, Figura 6 e Tabela 20). Outros critérios de discriminação podem ser utilizados para comparar esses três modelos (GELFAND; GHOSH, 1998).

$\mathrm{Na}$ análise de dados considerada como exemplo, observa-se um melhor ajuste ao modelo 3 (um modelo de "fragilidade" aditivo) assumindo $r=4$. Considerando esse modelo e observando os resultados da Tabela 18, percebe-se que, a partir dessa amostra, há evidências de que a contagem média de células CD4 dos indivíduos que receberam o tratamento baseado no esquema terapêutico efavirenz se difere dos indivíduos que receberam o tratamento baseado em lopinavir. Essa conclusão é baseada no fato que a maioria dos intervalos de credibilidade para os parâmetros $\beta_{j}, j=1, \ldots, 6$, não contém o valor zero $\left(\beta_{3}, \beta_{4}, \beta_{5}\right.$ e $\left.\beta_{6}\right)$, indicando significância dos parâmetros para o modelo. 


\section{Referências}

ACHCAR, J.; COELHO-BARROS, E. A.; MARTINEZ, E. Statistical analysis for longitudinal counting data in the presence of a covariate considering different "frailty" models. Brazilian Journal of Probability and Statistics, São Paulo, v. 22, n. 2, p. 183-205, 2008. ISSN 0103-0752.

ALBERT, J. H.; CHIB, S. Bayesian analysis of binary and polychotomous response data. J. Amer. Statist. Assoc., v. 88, n. 422, p. 669-679, 1993. ISSN 0162-1459.

BERNARDO, J.-M.; SMITH, A. F. M. Bayesian theory. Chichester: John Wiley \& Sons Ltd., 1994. xiv+586 p. (Wiley Series in Probability and Mathematical Statistics: Probability and Mathematical Statistics). ISBN 0-471-92416-4.

BERRY, D. A. Bayesian clinical trials. Nature Rewiews, London, v. 5, p. 27-36, 2006.

BERRY, D. A.; STANGL, D. K. Bayesian Biostatistics. New York: Marcel Dekker, 1996. $696 \mathrm{p}$.

BRESLOW, N. Extra-poisson varition in log-linear models. Aplied Statistics, v. 33, p. 38-44, 1984.

BRILLINGER, D. R. The natural variability of vital rates and associated statistics. Biometrics, v. 42, n. 4, p. 693-734, 1986. ISSN 0006-341X. With discussion and a reply by the author.

CHIB, S.; GREENBERG, E. Understanding the metropolis-hastings algorithm. The American Statistician, v. 49, n. 4, p. 327-335, 1995.

CHIB, S.; GREENBERG, E.; WINKELMANN, R. Posterior simulation and bayes factors in panel count data models. Journal of Econometrics, v. 86, p. 33-54, 1998.

CLAYTON, D. G. A monte carlo method for bayesian inference in frailty models.

Biometrics, v. 47, p. 467-485, 1991. 
COELHO-BARROS, E. A. et al. Uma análise bayesiana para dados longitudinais de poisson. Revista de Matemática e Estatística, v. 24, n. 3, p. 95-113, 2006.

COLARES, J. K. B. Estudo comparativo de esquemas anti-retrovirais utilizando efavirenz ou lopinavir-ritonavir no tratamento inicial de pacientes infectados pelo Vírus da Imunodeficiência Humana. Tese (Doutorado) — Faculdade de Medicina de Ribeirão Preto - USP, Ribeirão Preto - SP - Brasil, 2007.

CROUCHLEY, R.; DAVIES, R. B. A comparasion of population average and random effects models for the analysis of longitudinal count data with baseline information. Journal of the Royal Statistical Society, A, v. 162, p. 331-347, 1999.

DUNSON, D. B. Bayesian latent variable models for clustered mixed outcomes. J. R. Stat. Soc. Ser. B Stat. Methodol., v. 62, n. 2, p. 355-366, 2000. ISSN 1369-7412.

DUNSON, D. B. Dynamic latent trait models for multidimensional longitudinal data. J. Amer. Statist. Assoc., v. 98, n. 463, p. 555-563, 2003. ISSN 0162-1459.

DUNSON, D. B.; BAIRD, D. D. A proportional hazards model for incidence and induced remission of disease. Biometrics, v. 58, n. 1, p. 71-78, 2002. ISSN 0006-341X.

DUNSON, D. B.; HERRING, A. H. Bayesian latent variable models for mixed discrete outcomes. Biostatistics, v. 6, n. 1, p. 11-25, 2005.

GELFAND, A. E.; GHOSH, S. K. Model choice: a minimum posterior predictive loss approach. Biometrika, v. 85, n. 1, p. 1-11, 1998. ISSN 0006-3444.

GELFAND, A. E.; SMITH, A. F. M. Sampling-based approaches to calculating marginal densities. J. Amer. Statist. Assoc., v. 85, n. 410, p. 398-409, 1990. ISSN 0162-1459.

GELMAN, A.; RUBIN, B. D. Inference from iterative simulation using multiple sequences. Statistical Sciences, v. 4, p. 457-511, 1992.

GOURIEROuX, C.; MONFORT, A.; TrOGnON, A. Pseudo maximum likelihood methods: Applications to poisson models. Econometrica, Chicago, v. 52, n. 3, p. 701-720, 1984. 
HENDERSON, R.; SHIMAKURA, S. A serially correlated gamma frailty model for longitudinal count data. Biometrika, v. 90, n. 2, p. 355-366, 2003. ISSN 0006-3444.

HILLS, M.; ARMITAGE, P. The two-period crossover clinical trial. British Journal of Clinical Pharmacology, v. 8, p. 7-20, 1979.

JØRGENSEN, B. et al. A state space model for multivariate longitudinal count data. Biometrika, v. 86, n. 1, p. 169-181, 1999. ISSN 0006-3444.

KORSGAARD, I. R.; ANDERSEN, A. H. The additive genetic gamma frailty model. Scand. J. Statist., v. 25, n. 2, p. 255-269, 1998. ISSN 0303-6898.

LAWLESS, J. F. Regression methods for Poisson process data. J. Amer. Statist. Assoc., v. 82, n. 399, p. 808-815, 1987. ISSN 0162-1459.

LEGLER, J. M.; RYAN, L. M. Latent variable models for teratogenesis using multiple binary outcomes. Journal of the American Statistical Association, v. 92, p. 13-20, 1997.

LI, H. An additive genetic gamma frailty model for linkage analysis of diseases with variable age of onset using nuclear families. Lifetime Data Anal., v. 8, n. 4, p. 315-334, 2002. ISSN 1380-7870.

MCCULLAGH, P.; NELDER, J. A. Generalized linear models. London: Chapman \& Hall, 1983. xiii+261 p. (Monographs on Statistics and Applied Probability). ISBN 0-412-23850-0.

MOUSTAKI, I. A latent trait and a latent class model for mixed observed variables.

British Journal of Mathematical and Statistical Psychology, v. 49, p. 313-334, 1996.

MOUSTAKI, I.; KNOTT, M. Generalized latent trait models. Psychometrika, v. 65, n. 3, p. 391-411, 2000. ISSN 0033-3123.

PAUlinO, C.; TURKMAN, M.; MURTEIRA, B. Estatística Bayesiana. Lisboa, Portugal: Fundação Calouste Gulbenkian, 2003. 446 p. 
PETERSEN, J. H. An additive frailty model for correlated life times. Biometrics, v. 54, p. $646-661,1998$.

POISSON, S. D. Recherches Sur La Probabilité Des Jugements En Matière Criminelle Et En Matière Civile: Précédées Des Règles Générales Du Calcul Des Probabilités. Paris: Bachelier, 1837.

RAO, C. R.; TOUTENBURG, H. Linear models. Second. New York: Springer-Verlag, 1999. xvi+427 p. (Springer Series in Statistics). Least squares and alternatives, With contributions by Andreas Fieger. ISBN 0-387-98848-3.

SAMMEL, M. D.; RYAN, L. M.; LEGLER, J. M. Latent variable models and mixed discrete and continuous outcomes. Journal of the Royal Statistical Society, B, v. 59, p. 667-678, 1997.

SANTNER, T. J.; DUFFY, D. E. The statistical analysis of discrete data. New York: Springer-Verlag, 1989. xii+367 p. (Springer Texts in Statistics). ISBN 0-387-97018-5.

SENN, S. Cross-over Trials in Clinical Research. [S.l.]: John Wiley \& Sons, 1993.

SMITH, A. F. M.; ROBERTS, G. O. Bayesian computation via the Gibbs sampler and related Markov chain Monte Carlo methods. Journal of the Royal Statistical Society, B, v. 55, n. 1, p. 3-23, 1993. ISSN 0035-9246.

SPIEGELHALTER, D. J.; BEST, N. G.; LINDE, A. V. A bayesian measure of model complexity and fit (with discussion). Journal of the Royal Statistical Society, B, v. 64, p. $583-639,2000$.

SPIEGELHALTER, D. J. et al. BUGS: Bayesian Inference Using Gibbs Sampling, Version 0.50. [S.1.]: Cambridge: MRC Biostatistics Unit, 1995.

SPIEGELHALTER, D. J. et al. Bugs: Bayesian inference using gibbs sampling, version 0.50. http://www.mrcbsu.cam.ac.uk/bugs, 2004. 
STUKEL, T. A. Generalized logistic models. J. Amer. Statist. Assoc., v. 83, n. 402, p. 426-431, 1988. ISSN 0162-1459.

WOLFINGER, R. D. Fitting Nonlinear Mixed Models with the New NLMIXED Procedure. Cary, NC: SAS Institute Inc., 2004.

YAKOVLEV, A. Y.; TSODIKOV, A. D. Stochastic models of tumor latency and their biostatistical applications. Singapore: World Scientific, 1996. 


\section{A Ferramentas Computacionais}

Este Apêndice apresenta uma introdução a respeito do software Winbugs e da PROC NLMIXED do software $S A S$. Estes dois recursos foram utilizados para a resolução de alguns problemas propostos nessa dissertação de mestrado.

\section{A.1 PROC NLMIXED do Software $S A S$}

A Procedure NLMIXED (WOLFINGER, 2004) do Software SAS foi criada para ajustar modelos mistos não lineares, ou seja, modelos não lineares que apresentam efeitos fixos e aleatórios. Estes modelos apresentam inúmeras aplicações, sendo muito utilizados na área de farmacocinética e de dados binomiais com sobredispersão. Esta Procedure permite especificar uma distribuição condicional para os dados (dado o efeito aleatório), permitindo especificar uma distribuição usual (Normal, Binomial, Poisson, etc) já implementa pela Procedure ou uma distribuição qualquer implementada pelo usuário utilizando códigos de programação em $S A S$.

A Procedure NLMIXED estima os parâmetros do modelo maximizando a função de verossimilhança. Tem-se a disposição uma variedade de técnicas de otimização para realizar a maximização, o default utilizado pela Procedure é o algoritmo de Quasi-Newton Dual. A convergência do problema de otimização é baseada na matriz de segunda derivadas da função de verossimilhança. Os erros padrão dos parâmetros estimados são calculados utilizando o inverso da matriz de informação de Fisher ou o método delta, dependendo do interesse do pesquisador. 


\section{A.2 Software Winbugs}

A análise Bayesiana exige um esforço computacional muito alto, pois depende de algoritmos que nem sempre são de fácil implementação. Visto este grande esforço computacional, foi desenvolvido o software Winbugs, (SPIEGELHALTER et al., 2004), que apesar de ser programavel, não é necessário a implementação dos algoritmos necessários na análise Bayesiana ( Gibbs-Sampling, Metropolis-Hastings), pois os mesmos já estão implementados internamente no programa. Com uma fácil linguagem de programação, semelhante a $\mathrm{C}^{++}$, o software Winbugs vem sido utilizado em grande escala pelos usuários da estatística Bayesiana. Uma das grandes vantagens deste software é que, além dele ser muito eficaz na obtenção de resultados baseados na inferência Bayesiana, ele é distribuído gratuitamente. O software Winbugs pode ser obtido via download pelo site

http://www.mrc-bsu.cam.ac.uk/bugs 


\section{B Programas}

Esse apêndice apresenta alguns programas computacionais utilizados na resolução de alguns problemas dessa dissertação de mestrado. Os programas utilizados em cada seção dessa dissertação estão apresentados nas seções desse apêndice.

\section{B.1 Seção 2}

O programa desenvolvido na Procedure NLMIXED utilizado para resolver o problema proposto na Seção 2 pode ser visto na Listagem 1.

Listagem 1: Programa Desenvolvido na Procedure NLMIXED.

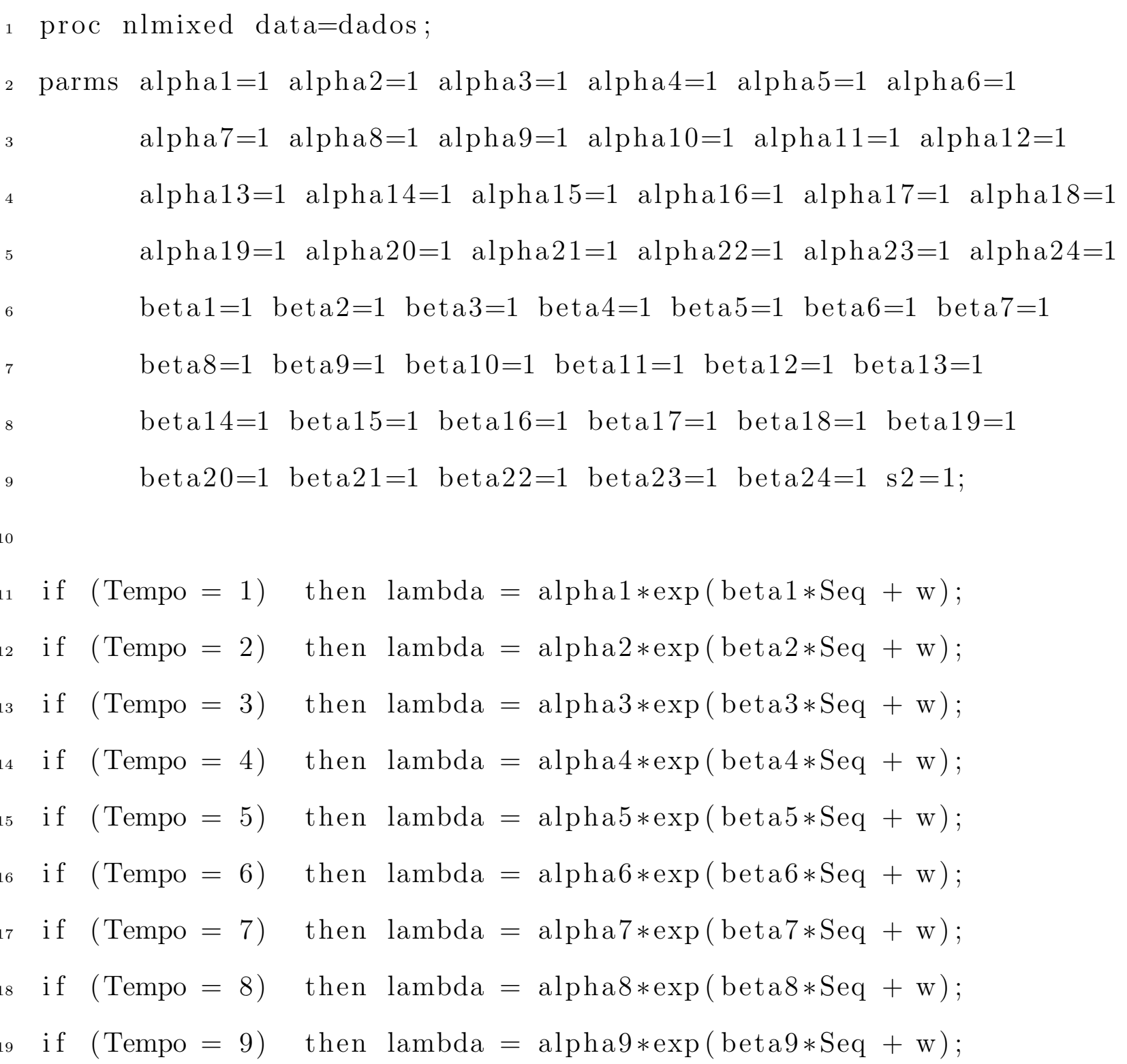


20 if $($ Tempo $=10)$ then lambda $=\operatorname{alpha10} * \exp ($ beta10 $* \mathrm{Seq}+\mathrm{w})$;

${ }_{21}$ if $($ Tempo $=11)$ then lambda $=\operatorname{alpha11} * \exp (\operatorname{beta} 11 * \mathrm{Seq}+\mathrm{w})$;

${ }_{22}$ if $($ Tempo $=12)$ then lambda $=\operatorname{alpha} 12 * \exp (\operatorname{beta} 12 * \mathrm{Seq}+\mathrm{w})$;

23 if $($ Tempo $=13)$ then lambda $=\operatorname{alpha} 13 * \exp (\operatorname{beta} 13 * \mathrm{Seq}+\mathrm{w})$;

${ }_{24}$ if $($ Tempo $=14)$ then lambda $=\operatorname{alpha} 14 * \exp ($ beta $14 * \mathrm{Seq}+\mathrm{w})$;

25 if $($ Tempo $=15)$ then lambda $=\operatorname{alpha} 15 * \exp ($ beta $15 * \mathrm{Seq}+\mathrm{w})$;

26 if $($ Tempo $=16)$ then lambda $=\operatorname{alpha16} * \exp ($ beta $16 * \mathrm{Seq}+\mathrm{w})$;

${ }_{27}$ if $($ Tempo $=17)$ then lambda $=\operatorname{alpha} 17 * \exp (\operatorname{beta} 17 * \mathrm{Seq}+\mathrm{w})$;

28 if $($ Tempo $=18)$ then lambda $=\operatorname{alpha} 18 * \exp ($ beta $18 * \mathrm{Seq}+\mathrm{w})$;

29 if $($ Tempo $=19)$ then lambda $=\operatorname{alpha19} * \exp ($ beta $19 * \mathrm{Seq}+\mathrm{w})$;

30 if $($ Tempo $=20)$ then lambda $=\operatorname{alpha} 20 * \exp (\operatorname{beta} 20 * \mathrm{Seq}+\mathrm{w})$;

31 if $($ Tempo $=21)$ then lambda $=\operatorname{alpha} 21 * \exp (\operatorname{beta} 21 * \operatorname{Seq}+\mathrm{w})$;

32 if $($ Tempo $=22)$ then lambda $=\operatorname{alpha} 22 * \exp (\operatorname{beta} 22 * \operatorname{Seq}+\mathrm{w})$;

33 if $($ Tempo $=23)$ then lambda $=\operatorname{alpha} 23 * \exp (\operatorname{beta} 23 * \mathrm{Seq}+\mathrm{w})$;

${ }_{34}$ if $($ Tempo $=24)$ then lambda $=\operatorname{alpha} 24 * \exp (\operatorname{beta} 24 * \mathrm{Seq}+\mathrm{w})$;

35

model Grooming poisson(lambda);

random $\mathrm{w} \sim \operatorname{normal}(0, \mathrm{~s} 2)$ subject=Rato ;

run ; 
O programa principal desenvolvido no software Winbugs utilizado para resolver o problema proposto na Seção 2 pode ser visto na Listagem 2.

Listagem 2: Programa Desenvolvido no software Winbugs.

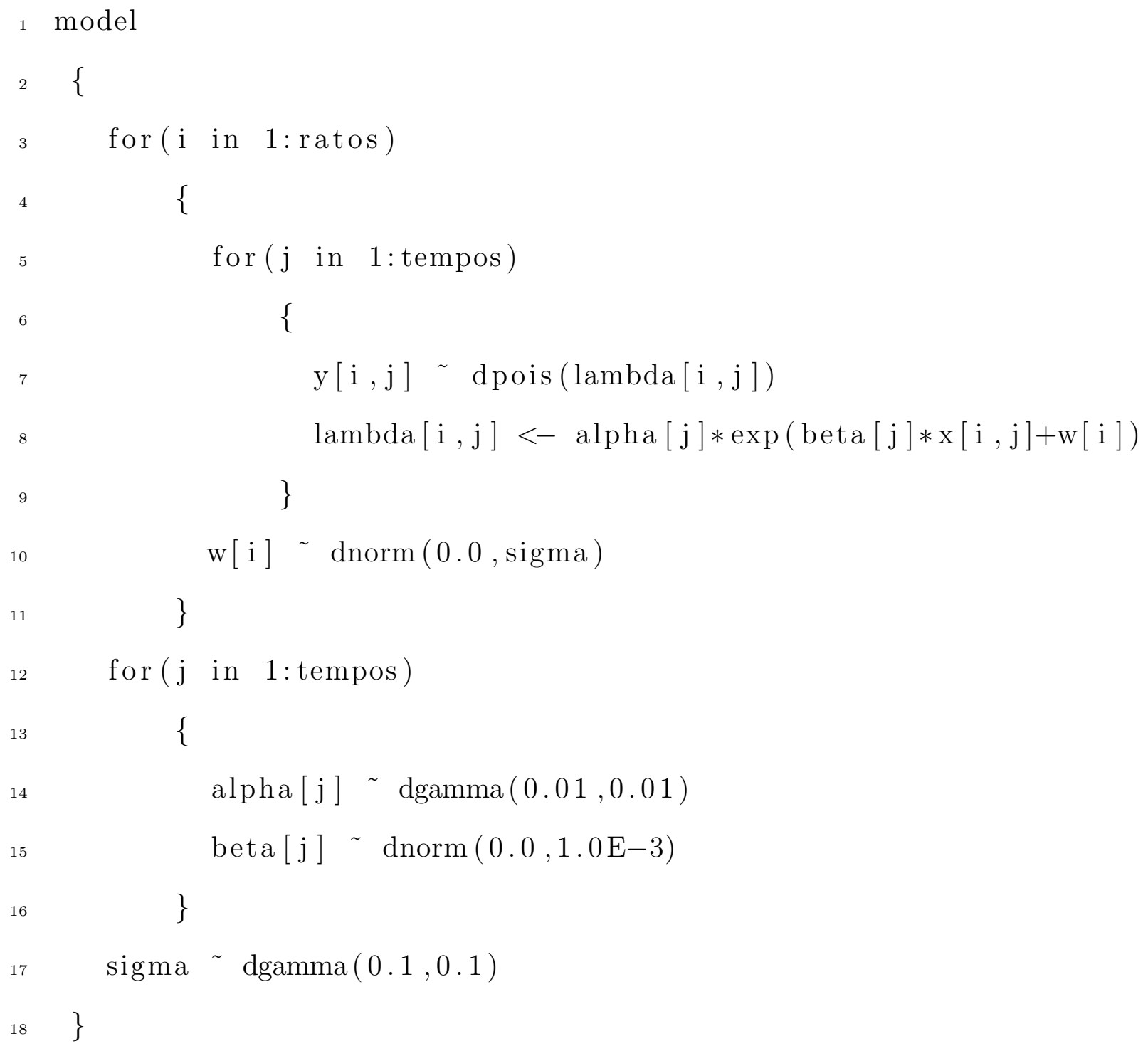




\section{B.2 Seção 3}

\section{B.2.1 Modelo 1}

Listagem 3: Programa Principal do Software Winbugs (Modelo 1).

1

2

3

4

6

7

8

9

10

11

12

13

14

15

16

17

18

19

model

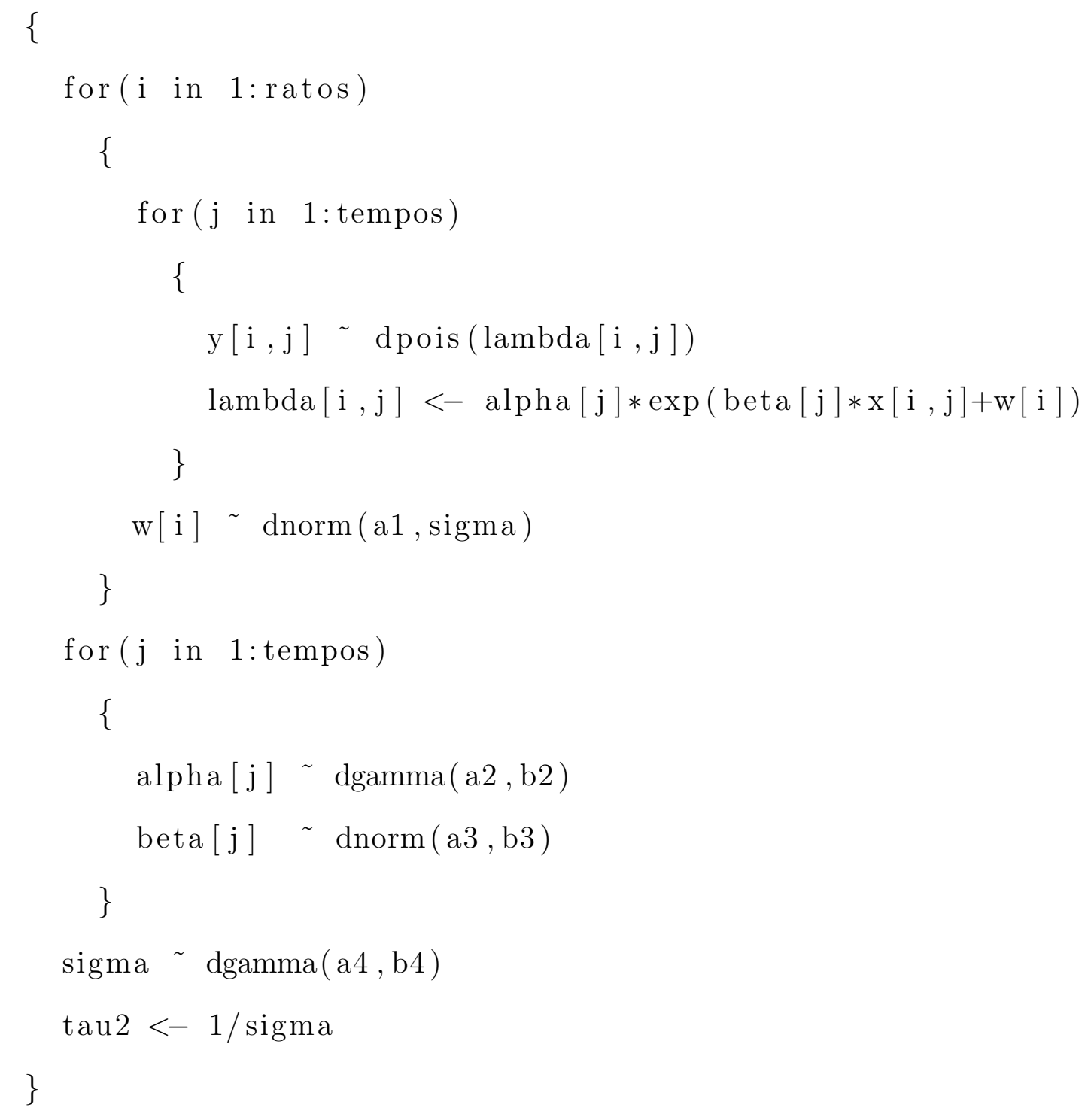

$(a k, b k), k=1, \ldots, 4$, representam hiperparâmetros conhecidos. 


\section{B.2.2 Modelo 2}

Listagem 4: Programa Principal do Software Winbugs (Modelo 2).

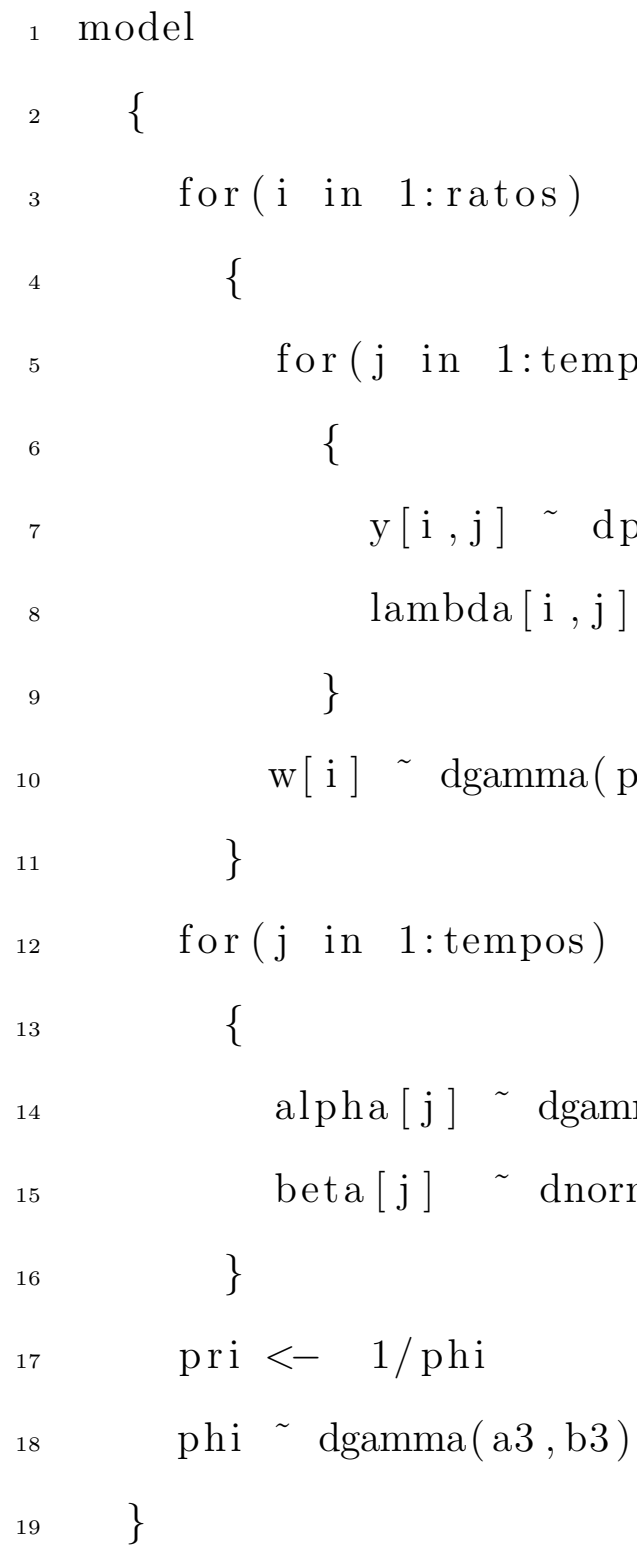




\section{B.2.3 Modelo 3}

Listagem 5: Programa Principal do Software Winbugs (Modelo 3).

model

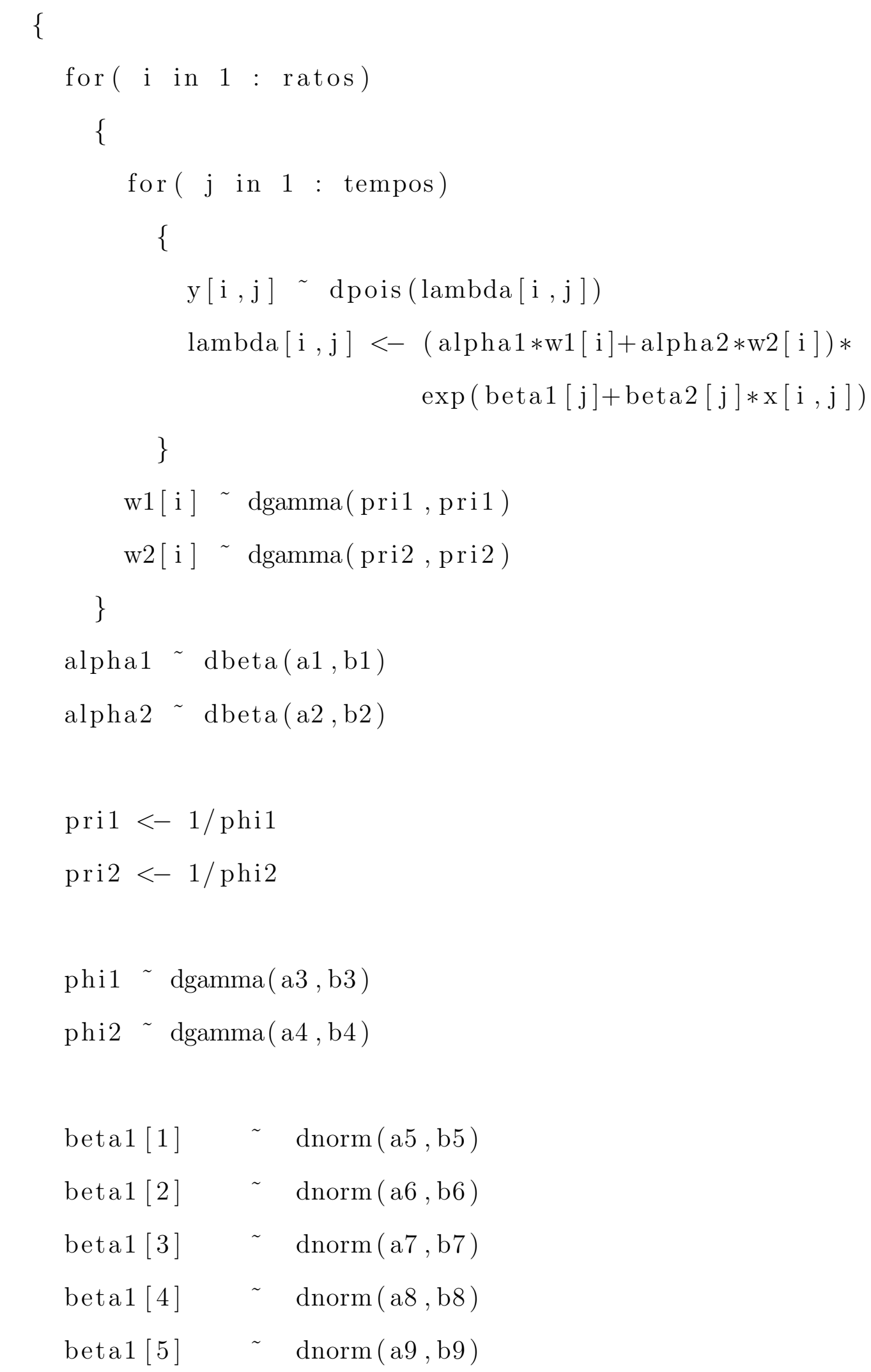




\begin{tabular}{|c|c|c|}
\hline 28 & beta1 $[6]$ & $\sim \operatorname{dnorm}(\mathrm{a} 10, \mathrm{~b} 10)$ \\
\hline 29 & beta1 [7] & $\sim \operatorname{dnorm}(\mathrm{a} 11, \mathrm{~b} 11)$ \\
\hline 30 & beta1 $[8]$ & $\operatorname{dnorm}(\mathrm{a} 12, \mathrm{~b} 12)$ \\
\hline 31 & beta1 $[9]$ & $\operatorname{dnorm}(\mathrm{a} 13, \mathrm{~b} 13)$ \\
\hline 32 & beta $1[10]$ & $\operatorname{dnorm}(\mathrm{a} 14, \mathrm{~b} 14)$ \\
\hline 33 & beta $1[11]$ & $\operatorname{dnorm}(\mathrm{a} 15, \mathrm{~b} 15)$ \\
\hline 34 & beta $1[12]$ & $\operatorname{dnorm}(\mathrm{a} 16, \mathrm{~b} 16)$ \\
\hline 35 & beta $1[13]$ & $\operatorname{dnorm}(\mathrm{a} 17, \mathrm{~b} 17)$ \\
\hline 36 & beta $1[14]$ & $\operatorname{dnorm}(\mathrm{a} 18, \mathrm{~b} 18)$ \\
\hline 37 & beta $1[15]$ & $\operatorname{dnorm}(\mathrm{a} 19, \mathrm{~b} 19)$ \\
\hline 38 & beta $1[16]$ & $\operatorname{dnorm}(\mathrm{a} 20, \mathrm{~b} 20)$ \\
\hline 39 & beta $1[17]$ & $\operatorname{dnorm}(\mathrm{a} 21, \mathrm{~b} 21)$ \\
\hline 40 & beta1 [18] & $\operatorname{dnorm}(\mathrm{a} 22, \mathrm{~b} 22)$ \\
\hline 41 & beta1 $[19]$ & $\operatorname{dnorm}(\mathrm{a} 23, \mathrm{~b} 23)$ \\
\hline 42 & beta $1[20]$ & $\operatorname{dnorm}(\mathrm{a} 24, \mathrm{~b} 24)$ \\
\hline 43 & beta $1[21]$ & $\operatorname{dnorm}(\mathrm{a} 25, \mathrm{~b} 25)$ \\
\hline 44 & beta $1[22]$ & $\operatorname{dnorm}(\mathrm{a} 26, \mathrm{~b} 26)$ \\
\hline 45 & beta $1[23]$ & $\operatorname{dnorm}(\mathrm{a} 27, \mathrm{~b} 27)$ \\
\hline 46 & beta $1[24]$ & $\operatorname{dnorm}(\mathrm{a} 28, \mathrm{~b} 28)$ \\
\hline 47 & & \\
\hline 48 & beta2 [1] & $\operatorname{dnorm}(\mathrm{a} 29, \mathrm{~b} 29)$ \\
\hline 49 & beta $2[2]$ & $\operatorname{dnorm}(\mathrm{a} 30, \mathrm{~b} 30)$ \\
\hline 50 & beta2 $[3]$ & $\operatorname{dnorm}(\mathrm{a} 31, \mathrm{~b} 31)$ \\
\hline 51 & beta $2[4]$ & $\operatorname{dnorm}(\mathrm{a} 32, \mathrm{~b} 32)$ \\
\hline 52 & beta $2[5]$ & $\operatorname{dnorm}(\mathrm{a} 33, \mathrm{~b} 33)$ \\
\hline 53 & beta2 $[6]$ & $\operatorname{dnorm}(\mathrm{a} 34, \mathrm{~b} 34)$ \\
\hline 54 & beta $2[7]$ & $\operatorname{dnorm}(\mathrm{a} 35, \mathrm{~b} 35)$ \\
\hline 55 & beta2 $[8]$ & $\operatorname{dnorm}(\mathrm{a} 36, \mathrm{~b} 36)$ \\
\hline 56 & beta $2[9]$ & $\operatorname{dnorm}(\mathrm{a} 37, \mathrm{~b} 37)$ \\
\hline
\end{tabular}




\begin{tabular}{|c|c|c|}
\hline 77 & beta $2[10]$ & $\sim \quad \operatorname{dnorm}(\mathrm{a} 38, \mathrm{~b} 38)$ \\
\hline & beta $2[11]$ & $\sim \operatorname{dnorm}(\mathrm{a} 39, \mathrm{~b} 39)$ \\
\hline & beta $2[12]$ & $\sim \operatorname{dnorm}(\mathrm{a} 40, \mathrm{~b} 40)$ \\
\hline & beta $2[13]$ & $\sim \operatorname{dnorm}(\mathrm{a} 41, \mathrm{~b} 41)$ \\
\hline & beta $2[14]$ & $\operatorname{dnorm}(\mathrm{a} 42, \mathrm{~b} 42)$ \\
\hline & beta $2[15]$ & $\sim \operatorname{dnorm}(\mathrm{a} 43, \mathrm{~b} 43)$ \\
\hline & beta $2[16]$ & $\sim \operatorname{dnorm}(\mathrm{a} 44, \mathrm{~b} 44)$ \\
\hline & beta $2[17]$ & $\operatorname{dnorm}(\mathrm{a} 45, \mathrm{~b} 45)$ \\
\hline & beta $2[18]$ & $\sim \operatorname{dnorm}(\mathrm{a} 46, \mathrm{~b} 46)$ \\
\hline & beta $2[19]$ & $\operatorname{dnorm}(\mathrm{a} 47, \mathrm{~b} 47)$ \\
\hline & beta $2[20]$ & $\operatorname{dnorm}(\mathrm{a} 48, \mathrm{~b} 48)$ \\
\hline & beta $2[21]$ & $\sim \operatorname{dnorm}(\mathrm{a} 49, \mathrm{~b} 49)$ \\
\hline & beta $2[22]$ & $\sim \operatorname{dnorm}(\mathrm{a} 50, \mathrm{~b} 50)$ \\
\hline & beta $2[23]$ & $\operatorname{dnorm}(\mathrm{a} 51, \mathrm{~b} 51)$ \\
\hline & beta $2[24]$ & $\sim \operatorname{dnorm}(\mathrm{a} 52, \mathrm{~b} 52)$ \\
\hline
\end{tabular}

$(a k, b k), k=1, \ldots, 52$, representam hiperparâmetros conhecidos. 


\section{Distribuições a Posteriori Condicionais}

Nesse apêndice é apresentado as distribuições a posteriori condicionais necessárias para o algoritmo Gibbs Sampling.

\section{C.1 Seção 3}

\section{C.1.1 Modelo 1}

$(i)$

$$
\alpha_{j} \mid \boldsymbol{\alpha}_{(j)}, \boldsymbol{\beta}, \mathbf{w}, \tau^{2}, \mathbf{y}, \mathbf{x} \sim \operatorname{Gamma}\left(a+\sum_{i=1}^{n} y_{i j}, b+\sum_{i=1}^{n} e^{w_{i}} e^{\beta_{j} x_{i j}}\right)
$$

em que, $\boldsymbol{\alpha}_{(j)}=\left(\alpha_{1}, \ldots, \alpha_{j-1}, \alpha_{j+1}, \ldots, \alpha_{k}\right) ; j=1, \ldots, k$.

(ii)

$$
\pi\left(\beta_{j} \mid \boldsymbol{\alpha}, \boldsymbol{\beta}_{(j)}, \mathbf{w}, \tau^{2}, \mathbf{y}, \mathbf{x}\right) \propto N\left(c, d^{2}\right) \psi_{1}\left(\boldsymbol{\alpha}, \boldsymbol{\beta}, \mathbf{w}, \tau^{2}, \mathbf{y}, \mathbf{x}\right)
$$

em que,

$$
\psi_{1}\left(\boldsymbol{\alpha}, \boldsymbol{\beta}, \mathbf{w}, \tau^{2}, \mathbf{y}, \mathbf{x}\right)=\exp \left(-\alpha_{j} \sum_{i=1}^{n} e^{w_{i}} e^{\beta_{j} x_{i j}}+\beta_{j} \sum_{i=1}^{n} y_{i j} x_{i j}\right) ; j=1, \ldots, k
$$

(iii)

$$
\pi\left(w_{i} \mid \boldsymbol{\alpha}, \boldsymbol{\beta}, \mathbf{w}_{(i)}, \tau^{2}, \mathbf{y}, \mathbf{x}\right) \propto N\left(0, \tau^{2}\right) \psi_{2}\left(\boldsymbol{\alpha}, \boldsymbol{\beta}, \mathbf{w}, \tau^{2}, \mathbf{y}, \mathbf{x}\right)
$$

em que,

$$
\psi_{2}\left(\boldsymbol{\alpha}, \boldsymbol{\beta}, \mathbf{w}, \tau^{2}, \mathbf{y}, \mathbf{x}\right)=\exp \left[-e^{w_{i}} \sum_{j=1}^{k} \alpha_{j} e^{\beta_{j} x_{i j}}+\sum_{j=1}^{k} w_{i} y_{i j}\right] ; \quad i=1, \ldots, n
$$

$(i v)$

$$
\tau^{2} \mid \boldsymbol{\alpha}, \boldsymbol{\beta}, \mathbf{w}, \mathbf{y}, \mathbf{x} \sim I G\left(f+\frac{n}{2}, g+\frac{1}{2} \sum_{i=1}^{n} w_{i}^{2}\right)
$$

Para esse modelo é necessário utilizar o algoritmo Metropolis-Hastings para simular as amostras de $\beta_{j}$ e $w_{i}$. 


\section{C.1.2 Modelo 2}

(i)

$$
\pi\left(\alpha_{j} \mid \boldsymbol{\alpha}_{(j)}, \boldsymbol{\beta}, \mathbf{w}, \tau^{2}, \mathbf{y}, \mathbf{x}\right) \propto \alpha_{j}^{a-1} e^{-b \beta_{j}} \psi_{1}(\boldsymbol{\alpha}, \boldsymbol{\beta}, \mathbf{w}, \phi, \mathbf{y}, \mathbf{x})
$$

em que,

$$
\psi_{1}(\boldsymbol{\alpha}, \boldsymbol{\beta}, \mathbf{w}, \phi, \mathbf{y}, \mathbf{x})=\exp \left(-\alpha_{j} \sum_{i=1}^{n} w_{i} e^{\beta_{j} x_{i j}}+\sum_{i=1}^{n} y_{i j} \ln \left(\alpha_{j}\right)\right) ; \quad j=1, \ldots, k
$$

(ii)

$$
\pi\left(\beta_{j} \mid \boldsymbol{\alpha}, \boldsymbol{\beta}_{(j)}, \mathbf{w}, \phi, \mathbf{y}, \mathbf{x}\right) \propto N\left(c, d^{2}\right) \psi_{2}(\boldsymbol{\alpha}, \boldsymbol{\beta}, \mathbf{w}, \phi, \mathbf{y}, \mathbf{x})
$$

em que,

$$
\psi_{2}(\boldsymbol{\alpha}, \boldsymbol{\beta}, \mathbf{w}, \phi, \mathbf{y}, \mathbf{x})=\exp \left(-\alpha_{j} \sum_{i=1}^{n} w_{i} e^{\beta_{j} x_{i j}}+\beta_{j} \sum_{i=1}^{n} y_{i j} x_{i j}\right) ; \quad j=1, \ldots, k
$$

(iii)

$$
\pi\left(w_{i} \mid \boldsymbol{\alpha}, \boldsymbol{\beta}, \mathbf{w}_{(i)}, \phi, \mathbf{y}, \mathbf{x}\right) \propto \operatorname{Gamma}\left(\phi^{-1}, \phi^{-1}\right) \psi_{3}(\boldsymbol{\alpha}, \boldsymbol{\beta}, \mathbf{w}, \phi, \mathbf{y}, \mathbf{x})
$$

em que,

$$
\psi_{3}(\boldsymbol{\alpha}, \boldsymbol{\beta}, \mathbf{w}, \phi, \mathbf{y}, \mathbf{x})=\exp \left[-w_{i} \sum_{j=1}^{k} \alpha_{j} e^{\beta_{j} x_{i j}}+\sum_{j=1}^{k} y_{i j} \ln \left(w_{i}\right)\right] ; \quad i=1, \ldots, n .
$$

$(i v)$

$$
\pi(\phi \mid \boldsymbol{\alpha}, \boldsymbol{\beta}, \mathbf{w}, \mathbf{y}, \mathbf{x}) \propto \operatorname{Gamma}(f, g) \psi_{4}(\boldsymbol{\alpha}, \boldsymbol{\beta}, \mathbf{w}, \phi, \mathbf{y}, \mathbf{x})
$$

em que,

$$
\begin{aligned}
\psi_{4}(\boldsymbol{\alpha}, \boldsymbol{\beta}, \mathbf{w}, \phi, \mathbf{y}, \mathbf{x})= & \exp \left[-n \phi^{-1} \ln (\phi)-n \ln \Gamma\left(\phi^{-1}\right)\right] \times \\
& \times \exp \left[\phi^{-1} \sum_{i=1}^{n} \ln \left(w_{i}\right)-\phi^{-1} \sum_{i=1}^{n} w_{i}\right] ; \quad i=1, \ldots, n .
\end{aligned}
$$


Para esse modelo é necessário utilizar o algoritmo Metropolis-Hastings para simular as amostras de $\alpha_{j}, \beta_{j}, w_{i}$ e $\phi$.

\section{C.1.3 Modelo 3}

(i)

$$
\pi\left(\alpha_{l} \mid \boldsymbol{\alpha}_{(l)}, \boldsymbol{\beta}_{1}, \boldsymbol{\beta}_{2}, \mathbf{w}_{1}, \mathbf{w}_{2}, \phi_{1}, \phi_{2}, \mathbf{y}, \mathbf{x}\right) \propto \alpha_{l}^{a_{l}-1}\left(1-\alpha_{l}\right)^{b_{l}-1} \psi_{1}(\boldsymbol{\theta}),
$$

em que, $\boldsymbol{\theta}=\left(\boldsymbol{\alpha}_{1}, \boldsymbol{\alpha}_{2}, \boldsymbol{\beta}_{1}, \boldsymbol{\beta}_{2}, \mathbf{w}_{1}, \mathbf{w}_{2}, \phi_{1}, \phi_{2}, \mathbf{y}, \mathbf{x}\right)$ e

$$
\psi_{1}(\boldsymbol{\theta})=\exp \left[-\sum_{i=1}^{n} \sum_{j=1}^{k} \lambda_{i j}\right] \times \prod_{i=1}^{n} \prod_{j=1}^{k} \lambda_{i j}^{y_{i j}} ; \quad l=1,2
$$

em que, $\lambda_{i j}$ é dado em (29).

(ii)

$$
\pi\left(\beta_{l j} \mid \boldsymbol{\beta}_{(l j)}, \boldsymbol{\alpha}_{1}, \boldsymbol{\alpha}_{2}, \mathbf{w}_{1}, \mathbf{w}_{2}, \phi_{1}, \phi_{2}, \mathbf{y}, \mathbf{x}\right) \propto \exp \left[-\frac{1}{2 d_{l}^{2}}\left(\beta_{l j}-\beta_{l j}^{*}\right)^{2}\right] \psi_{1}(\boldsymbol{\theta}),
$$

para $l=1,2 ; j=1, \ldots, k$.

(iii)

$$
\pi\left(w_{l i} \mid \mathbf{w}_{(l i)}, \boldsymbol{\alpha}_{1}, \boldsymbol{\alpha}_{2}, \boldsymbol{\beta}_{1}, \boldsymbol{\beta}_{2}, \phi_{1}, \phi_{2}, \mathbf{y}, \mathbf{x}\right) \propto w_{l i}^{\phi_{l}^{-1}-1} \exp \left[-\phi_{l}^{-1} w_{l i}\right] \psi_{1}(\boldsymbol{\theta})
$$

para $i=1, \ldots, n ; l=1,2$.

(iv)

$$
\pi\left(\phi_{l} \mid \phi_{(l)}, \boldsymbol{\alpha}_{1}, \boldsymbol{\alpha}_{2}, \boldsymbol{\beta}_{1}, \boldsymbol{\beta}_{2}, \mathbf{w}_{1}, \mathbf{w}_{2}, \mathbf{y}, \mathbf{x}\right) \propto \phi_{l}^{f_{l}-1} e^{-g_{l} \phi_{l}} \psi_{2}\left(\phi_{l}\right),
$$

em que,

$$
\psi_{2}\left(\phi_{l}\right)=\exp \left[-\frac{n}{\phi_{l}} \ln \phi_{l}-n \ln T\left(\phi_{l}^{-1}\right)-\frac{1}{\phi_{l}} \sum_{i=1}^{n} \ln w_{l i}-\frac{1}{\phi_{l}} \sum_{i=1}^{n} w_{l i}\right],
$$

para $l=1,2$.

Para esse modelo é necessário utilizar o algoritmo Metropolis-Hastings para simular as amostras de todos os parâmetros. 